PNNL-11798

UC-2030

\title{
Application of the Risk-Based Strategy to the Hanford Tank Waste Organic-Nitrate Safety Issue
}

\author{
V. L. Hunter \\ S. D. Colson \\ T. Ferryman \\ R. E. Gephart \\ P. Heasler \\ R. D. Scheele
}

December 1997

Prepared for

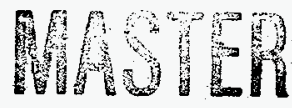

the U.S. Department of Energy

under Contract DE-AC06-76RLO 1830

DASTRIBUTION OF THIS DOCUWENT IS UNLLMITED

Pacific Northwest National Laboratory

Richland, Washington 99352 


\section{DISCLAIMER}

This report was prepared as an account of work sponsored by an agency of the United States Government. Neither the United States Government nor any agency thereof, nor any of their employees, make any warranty, express or implied, or assumes any legal liability or responsibility for the accuracy, completeness, or usefulness of any information, apparatus, product, or process disclosed, or represents that its use would not infringe privately owned rights. Reference herein to any specific commercial product, process, or service by trade name, trademark, manufacturer, or otherwise does not necessarily constitute or imply its endorsement, recommendation, or favoring by the United States Government or any agency thereof. The views and opinions of authors expressed herein do not necessar. ily state or reflect those of the United States Government or any agency thereof. 


\section{DISCLAIMER}

Portions of this document may be illegible electronic image products. Images are produced from the best available original document. 


\section{Executive Summary}

This report describes the results from application of the Risk-Based Decision Management Approach for Justifying Characterization of Hanford Tank Waste (Colson et al. 1997) to the organic-nitrate safety issue in Hanford single-shell tanks (SSTs). Existing chemical and physical models were used, taking advantage of the most current (mid-1997) sampling and analysis data. The purpose of this study is to make specific recommendations for planning characterization to help ensure the safety of each SST as it relates to the organic-nitrate safety issue. An additional objective is to demonstrate the viability of the Risk-Based Strategy (Colson et al. 1997) for addressing Hanford tank waste safety issues.

\section{Major Findings about the Application to the Organic-Nitrate Safety Issue}

The application of this risk-based strategy to the organic-nitrate safety issue resulted in risk estimates and a risk ranking for the 149 SSTs. Eleven SSTs had such limited data on their contents that they were not considered in the analysis. Additional characterization work is recommended for these tanks. Twelve tanks were identified as having a high priority for additional characterization or potential mitigative controls based on frequency of HEPA filter breach or tank dome failure greater than $10 \mathrm{E}-5$ per year. Forty-seven tanks had extremely low risk (less than 1E-10), and no additional characterization or mitigative controls are recommended. The remaining 79 tanks had frequencies of HEPA filter breach between $1 \mathrm{E}-10$ and $10 \mathrm{E}-5$ per year. Application of this risk-based strategy focuses additional characterization and potential mitigative actions on the higher-risk tanks. The major findings of this study are further described in the following paragraphs.

Quantitative risk predictions allow prioritization of decisions about management of risk. In order to conduct the most cost-effective safety actions, it is vital to be able to select the highest-value actions as determined by a defensible risk analysis. This work demonstrates the value of quantitative risk assessments (and the use of progressive risk screening criteria in the simplification of risk calculations) to aid in decision making for the organic-nitrate safety issue. It requires establishing a risk target that is defensible and acceptable as being essential to guide the management of the safety issue. Uncertainty is quantified in the risk estimate and can be managed in the ensuing decision making.

For most tanks, the largest contribution to the estimated risk is uncertainty in knowledge about the waste contents and their spatial distribution. This is uncertainty around the information or data. It is quantified and represented in the estimated risk. Individual samples taken from the tanks do not indicate significant risk. Furthermore, with the exception of a few tanks, sampling and analysis results are found to dramatically reduce the estimated risk. Full application of the recommended strategy would determine the value of gathering additional information by addressing the cost and benefit of additional samples. Tanks with a low estimated risk may only need sampling for confirmatory purposes just prior to actions that must be performed during the normal course of operations or programmatic actions. 
Eleven SSTs (Table ES.1) were not considered in this analysis because their waste is so diverse it precludes their being grouped with other tanks that have similar waste characteristics. Each of these 11 tanks formed a separate tank group, and thus there was no grouping basis for estimating tank contents and the uncertainties surrounding the tank contents estimates. Therefore, these tanks are a high priority for waste characterization work. Similarly, 64 of Hanford's SSTs do not have moisture and total organic carbon (TOC) measurements that could be used for the risk analysis, and approximately 113 SSTs have two or less TOC measurements. The limitations of decision making with such unknowns must be acknowledged.

Another contribution to information or data uncertainty is the reproducibility of the data set used for quantifying the estimated risk. For example, the tank waste contents data set continually changed as it was reviewed over the course of this project analysis. Independent review of data quality will provide assurance that the data provide the best possible representation of the tank contents and that uncertainties in the data set are well known, based upon sound technical evaluations, and represented in the predicted risk.

An additional contribution to the estimated risk is the uncertainty in relating what is known about the tank contents (from historical records and sampling data) risk. This is uncertainty around the models and is quantified and represented in the estimated risk. The information required by the risk model may not be faithfully represented by the data available. Since the existing model that relates TOC to waste energetics was not evaluated in this work, one of the parameters available to assess this safety issue (TOC measurements) may not be a reasonable measure of the value represented by the structured logic (in this case, energy). This is not just a difficulty with using a quantitative risk-based approach. The risk must be managed regardless of the problem-solving approach, and if one cannot relate what is known about the tank contents to the risk of an undesired outcome, actions must be taken.

\section{Path Forward for the Organic-Nitrate Safety Issue}

The following recommendations are based upon the findings that have resulted from applying the Risk-Based Focused Decision Management Approach for Justifying Characterization of Hanford Tank Waste (Colson et al. 1997) to the organic-nitrate safety issue.

Table ES.1. Tanks Not Currently Amenable to Grouping

$\begin{array}{lll}\text { B-201 } & \text { C-101 } & \text { C-201 } \\ \text { B-202 } & \text { C-102 } & \text { C-202 } \\ \text { B-203 } & \text { C-103 } & \text { C-203 } \\ \text { B-204 } & & \text { C-204 }\end{array}$


Take initial action to ascertain the risk of the 11 ungrouped SSTs. The 11 tanks in Table ES. 1 have the so much uncertainty associated with them that no risk calculations could be made during this analysis. These 11 tanks must have characterization work (from historical records and sampling) performed so that their tank contents can be estimated and the risk for organic-nitrate reaction calculated as it was for the other 138 SSTs. It is important to note that characterization work can include laboratory experiments designed to increase our understanding of the physical and chemical phenomena of concern, tests on wastes or waste simulants, and studies of historical records as well as sampling and analysis work.

Focus near-term characterization work on the tanks that show the highest estimated risk. Twelve tanks showed an annual event frequency leading to HEPA filter failure in excess of 10E-5 and thus could provide the greatest opportunity for beneficial use of additional, near-term characterization work. Further prioritization of these 12 tanks can be determined by observing that eight of them also show a predicted dome failure probability in excess of $10 \mathrm{E}-5$ and that only six of them show a predicted dome failure with potential continued release in excess of $10 \mathrm{E}-5$ per year. The progressive application of these risk screening results led to the recommended order of near-term characterization work that is shown in Table ES.2. The preparation of this priority listing represents the authors' assumptions about what might be reasonable and acceptable levels of risk.

Table ES.2. Prioritized Order for Near-Term Characterization Work

\begin{tabular}{|c|c|}
\hline Priority Order & Tank \\
\hline \hline 1 & AX-102 \\
\hline 2 & AX-101 \\
\hline 3 & SX-106 \\
\hline 4 & SX-101 \\
\hline 5 & AX-103 \\
\hline 6 & TX-104 \\
\hline 7 & C-106 \\
\hline 8 & U-103 \\
\hline 9 & TX-118 \\
\hline 10 & U-106 \\
\hline 11 & A-102 \\
\hline 12 & SX-103 \\
\hline
\end{tabular}


The risk calculation shows that the highest contribution to event initiation comes from surface ignition; therefore, understanding the ignition capability of the tank surface area will reduce uncertainty in the margin of safety:

Perform an independent review of the data set to confirm quality in its application and use. Two issues will be addressed by this recommendation. First, since the existing model that relates TOC to waste energetics was not evaluated in this analysis, this basic presumption must be reviewed. In any case, the TOC measurements are used as an indirect measure of energetic contents, so at a minimum that uncertainty must be quantified and included in the risk evaluation. Ideally, a direct measure of energetics is preferred. However, unless a connection can be made to the body of existing data, any different measurements will need to be obtained multiple times in multiple tanks to obtain a reasonable approximation of the spatial distribution of the waste in the tanks of concern. Secondly, high confidence in the data used to complete an analysis must be maintained by a finalizing a data set of historical records that is stationary except for the addition of new data points from incremental characterization actions.

Declare tanks with extremely low risk to be safe and thus not in need of additional characterization remediation or controls in relation to this safety issue. Organic-nitrate reaction risk for the tanks listed in Table ES.3 was predicted to be less than 1E-10. Based upon the risk targets used in this analysis and the existing data, these tanks are candidates for no additional characterization in relation to this safety issue. As stated earlier, tanks with low estimated risk may only need sampling for confirmatory purposes just prior to actions that must be performed during the normal course of operations.

The 79 tanks not explicitly described in this summary have calculated event frequencies between $1 \mathrm{E}-10$ and 10E-5 for HEPA filter failure. While using the risk targets presumed for this analysis does not show risk for these tanks to be extremely low, the estimated risk is sufficiently low to be acceptable while additional information is obtained about the 23 high-priority tanks.

Table ES.3. Tanks with Extremely Low Calculated Risk for Organic-Nitrate Event

$\begin{array}{lllll}\text { A-101 } & \text { BX-103 } & \text { C-104 } & \text { T-102 } & \text { U-107 } \\ \text { B-103 } & \text { BX-104 } & \text { C-108 } & \text { T-104 } & \text { U-108 } \\ \text { B-106 } & \text { BX-107 } & \text { C-109 } & \text { T-105 } & \text { U-109 } \\ \text { B-109 } & \text { BX-109 } & \text { C-110 } & \text { T-107 } & \text { U-201 } \\ \text { B-110 } & \text { BX-111 } & \text { C-112 } & \text { T-111 } & \text { U-203 } \\ \text { B-111 } & \text { BX-112 } & \text { S-101 } & \text { TY-101 } & \text { U-204 } \\ \text { B-112 } & \text { BY-102 } & \text { S-104 } & \text { TY-102 } & \\ & \text { BY-106 } & \text { S-107 } & \text { TY-103 } & \\ & \text { BY-107 } & \text { S-109 } & \text { TY-104 } & \\ & \text { BY-108 } & \text { S-111 } & \text { TY-105 } & \\ & \text { BY-110 } & \text { SX-108 } & \text { TY-106 } & \\ & \text { BY-112 } & & & \end{array}$


It is quite likely that such additional information will also reduce the uncertainty about (and hence the risk associated with) many if not all of the tanks. Some of the 79 tanks with the highest risk are candidates for controls to reduce the expected frequency of the most likely event initiators while additional information about their risk is obtained and until tolerable and defensible risk criteria are determined.

\section{Main Finding About the Use of the Risk-Based Strategy}

One of the objectives of this work was to demonstrate the viability of the risk-based strategy (Colson et al. 1997) for addressing Hanford tank waste safety issues. The following finding resulted from use of the Colson et al. (1997) recommended strategy to help ensure resolution of the Hanford organic-nitrate safety issue.

The risk-based strategy (Colson et al. 1997) was successfully applied to Hanford's organic-nitrate safety issue. The results obtained demonstrate the value and effectiveness of a risk-based strategy to support decision making. The strategy is tailored to the problem addressed such that analyses conducted and models used are as simple as the problem requires. This is accomplished by matching problem-solving methods and activities to practical needs. The strategy is integrated within a single safety problem (e.g., from defining desired outcomes to taking actions to achieve those outcomes) and, when fully implemented, across multiple waste safety and disposal issues. This strategy includes using structured logic techniques to describe the safety problem and decision analysis methods (e.g., risk assessment, uncertainty evaluation, sensitivity analyses) to assess the cost and risk of following one solution approach rather than another. The risk-based strategy helps identify critical data and modeling uncertainties whose resolution is the foundation for implementing technically defensible waste characterization studies or remediation actions. Funding available for this project limited its application to the organicnitrate problem such that cost analyses (i.e., where the value of information for resolution of a variety of safety and waste processing needs must be considered) were not performed.

\section{Reference}

Colson SD, RE Gephart, VL Hunter, J Janata, and LG Morgan. 1997. A Risk-Based Focused Decision-Management Approach for Justifying Characterization of Hanford Tank Waste. PNNL-11231, Pacific Northwest National Laboratory, Richland, Washington. 



\section{Acknowledgments}

The authors would especially like to acknowledge the instrumental role played by Resolution Team members for their insight and experience in each of their specific areas of expertise: Gene Ashby at Georgia Institute of Technology; Jim Chinnis and Jake Ulvila at Decision Science Associates; David Leggett at Hazard Evaluation Laboratories; T. Ffrancon Williams at University of Tennessee; Barry Wise at Eigenvector Research, Incorporated; and Leon Stock, University of Chicago-retired. Also, we would like to thank Tom DeForest, Guang Chen, Feng Gao, and Nancy Wildung for their analyses and support throughout the project, Marsha Patridge and Gailann Rice for administrative support, and Sheila Bennett for editing and pulling the final document together. Finally, we would like to thank Billy Shipp and Gerald Stokes for their help in getting this project completed. 


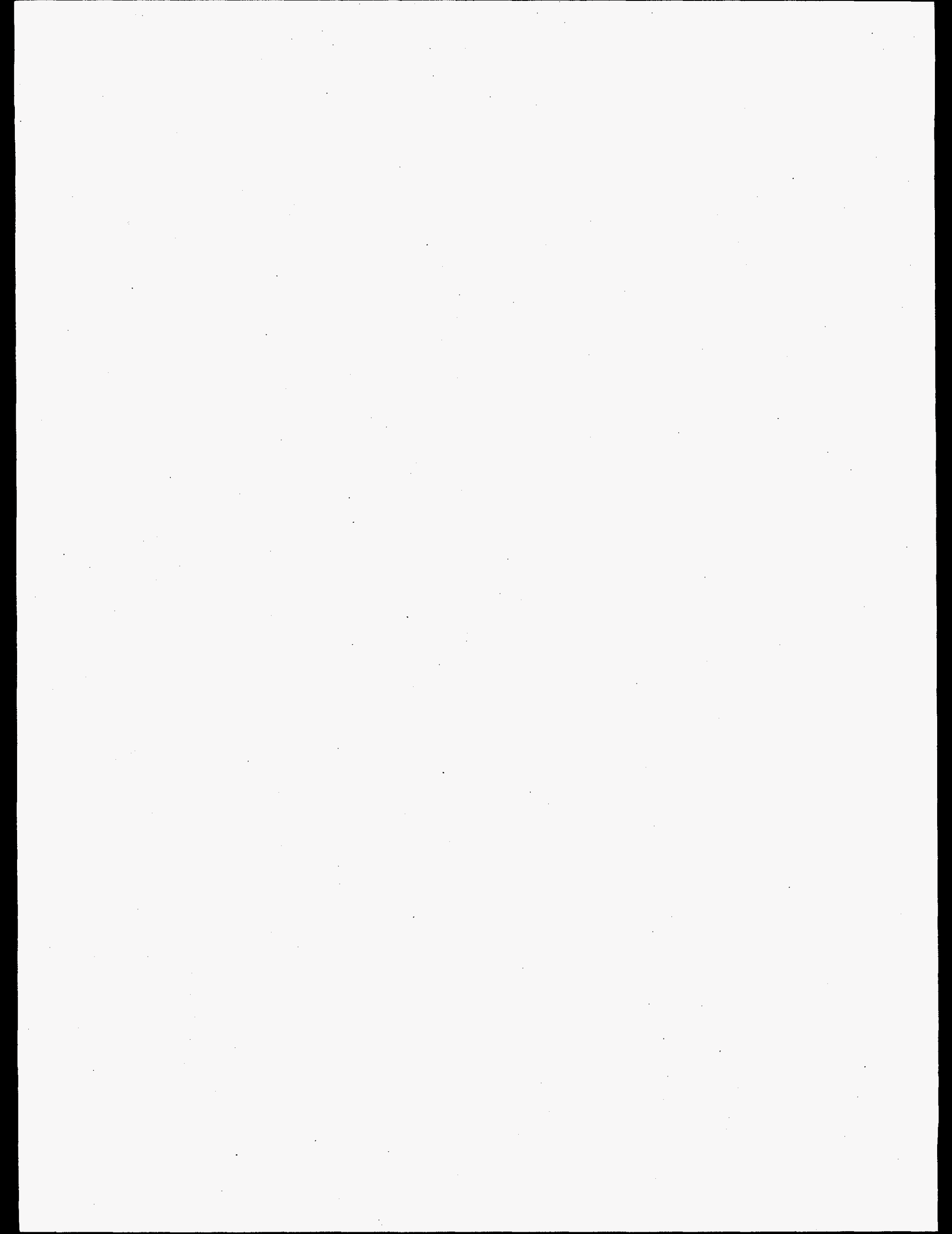




\section{Contents}

Executive Summary $\ldots \ldots \ldots \ldots \ldots \ldots \ldots \ldots \ldots \ldots \ldots \ldots \ldots \ldots \ldots \ldots$

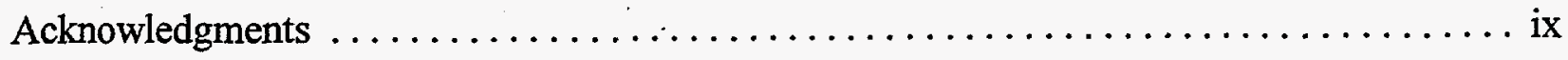

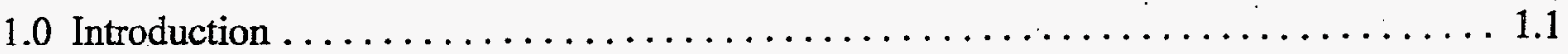

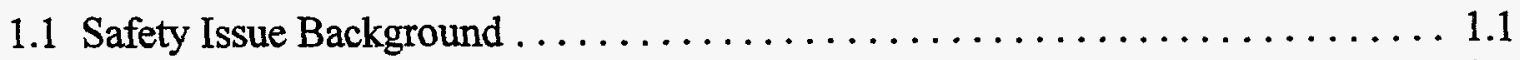

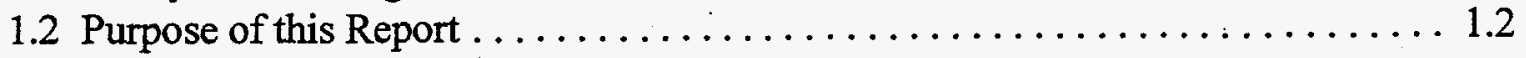

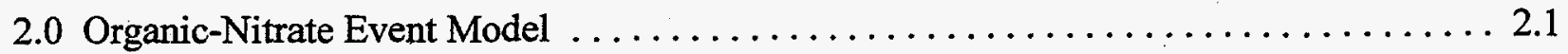

2.1 Potential Consequences of Organic-Nitrate Reaction . . . . . . . . . . . 2.1

2.2 Structured Logic Representation of Organic-Nitrate Safety Issue . . . . . . . . . 2.1

2.2.1 Comprehensive Structured Logic Diagram . . . . . . . . . . 2.2

2.2.2 Simplified Structured Logic Diagram . . . . . . . . . . . . 2.2

2.3 Reaction Risk Calculation . . . . . . . . . . . . . . . . . . . 2.8

2.3.1 Assumptions Considered in the Reaction Risk Calculation . . . . . . 2.8

2.3.2 Calculation Concept and Structure . . . . . . . . . . . . . . 2.9

2.3 .3 Reaction Frequency Estimates . . . . . . . . . . . . . 2.9

2.3.3.1 Structure of the Organic-Nitrate Risk Calculation . . . . 2.10

2.3.3.2 Input and Output . . . . . . . . . . . . $\ldots \ldots$

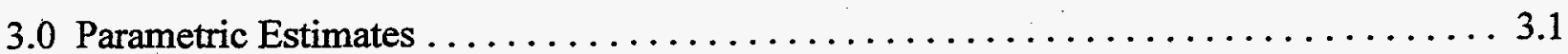

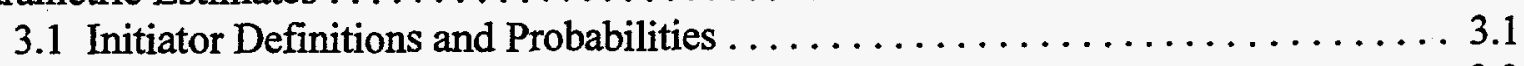

3.2 Tank Contents . . . . . . . . . . . . . . . . . . . . . . . . 3

3.2.1 Assumptions Considered in Estimating Tank Contents . . . . . . 3.3

3.2.2 Tank Contents Definitions . . . . . . . . . . . . . . . . 3.3

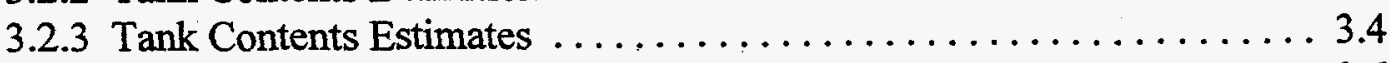

3.2.3.1 Review of the Data . . . . . . . . . . . . . . . . .

3.2.3.2 Estimation Methodology . . . . . . . . . . . . 3.9

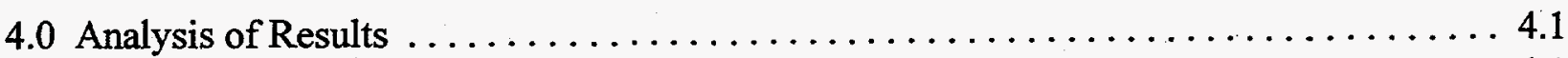

4.1 Base-Case Results . . . . . . . . . . . . . . . . . . . . . . . . . 4.1

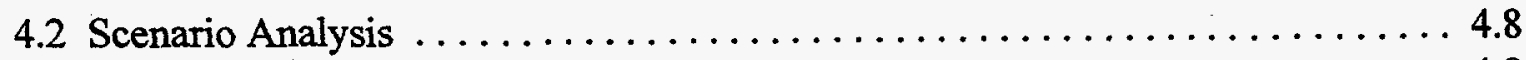

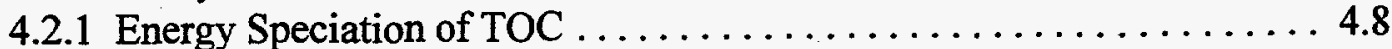

4.2 .2 Mitigation Scenario Analysis . . . . . . . . . . . . . . 4.12

4.2.2.1 Control Ignition Sources . . . . . . . . . . . . . 4.12

4.2.2.2 Add Moisture to Waste . . . . . . . . . . . . . 4.13

4.2.2.3 Reduce Energy Content of Waste . . . . . . . . . 4.13

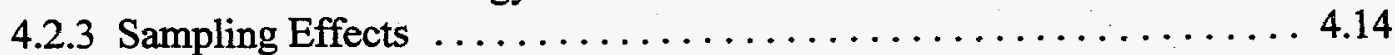

4.2 .4 Conclusions from Scenario Tests . . . . . . . . . . . . . 4.15

4.3 Make Decisions ............................... 4.16 


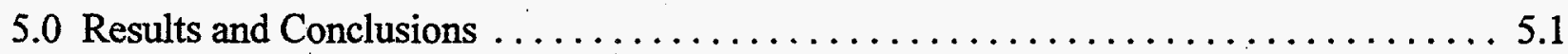

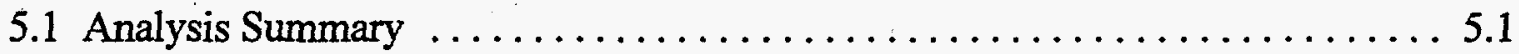

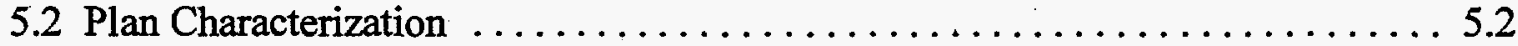

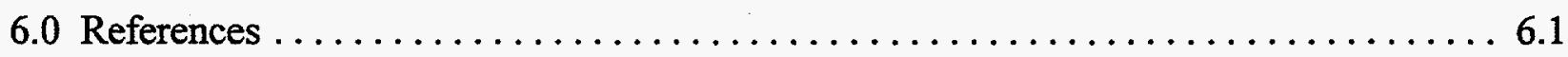

Appendix A: Implementing the Recommended Strategy $\ldots \ldots \ldots \ldots \ldots \ldots \ldots \ldots$ A.1

Appendix B: Structured Logic Diagram $\ldots \ldots \ldots \ldots \ldots \ldots \ldots \ldots \ldots \ldots \ldots \ldots \ldots \ldots \ldots \ldots$

Appendix C: Initiator Frequencies for Organic-Nitrate Waste $\ldots \ldots \ldots \ldots \ldots \ldots \ldots \ldots$ C.1

Appendix D: Review of ANOVA Model Calculations $\ldots \ldots \ldots \ldots \ldots \ldots \ldots \ldots \ldots$ D. 1 


\section{Figures}

2.1 Simplified Structured Logic Diagram for the Organic-Nitrate Safety Issue in Hanford Waste Tanks

2.2 Contact Temperature Ignition Energetics Criteria for Organic-Bearing Hanford Wastes . 2.7

2.3 Schematic Representation of Organic-Nitrate Risk Calculation . . . . . . . . . . . 2.10

3.1 Ignition Sources and the Reactive Waste that Could Ignite $\ldots \ldots \ldots \ldots \ldots \ldots \ldots .2$

3.2 State Space Representation of Tank Contents $\ldots \ldots \ldots \ldots \ldots \ldots \ldots \ldots \ldots \ldots .4$

4.1 HEPA Filter Failure Frequency Versus Number of TOC Observations per Tank ...... 4.6

4.2 Tanks Sorted by Dome Failure with Continued Release Frequency $\ldots \ldots \ldots \ldots \ldots .6$

4.3 Dome Failure with Continued Release Frequency Versus Waste Depth $\ldots \ldots \ldots \ldots .7$

4.4 Dome Failure with Continued Release Frequency Versus Percent Surface Moisture . . . 4.7

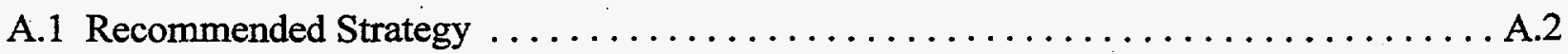

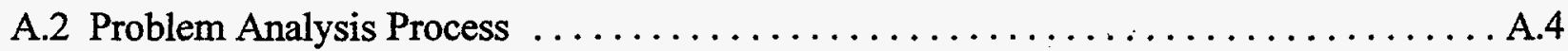

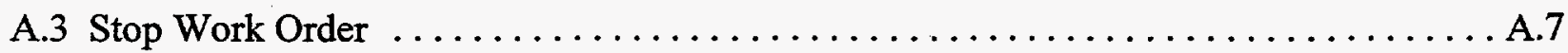

C.1 Illustration of Tank Waste Surface Cross-Section $\ldots \ldots \ldots \ldots \ldots \ldots \ldots \ldots \ldots \ldots \ldots$

\section{Tables}

3.1 Summary of Organic-Nitrate Reaction Initiators $\ldots \ldots \ldots \ldots \ldots \ldots \ldots \ldots \ldots .1$

3.2 Representative Region and Total Volume of Reactive Waste $\ldots \ldots \ldots \ldots \ldots \ldots . .5$

3.3 Summary of Data Prepared for ANOVA $\ldots \ldots \ldots \ldots \ldots \ldots \ldots \ldots \ldots \ldots \ldots \ldots \ldots \ldots \ldots \ldots$

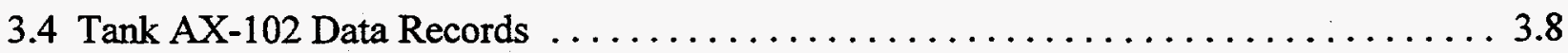

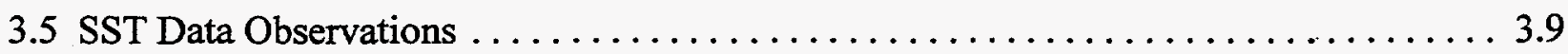

xiii 
4.1 Tank-by-Tank Base-Case Risk Results for Three Event Severity Consequences . . . . . 4.2

4.2 Energetics Conversion Factors for Organic Species . . . . . . . . . . . . 4.9

4.3 Distribution of Non-Oxalate Organics $\ldots \ldots \ldots \ldots \ldots \ldots \ldots \ldots \ldots \ldots \ldots \ldots$

4.4 Conversion Factors for Tanks with Measured Oxalate . . . . . . . . . . . . 4.11

4.5 Number of Tanks with Calculated Frequencies Less Than Threshold Criteria

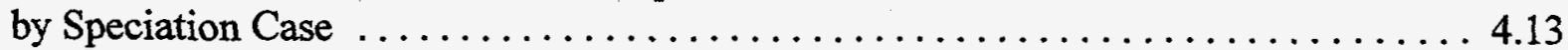

4.6 Organic-Nitrate Initiator Frequencies $\ldots \ldots \ldots \ldots \ldots \ldots \ldots \ldots \ldots \ldots \ldots \ldots \ldots \ldots \ldots \ldots$

4.7 Number of Tanks with Calculated Frequencies Less Than Threshold Criteria by Mitigative Action Scenario

4.8 Number of Tanks with Calculated Frequencies Less Than Threshold Criteria by Sampling Effects Case

5.1 Tanks Not Currently Amenable to Grouping

5.2 Prioritized Order for Near-Term Characterization Work

5.3 Tanks with Extremely Low Estimated Risk for Organic-Nitrate Event

A.1 Resolution Team for Organic-Nitrate Safety Issue

C.1 Organic-Nitrate Initiator Frequencies 


\subsection{Introduction}

\subsection{Safety Issue Background}

Years of production and recovery of nuclear defense materials, facility decontamination operations, and management of wastes from chemical recovery operations have generated organic-bearing, radioactive high-level waste (HLW). These wastes, which contain the inorganic oxidants nitrate and nitrite and could contain organic solvents, organic complexants, and organic radiolytic alkaline hydrolysis degradation products, are stored in underground tanks at the U.S. Department of Energy's (DOE) Hanford Site. The potential chemical reaction hazards associated with these organic-bearing radioactive wastes have been recognized as priority safety issues, and plans have been developed to resolve the safety issues for continued storage of these wastes (Wilson and Reep 1991; Wodrich and Deichman 1992; Babad and Turner 1993; Babad et al. 1993) and to develop safe storage criteria similar to those developed for the ferrocyanide wastes (Postma et al. 1994).

The compositions of the organic-bearing wastes in the Hanford tanks are quite diverse (Strachan et al. 1993; Klem 1990). The added organics include 1) the PUREX solvent and diluent (30 vol\% tributyl phosphate [TBP] in normal paraffin hydrocarbon [NPH]); 2) TBP radiolytic degradation products dibutyl phosphate (DBP), monobutyl phosphate (MBP), butanol, and phosphoric acid; and 3) organic complexants such as ethylene-diamine-tetraacetate (EDTA), hydroxy-acetate-ethylene-diamine-triacetate (HEDTA), hydroxyacetate, citrate, and tartrate. Adding complexity to the nature of the organics is the potential for different aging processes (vida infra) because of exposure to high $\mathrm{pH}$; inorganic oxidants such as nitrate; nitrite; and radiation. The HLW also includes nonorganic constituents such as hydroxide that was added to neutralize the acidic wastes and make them chemically compatible with the carbon steel tanks. Fission products are also present in the waste, as are other process additives such as iron and nitrate; nitrite, which either resulted from radiolysis of nitrate or was added as a corrosion inhibitor, is also present.

Because these organic-bearing wastes are mixtures of organic fuels, strong inorganic oxidants, and heat-producing radionuclides, the potential exists for rapid energetic reactions similar to the explosion that occurred in Kyshtym in the former Soviet Union in 1957 (Medvedev 1979). The Kyshtym explosion occurred when the tank cooling system failed and the heat from radioactive decay raised the temperature of a sodium acetate-sodium nitrate radioactive waste mixture to the point at which a thermal runaway reaction occurred. Fisher (1990) assessed available data for Hanford wastes with respect to the Kyshtym event and other available reactivity data and concluded that the temperatures of wastes stored in Hanford's waste tanks are well below those required to initiate reactions between sodium acetate (as a surrogate for the mixture of organics in the waste tanks) and sodium nitrate and/or nitrite. Nevertheless, the possibility remains of ignition of the fuel/oxidant mixtures from sources other than bulk thermal heating. This possibility defines the safety issue addressed in this report. 
Chemical reactivity hazards are controlled by several thermochemical and physical factors such as the amount of energy produced by a reaction, the rate at which energy is produced, and the rate at which heat is dissipated from the system (Sharkey et al. 1992). For the organic-bearing waste system, factors that determine the energy produced include fuel concentration, the chemical nature of the organic fuel, oxidant concentration, the nature of the oxidant(s), and the chemical reaction mechanism. The rate at which energy is produced will be controlled by the fundamental reaction kinetics of the organic reaction with nitrate or nitrite, catalytic properties of waste constituents, and catalytic properties of the containment vessel. The heat capacities of the waste constituents, the energy required for physical transitions of waste constituents, and the thermal conductivity of the waste and its containment will be among the factors controlling heat dissipation.

\subsection{Purpose of this Report}

The work leading to this report was initiated at the request of DOE to demonstrate that the Pacific Northwest National Laboratory recommended strategy (Colson et al. 1997) could be successfully applied to one of the Hanford HLW tank safety issues. The organic-nitrate safety issue was selected for this purpose. Even though the scope and schedule did not allow demonstration of the full breadth of the strategy, the results provide concrete estimates of risk (Section 4) and specific recommendations (Section 5) for the next appropriate steps leading to the resolution of this safety issue.

Preliminary findings from this report and the relationship between this work and elements of the full recommended strategy were presented at the 1997 American Chemical Society workshop on Science and Technology for Disposal of Radioactive Tank Wastes and will be published in the proceedings of that workshop (Colson et al. 1998). The relationship between this work and the recommended strategy is also provided in Appendix A. 


\subsection{Organic-Nitrate Event Model}

This section of the report presents the organic-nitrate reaction event structure. The main technical components are acceptable risk thresholds, the structured logic and its diagram, and the reaction risk calculation. Risk is defined by both a probability (or frequency) and an associated consequence. This analysis quantitatively presents the probability for the consequences described in Section 2.1. Those consequences are quantified in Section 3.2.2.

\subsection{Potential Consequence of Organic-Nitrate Reaction}

A propagating organic-nitrate reaction in a tank could result in a wide range of event severities due to the possible variation in fuel concentrations, the spatial extent of fuel with concentration sufficient to support propagating reactions, and the moisture concentration in and near the reacting region. In addition to these factors, the amount of free headspace volume in the tank and the configuration of headspace ventilation are important in determining the pressures reached and the severity of consequences.

To capture the potential range of event severities, four consequences were defined in the risk calculation: 1) no event, 2) breach of high efficiency particulate air (HEPA) filter, 3) tank dome failure; and 4) tank dome failure with continued release of tank contents. These four consequences were used as a framework for estimating reaction frequencies. Event severity classes and their corresponding thresholds are the framework within which the risk calculation provides the frequency of the organic-nitrate reaction events of interest.

\subsection{Structured Logic Representation of Organic-Nitrate Safety Issue}

The radioactive wastes contained in Hanford's SSTs are composed of intimate mixtures of organic complexants and nitrogen-based oxidants and have the potential to react vigorously and breach the integrity of the tank. The probability and consequences of an organic-based disruptive reaction event are determined by several interrelated factors, including the chemical identity of the organic, the energy released by the reaction (energetics), the concentration of the organic and/or oxidant (energy density), the reaction rate (how rapidly heat is produced), the heat dissipation rate (how rapidly heat is transferred out of the reactive system), the nature of the other waste constituents (diluents, catalysts, alternative oxidants, and other reactive materials), the sensitivity of the mixture to initiating events, possible initiating events, the probability of an initiating event, the strength of the containment system, and the dispersion pathways. Interrelationships exist among many of these factors; for example, the reaction rate depends on the temperature of the system, the temperature of the system depends on the energy produced by the organic-oxidant reaction and on the heat dissipation rate.

Goheen et al. (1997), in support of the effort to develop the recommended strategy, developed a structured logic showing the potentially hazardous issue of organic-oxidant reaction 
by determining the risk of observing an accident associated with that waste. The structured logic diagram (SLD) identified the information needs to determine whether a particular organicbearing waste presented a chemical reactivity hazard. The SLD provides the linked pathways to identify critical information needed to quantify the risk associated with an organic complexant and oxidant reaction disruptive event. An SLD is similar to a Fault Tree diagram in structure but, as implemented, focuses on the pathway to success rather than a pathway to system failure. Success in this instance is acceptable risk; i.e., a risk level determined by decision makers as acceptable and the probability of achieving that risk level. One advantage of this approach is that it identifies the critical waste, tank, or system properties that must be measured, controlled, or adjusted to achieve the acceptable risk level.

The challenge was to develop a characterization plan that will aid in identifying the information needs required to determine whether the risk of a chemical reaction event between the organic complexants and the nitrogen-based oxidants present in some of Hanford's stored HLW is acceptable. Given the complexity of the organic complexant issue and the difficulties associated with gathering information about radioactive wastes stored in SSTs, the structured logic was refined and simplified to focus on the probability of a disruptive event using information gathered to support the current DOE implemented safety strategy (DOE 1996).

This section presents both the comprehensive SLD refined from that originally developed in Goheen et al. (1997) and the simplified SLD exercised by the resolution team formed at Pacific Northwest National Laboratory to study the organic-nitrate issue. The refined, comprehensive SLD is discussed briefly in Section 2.2.1, and the SLD exercised by the team is discussed in more detail in Section 2.2.2.

\subsubsection{Comprehensive Structured Logic Diagram}

In general, the refined SLD (Appendix B) developed by the team with the assistance of Goheen and Burger of PNNL obtains and uses all of the information mentioned earlier that is needed to determine the potential hazard associated with an organic complexant-bearing waste and whether an event occurring in that waste will breach the integrity of the tank, causing damage. The SLD comprises two major branches that identify pathways providing the two elements that define risk: the probability of a disruptive event and the potential consequences of that event. (For a detailed discussion of the overall SLD the reader is referred to Goheen et al. 1997.)

\subsubsection{Simplified Structured Logic Diagram}

Using the SLD developed by Goheen et al. (1997) as the basis, the resolution team developed and used the simplified approach depicted by the SLD in Figure 2.1. Risk, as the SLD shows, is the product of the probability and the consequences of an event. To minimize the uncertainty in the risk calculation, this iteration concentrates on the probability of a reaction event with a given magnitude (consequence) rather than addressing both the complex 

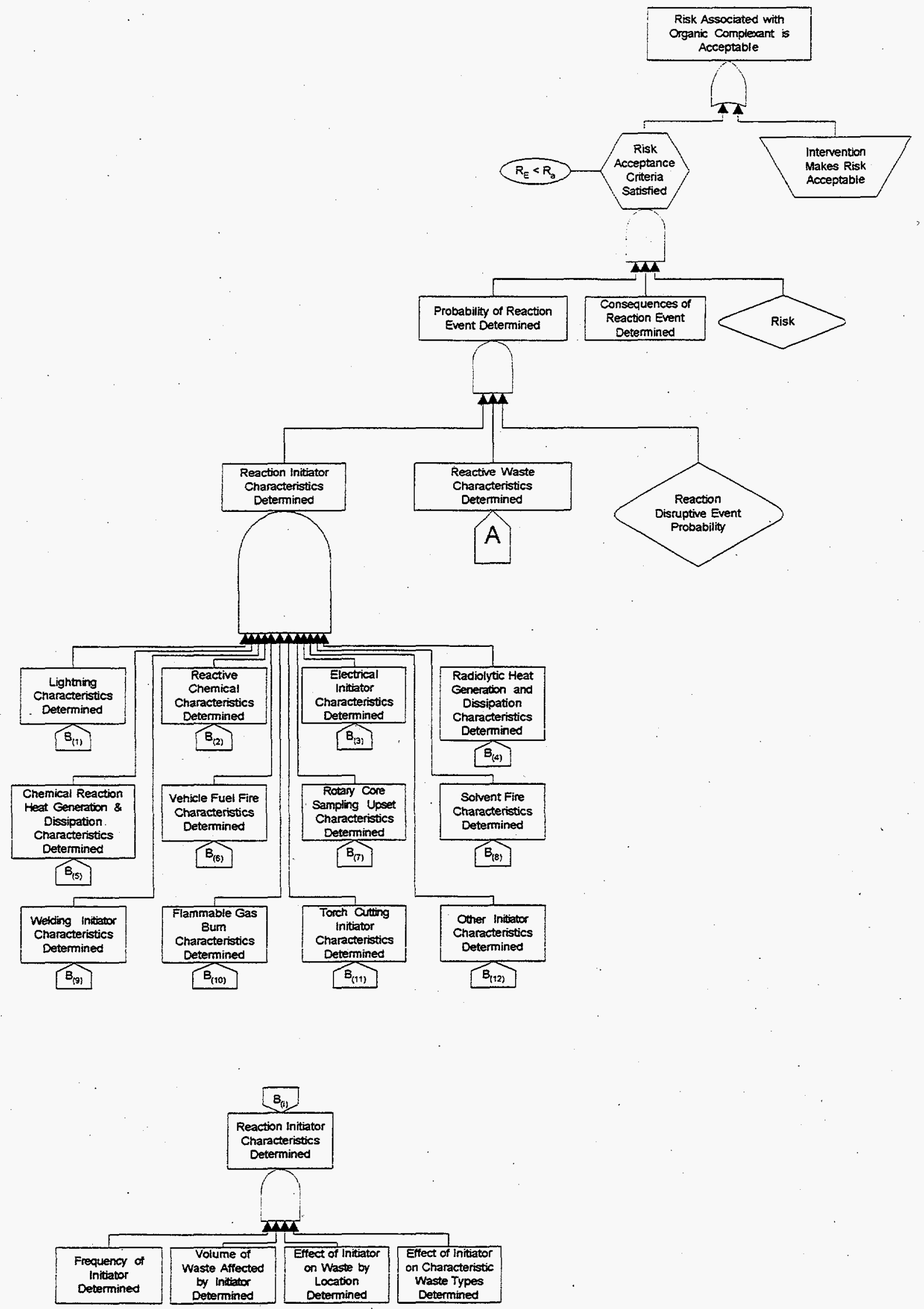

Figure 2.1. Simplified Structured Logic Diagram for the Organic-Nitrate Safety Issue in Hanford Waste Tanks 


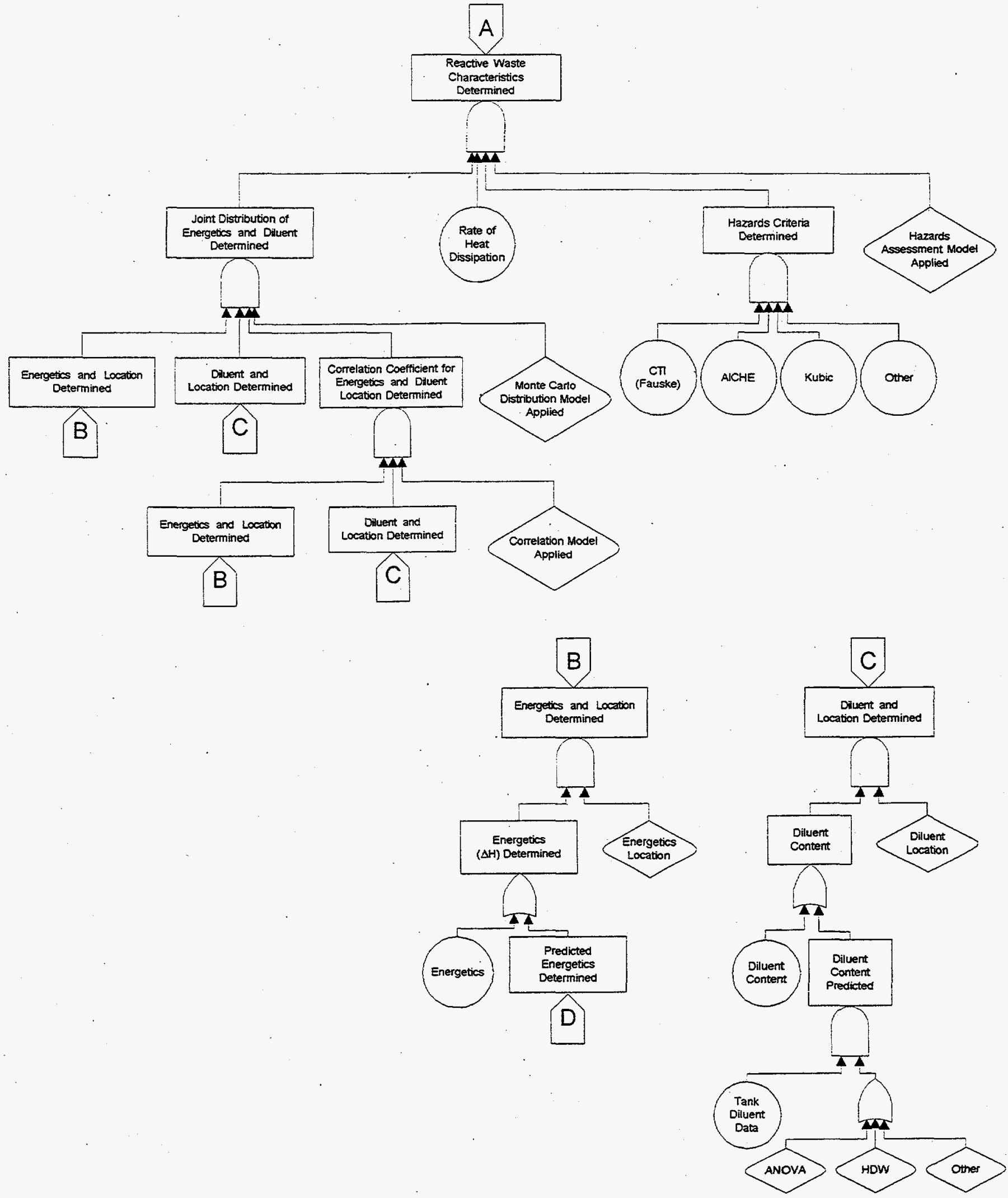

Figure 2.1 (contd) 
(p1400) I'ๆ ว.มnถิ!

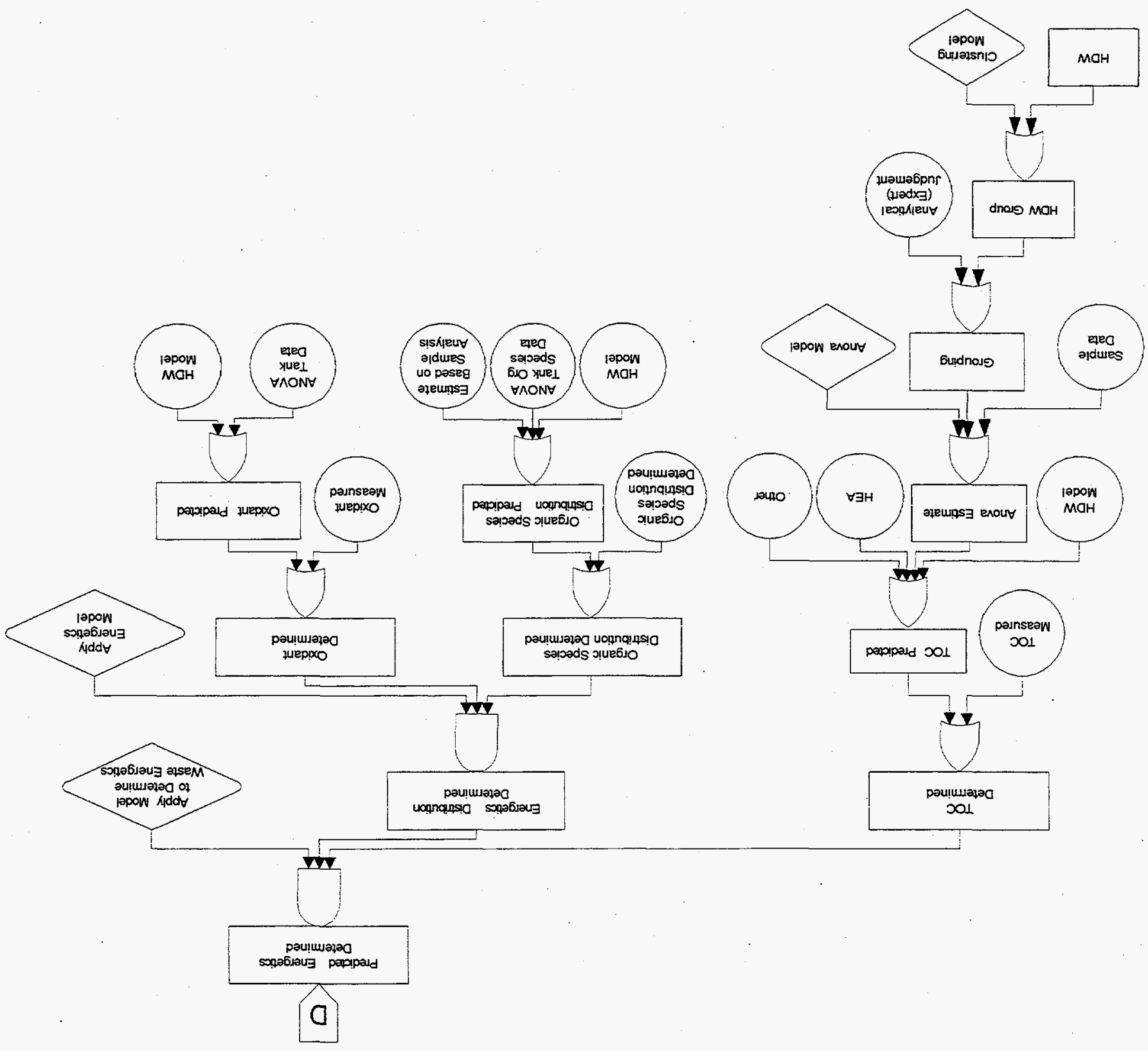


consequence branch of the SLD and the probability branch. If events are predicted to have significant probability, their full consequences can be considered in a future iteration. The following discussion progresses downward through the SLD.

To achieve the state where risk is acceptable, the waste storage system can itself satisfy the acceptable risk criteria or intervention may be required to satisfy the risk criteria. To determine whether the risk is acceptable, the probability and consequences of a reaction event are addressed. To determine the probability of a reaction event, the characteristics of the initiators and the characteristics of the reactive waste are used to determine the reaction disruptive event. The initiator characteristics include the frequency of occurrence and the initiator's sphere of influence (e.g., does it affect the whole tank, or the surface, or the subsurface?).

As the simplified SLD (Figure 2.1) shows, the reactive waste volume and location are determined by 1) the joint distribution of energetics and diluent, 2) the heat dissipation rate for the system, and 3) the hazard criteria into a hazards assessment model. The hazard assessment model employed the contact temperature ignition (CTI) energetics criteria currently used by the Hanford Site to identify reactive wastes (Webb et al. 1995). The team made no judgement on the validity of the hazards assessment model used for the CTI criterion. Fauske et al. (1995) developed the CTI criteria by studying the effects of organic identity, organic concentration, and water concentration in surrogate wastes on the capability of the mixture to support a downward propagating reaction initiated by heating the upper portion of a cylinder of the test mixture. The surrogate wastes were composed of mixtures of organics and nitrate and/or nitrite. The resulting criterion on an energetics basis was that wastes containing less than $20 \mathrm{wt} \%$ water would not support a propagating reaction in the ignition tube test if

$$
\Delta H<1200-45\left[\mathrm{H}_{2} \mathrm{O}\right]
$$

where $\Delta \mathrm{H}$ is enthalpy measured in $\mathrm{J} / \mathrm{g}$ dry waste and $\left[\mathrm{H}_{2} \mathrm{O}\right]$ is water concentration measured in weight percent up to $20 \mathrm{wt} \%$. Fauske et al. (1995) found that the tested organic-bearing mixtures would not support a propagating reaction above $20 \mathrm{wt} \%$ water. Figure 2.2 is a near reproduction of the Webb et al. (1995) original figure with the ordinate scale converted to joules from calories and the defining relationship between ignition temperature and reaction enthalpy omitted.

Fauske et al. (1995) prepared the various tested organic complexant and oxidant mixtures at target total organic carbon (TOC) contents and converted to an energetics scale using Burger's (1995) calculated maximum thermodynamic enthalpies for each complexant and nitrate as the oxidant. The team used the implicit assumption of the empirically developed CTI criterion that the heat dissipation rate of the tank waste storage system is equivalent to or greater than the heat dissipation rate of the ignition tube test device. In addition, because data on the effects of diluents were limited to water in the CTI criterion, water was the only diluent considered in this 


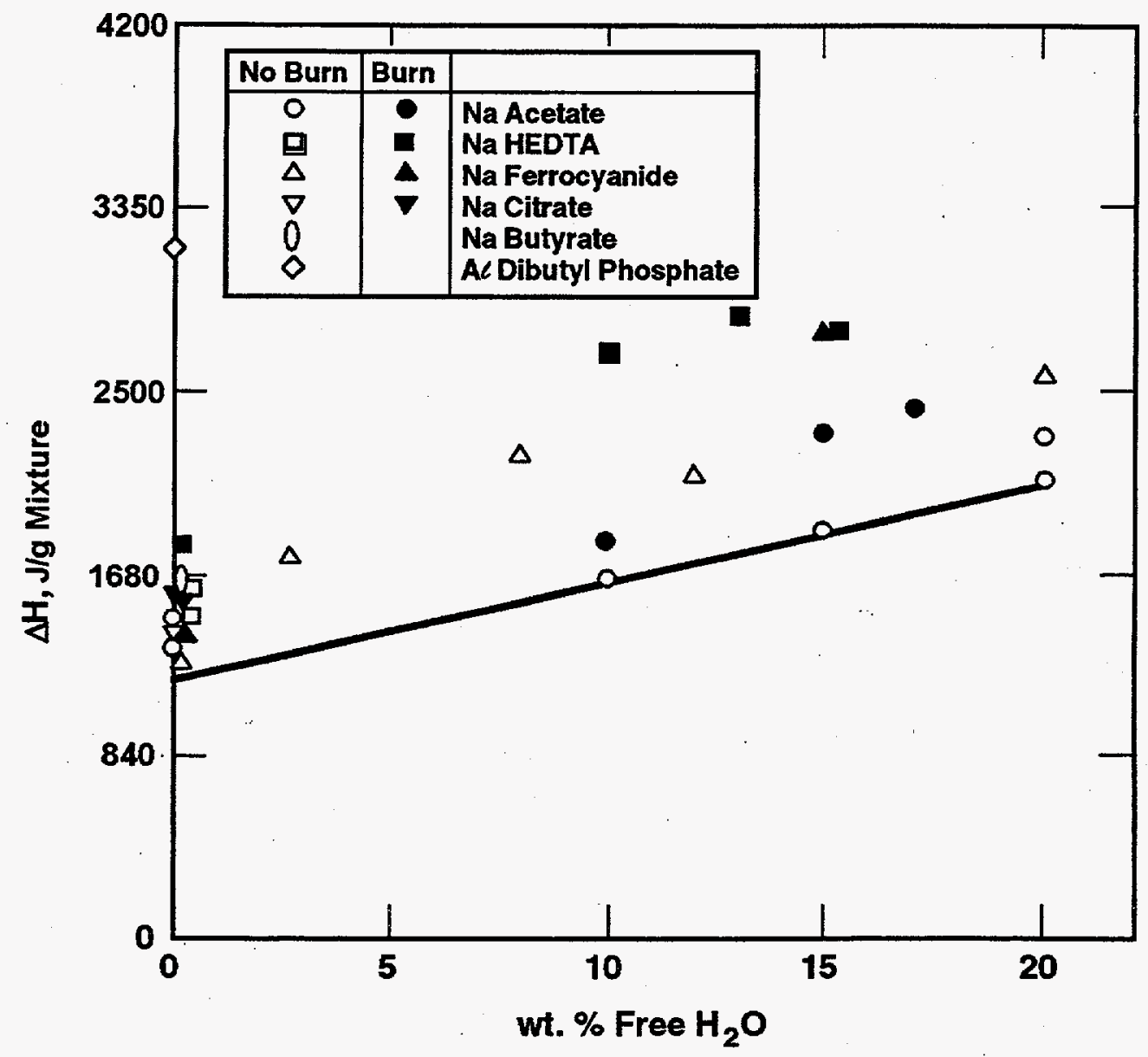

Figure 2.2. Contact Temperature Ignition Energetics Criteria for Organic-Bearing Hanford Wastes

exercising of the strategy. It should be noted that Kubic (1996) of LANL and the AIChE (1995) provide similar criteria based on energy density. The hazards assessment model determines whether a waste at a particular location is reactive by comparing the energy density and the water content to the hazards criterion.

An estimate of energetics and diluent is determined using the parameters of energetics and diluent concentration and uncertainty in those concentrations for the tank surface and subsurface. The energetics parameters are estimated from measured or predicted TOC contents and Burger's calculated enthalpy. The diluent parameters are estimated from direct measurements or statistical prediction. 


\subsection{Reaction Risk Calculation}

The following sections describe the risk calculation used for the organic-nitrate reaction frequencies. Included is a description of the key assumptions made in the analysis, the structure of the risk calculation, the state-space descriptions, and the information and/or data flow.

\subsubsection{Assumptions Considered in the Reaction Risk Calculation}

The following assumptions were made in using the condensed phase organic-nitrate SLD previously described to make a reaction risk calculation. In general, assumptions were made that tend to provide conservative assessments of the risks of organic-nitrate reactions.

- The reactive waste volume, fraction of reactive waste at the surface, and fraction of reactive waste at the surface that is dry are independent.

- The reactive waste volume, fraction of reactive waste at the surface, and fraction of reactive waste at the surface are represented as discrete approximations of their continuous distribution.

- The waste surface is $20 \mathrm{~cm}$ in depth.

- The probability of ignition by a point source is the ratio of the volume of material that could be ignited to the volume of all waste in the appropriate region (surface or entire waste volume) of the tank.

- The probability of ignition by a non-point source depends on the footprint of the source and reactive waste volume. A torch is assumed to have a footprint of $1 \mathrm{~m}$ radius. A vehicle fuel fire is assumed to have a footprint of $2 \mathrm{~m}$ radius. Lightning, flammable gas, solvent fire, and bulk heating are assumed to have a footprint that covers the diameter of the tank.

- Ignition sources are treated as independent events.

- The solvent fire initiator was considered redundant to the condensed phase organic-nitrate reaction and given a zero probability to avoid double-counting its impact.

- The probability of ignition is calculated as the sum of its component probabilities.

- Each initiator can ignite waste in any tank, except the bulk heatup, which only applies to Tank C-106.

- The midpoint of each reactive waste region from the fuel/moisture analysis was assumed to be the representative point for estimation of consequences and basis for volume ratio/footprint. 
- All reactive waste is located in a single contiguous mass.

\subsubsection{Calculation Concept and Structure}

In the probabilistic risk framework, data on the organic constituents, moisture level, and vertical location within a tank becomes a risk-management tool. The basic concept of the reaction risk calculation is to predict the risk (i.e., frequencies of events with specific severity/ consequences) of organic-nitrate reactions as a function of tank contents.

Tank contents are described in terms of state-space descriptors, which are equivalent to the amount of reactive waste (R), the fraction of reactive waste at surface (S), the fraction of reactive waste at surface that is dry (D), and the uncertainty in these estimates. The probabilistic risk calculation was implemented using estimates of the frequencies of reaction initiation events and conditional probabilities of reaction propagation (given an initiator was present) expressed as functions of $R, S$, and $D$. The basic probability structure of the calculation was thus:

$$
\operatorname{Pr}\left(E_{i j} \mid I_{k}\right)=\operatorname{Pr}\left[R_{l}, S_{m}, D_{n}\right]_{p}
$$

where

$\operatorname{Pr}\left(E_{i j} \mid I_{k}\right)=$ probability that a reaction event will proceed from stage $i$ to stage $j$ given that initiator $I_{k}$ has occurred in tank $p$.

$\mathrm{R}_{1} \quad=$ reactive waste state 1 (one of several discrete states defined by reactive waste volume).

$\mathrm{S}_{\mathrm{m}} \quad=$ reactive waste at the surface state $\mathrm{m}$ (one of several discrete states of reactive waste at the tank surface).

$\mathrm{D}_{\mathrm{n}} \quad=$ reactive waste at the surface that is dry state $\mathrm{n}$ (one of several discrete states of reactive waste at the tank surface that is dry).

Since knowledge of the R-S-D status will be subject to some (often considerable) uncertainty even with respect to fairly large ranges representing the discrete fuel and moisture states, four event severity consequences defined over 12 discrete volumes of reactive waste were used to define the range of possible organic-nitrate reaction scenarios and the consequences of release events.

The frequency of an organic-nitrate reaction event was calculated as the product of the frequencies of various initiators and the conditional probabilities that specific tanks contain wastes in given $\mathrm{R}, \mathrm{S}$, and $\mathrm{D}$ states.

\subsubsection{Reaction Frequency Estimates}

The next section illustrates how the tank contents estimates are used in conjunction with reaction initiator frequencies and the behavior of the initiator relative to the reactive waste distributions to calculate the frequency of an event in each severity/consequence class. 


\subsubsection{Structure of the Organic-Nitrate Risk Calculation}

Figure 2.3 is the schematic tree representation of the calculation for describing the risk parameter about each tank's organic and moisture contents. This schematic is an interpretation of the calculations represented in the SLD and clearly shows how uncertainty in the values of measurements are pervasive throughout the risk calculation. The tree follows all of the same conventions of any decision tree calculation; namely, uncertain event nodes are shown as circles, and a probability distribution represents uncertainty about which branch will occur at event nodes, the path leading to any point in the tree is determined, and the paths to the right of any point are not yet determined. Reading left to right, the first uncertainty is the volume of reactive waste that exists in the tank. This is followed by the uncertainty of the fraction of reactive waste at the surface. Next is the uncertainty of fraction associated with the reactive waste at the surface that is dry. The final node is an uncertain event node of outcome severity, which ranges from no event to dome failure and its potential release of tank contents.

The tree in Figure 2.3 is schematic; it shows the details of each node but does not show the interconnections of nodes and branches that determine the tree. The tree is formed by attaching each node to every branch of its preceding node. For example, the node containing all of the fractions of reactive waste at the surface is attached to every branch of the node containing volume of reactive waste.

\begin{tabular}{|c|c|c|c|}
\hline $\begin{array}{l}\text { Volume of } \\
\text { Reactive } \\
\text { Waste }\end{array}$ & $\begin{array}{l}\text { Fraction of } \\
\text { Reactive Waste at } \\
\text { the Surface }\end{array}$ & $\begin{array}{c}\text { Fraction of Dry } \\
\text { Surface Reactive } \\
\text { Waste }\end{array}$ & Event \\
\hline$<$ HEPA & $<5 \%$ & $<5 \%$ & No Release \\
\hline Blown HEPA 1 & $5-15 \%$ & $5-15 \%$ & Blown HEPA \\
\hline Blown HEPA2 & $15-25 \%$ & $15-25 \%$ & Dome Failure \\
\hline Blown $\mathrm{HEPA}_{3}$ & $25-35 \%$ & $25-35 \%$ & Dome Failure \\
\hline Blown HEPA4 & $35-45 \%$ & $35-45 \%$ & with Continued \\
\hline 1-3X Dome Failure & $45-55 \%$ & $45-55 \%$ & \\
\hline 3-6x Dome Failure & $55-65 \%$ & $55-65 \%$ & \\
\hline 6-12X Dome Failure & $65-75 \%$ & $65-75 \%$ & \\
\hline 24-48X Dome Failure & $75-85 \%$ & $75-85 \%$ & \\
\hline \multirow[t]{2}{*}{$>96 \times$ Dome Failure } & $85-95 \%$ & $85-95 \%$ & \\
\hline & $>95 \%$ & $>95 \%$ & \\
\hline
\end{tabular}

Figure 2.3. Schematic Representation of Organic-Nitrate Risk Calculation 


\subsubsection{Input and Output}

Inputs to the risk calculation, based on the SLD, are 1) tank volume, 2) tank diameter, 3) total waste volume, 4) thresholds for each event pathway, 5) the probability distribution on volume of reactive waste, 6 ) the probability distribution of the fraction of reactive waste at the surface, 7) the probability distribution of the fraction of reactive waste at the surface that is dry, and 8) ignition frequencies for all reaction initiators.

Results are calculated using the standard rollback procedure for decision trees. The expected value for the tank is the sum of products of the initiator frequencies, state-space $(R, S$, D) conditional probabilities, and the expected consequence given the event frequencies (Equation 2.2).

Output from the risk calculation includes the complementary cumulative distribution of the frequencies of each of 11 consequence (reacted waste volume) regions described in Section 3. The complementary cumulative distribution describes the frequency that the tank will have an event that exceeds the given frequency threshold. 


\subsection{Parameter Estimates}

This section presents the collection of data including parameter estimates and their development for use in the risk calculation.

\subsection{Initiator Definitions and Probabilities}

Nine initiators have been considered in the condensed phase organic-nitrate reaction risk calculation: electrical, torch, cutting, a vehicle fuel fire, rotary mode core drilling upsets, lightning, flammable gas, solvent fires, and bulk heating. Bulk heating as an initiator was applied only to Tank C-106. A summary of these initiators, their behavior, and the frequency assigned is shown in Table 3.1.

Initiators are categorized as a point source or non-point source. The probability of ignition by a point source is the ratio of the volume of material that could be ignited to the volume of all waste in the appropriate region of the waste in the tank. The probability of ignition by a non-point source depends on the footprint of the source. A torch is assumed to have a footprint of $1 \mathrm{~m}$ radius. A vehicle fuel fire is assumed to have a footprint of $2 \mathrm{~m}$ radius.

Table 3.1. Summary of Organic-Nitrate Reaction Initiators

\begin{tabular}{|l|l|c|c||}
\hline Initiator Type & $\begin{array}{c}\text { Point Source } \\
\text { Versus Non-Point } \\
\text { Source }\end{array}$ & $\begin{array}{c}\text { Waste } \\
\text { Affected }\end{array}$ & $\begin{array}{c}\text { Frequency } \\
\text { (per SST-year) }\end{array}$ \\
\hline Electrical & point source & $\begin{array}{c}\text { surface } \\
\text { dry }\end{array}$ & $1.8 \mathrm{E}-02$ \\
\hline Torch & non-point source & surface & $2.70 \mathrm{E}-02$ \\
\hline Cutting & point source & $\begin{array}{c}\text { surface } \\
\text { dry }\end{array}$ & $2.70 \mathrm{E}-02$ \\
\hline Vehicle Fuel Fire & non-point source & surface & $3.30 \mathrm{E}-03$ \\
\hline $\begin{array}{l}\text { Rotary Core Drill } \\
\text { Upset }\end{array}$ & point source & all & $2.70 \mathrm{E}-02$ \\
\hline Lightning & point source & all & $2.50 \mathrm{E}-06$ \\
\hline Flammable Gas & non-point source & $\begin{array}{c}\text { surface } \\
\text { dry }\end{array}$ & $9.30 \mathrm{E}-04$ \\
\hline Solvent Fire & non-point source & surface & redundant ${ }^{(a)}$ \\
\hline $\begin{array}{l}\text { Bulk Heating } \\
\text { (C-106 only) }\end{array}$ & non-point source & all & $2.00 \mathrm{E}-01$ \\
\hline $\begin{array}{l}\text { (a) The solvent fire initiator was considered, but a frequency was not } \\
\text { estimated because it was considered an event with redundant initiators to } \\
\text { the organic-nitrate reaction. }\end{array}$ \\
\hline
\end{tabular}


Lightning, flammable gas, solvent fire, and bulk heating (bulk heating applies to Tank C-106 only) are assumed to have a footprint that covers the diameter of a tank. Each ignition source and the waste region that it may ignite are shown in Figure 3.1. Details of the derivation of initiator frequency behavior can be found in Appendix C.

The probability of ignition is calculated as the sum of its component probabilities. This treats ignition sources as mutually exclusive. It is a good approximation if component probabilities are small.

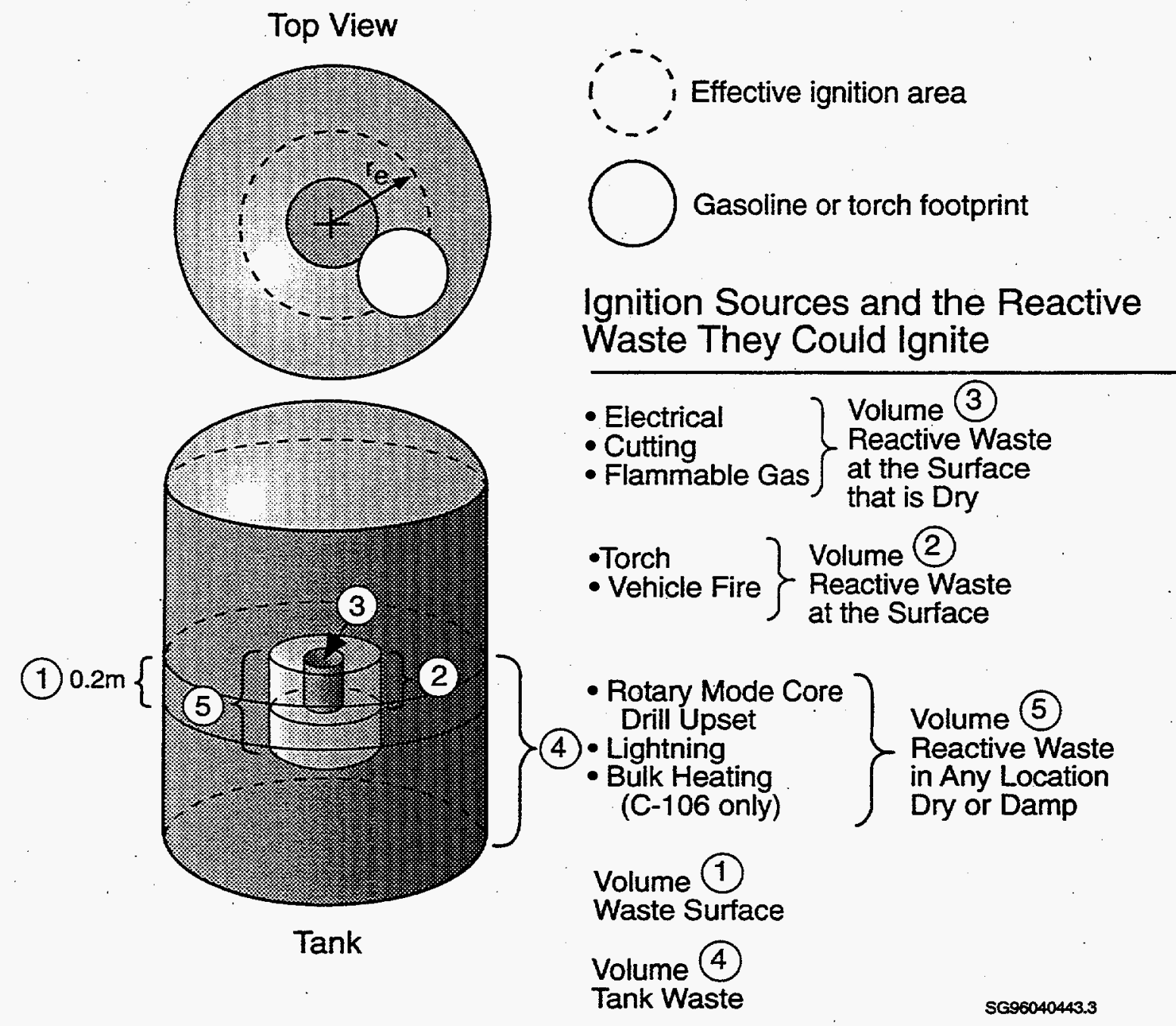

Figure 3.1. Ignition Sources and the Reactive Waste that Could Ignite 


\subsection{Tank Contents}

This section describes how tank contents are defined for this analysis and how the contents estimates were made.

\subsubsection{Assumptions Considered in Estimating Tank Contents}

The following simplifying assumptions were made in estimating tank contents for this analysis. In general, the assumptions tended to provide more conservative assessments of the risks of organic-nitrate reactions.

- The distribution of TOC and water was assumed to be lognormal.

- Nitrate was the only oxidant considered.

\subsubsection{Tank Contents Definitions}

Tank contents are described in terms of state-space probabilistic distributions, which are defined as the amount of reactive waste (R), the fraction of reactive waste at surface (S), the fraction of reactive waste at surface that is dry (D), and the uncertainty in $R, S$, and D (see Section 2.3.2). An illustration of the state-space representation of the waste in a tank is shown in Figure 3.2. A detailed description of the development of the state-space estimates is provided in the following section.

The volume of reactive waste (R) in a tank is described in terms of the probability that specific volumes of reactive waste exist in the waste. This probability density function represents a discrete approximation of the continuous distribution of reactive waste volume probabilities. The reactive waste volumes are divided into 12 discrete regions that become progressively larger. Region 1 represents the volume of reactive waste less than that amount which, if ignited, can burn to create enough pressure $(<1.5 \mathrm{psig})$ to fail a HEPA filter. Regions 2 through 5 represent progressively larger volumes of reactive waste which, if ignited, can burn to create enough pressure (1.5 to $11 \mathrm{psig}$ ) to fail a HEPA filter but will not cause tank dome failure. Region 6 represents a progressively larger volume of reactive waste, which, if ignited, can burn to create just enough pressure ( $11 \mathrm{psig})$ to cause tank dome failure. Regions $7-12$ represent progressively larger volumes of reactive waste, which, if ignited, can burn to create enough pressure ( $>11 \mathrm{psig}$ ) to cause tank dome failure; these regions also have enough volume to have continuous release or ejection of tank contents to the environment. Table 3.2 shows the discrete regions of total reactive waste in a tank and the representative volumes as calculated from event threshold volumes.

Reactive waste at the surface (S) is expressed as the fraction of reactive waste that is in the top $20 \mathrm{~cm}$ of the tank waste. Reactive waste at the surface that is dry (D) is expressed as the fraction of reactive waste in the top $20 \mathrm{~cm}$ of the tank waste that is dry. The probability 


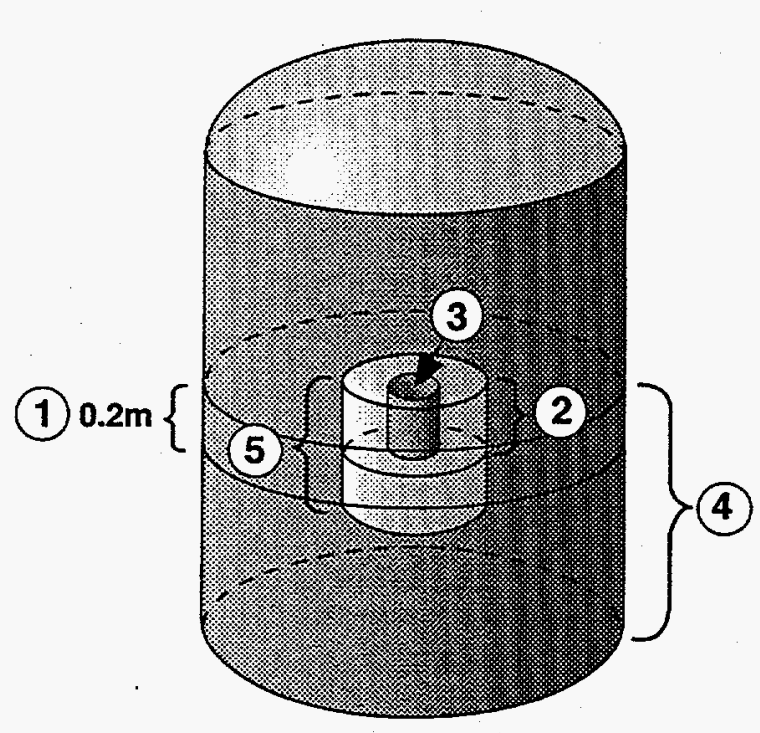

Volumes

(1) Tank Waste @ Surface $=W_{S}$

(2) Reactive Waste @ Surface = S

(3) Dry Reactive Waste @ Surface = D

(4) Tank Waste $=W$

(5) Reactive Waste $=R$

Fraction of Reactive Waste at Surface $=F_{S}$

Fraction of Reactive Waste at Surface that is Dry $=$ FD

SG96040443.1

Figure 3.2. State-Space Representation of Tank Contents

distribution that represents these parameters consist of discrete approximations of the continuous distributions derived by the fuel/moisture analysis described in the next section.

\subsubsection{Tank Contents Estimates}

This section presents the statistical calculations used to estimate the fraction of reactive waste in each of the 138 SSTs that were analyzed. A collection of moisture $\left(\mathrm{H}_{2} \mathrm{O}\right)$ and TOC measurements from waste samples is used in this effort. For these calculations, reactive waste is defined as having concentrations of $\mathrm{H}_{2} \mathrm{O}$ and TOC that fall within the Fauske region (Fauske et al. 1995) (Section 2.2) given current waste conditions. Reactive waste distributions are estimated for each tank from the data on TOC and $\mathrm{H}_{2} \mathrm{O}$ provided by Meacham et al. (1997) (see subsection 3.3.3.1) and statistical preparation (tank grouping, analysis of variance [ANOVA] and variable transformation, and Monte Carlo approach) as described in subsection 3.3.3.2.

The reactive waste distributions describe our estimate of reactive waste as an average or mean and the uncertainty about that mean, given current data. The estimates representing the tank contents are Bayesian posterior distributions (expected value probability distributions derived from current data). The methodology used to calculate the posterior distributions uses a random effects ANOVA calculation and a "variable transformation." ANOVA produces a Bayesian posterior distribution of moisture and TOC in a tank, while the variable transformation converts the posterior distribution of moisture and TOC to a posterior distribution describing 
Table 3.2. Representative Region and Total Volume of Reactive Waste

\begin{tabular}{||l|l|l||}
\hline \begin{tabular}{|l|l||} 
Representative \\
Region
\end{tabular} & Tank Response & Total Volume of Reactive Waste \\
\hline Region 1 & no event & less than volume necessary for HEPA failure \\
\hline Region 2 & HEPA failure & HEPA threshold volume to 1/3 dome failure volume \\
\hline Region 3 & HEPA failure & $1 / 8$ to $1 / 4$ dome failure volume \\
\hline Region 4 & HEPA failure & $1 / 4$ to $1 / 2$ dome failure volume \\
\hline Region 5 & HEPA failure & $1 / 2$ to just less than dome failure volume \\
\hline Region 6 & $\begin{array}{l}\text { HEPA failure, dome } \\
\text { failure }\end{array}$ & 1 to 3 times dome failure volume \\
\hline Region 7 & $\begin{array}{l}\text { HEPA failure, } \\
\text { dome failure, } \\
\text { continued release }\end{array}$ & 3 to 6 times dome failure volume \\
\hline Region 8 & $\begin{array}{l}\text { HEPA failure, } \\
\text { dome failure, } \\
\text { continued release }\end{array}$ & 6 to 12 times dome failure volume \\
\hline Region 9 & $\begin{array}{l}\text { HEPA failure, } \\
\text { dome failure, } \\
\text { continued release }\end{array}$ & 12 to 24 times dome failure volume \\
\hline Region 10 & $\begin{array}{l}\text { HEPA failure, } \\
\text { dome failure, } \\
\text { continued release }\end{array}$ & 24 to 48 times dome failure volume \\
\hline Region 11 & $\begin{array}{l}\text { HEPA failure, } \\
\text { dome failure, } \\
\text { continued release }\end{array}$ & 48 to 96 times dome failure volume \\
\hline Region 12 & $\begin{array}{l}\text { HEPA failure, } \\
\text { dome failure, } \\
\text { continued release }\end{array}$ & greater than 96 times dome failure volume \\
\hline
\end{tabular}

reactive waste. The specific posterior distribution produced by the ANOVA describes the uncertainty on the tank means and standard deviations and is of the form

$$
p\left(\mu_{\mathrm{H}_{2} \mathrm{O}}, \mu_{T O C}, \sigma_{\mathrm{H}_{2} \mathrm{O}}, \sigma_{T O C} \mid \mathrm{H}_{2} \mathrm{O} \text { and TOC data }\right)
$$

where the mean $(\mu)$ appearing in equation (3) represents the mean $\mathrm{H}_{2} \mathrm{O}$ and TOC values in a specific tank on the log scale. The standard deviation $(\sigma)$ in equation (3) represents the within tank variability. This posterior is transformed into a distribution on reactive waste by using the Fauske criteria (Section 2.2) to relate reactive waste to the $\operatorname{tank}\left(\mathrm{H}_{2} \mathrm{O}, \mathrm{TOC}\right)$ statistics. This variable transformation can be summarized as follows:

$$
\text { Reactive Waste } R W=H\left(\mu_{H_{2} O}, \mu_{T O C}, \sigma_{H_{2} O}, \sigma_{T O C}\right)
$$


A Monte Carlo approach is used to construct the posterior distribution from the original posterior and the variable transformation:

$$
p\left(\mathrm{RW} \mid \mathrm{H}_{2} \mathrm{O} \text { and TOC data }\right)
$$

A review of the TOC and $\mathrm{H}_{2} \mathrm{O}$ data is given in subsection 3.3.3.1, including descriptions of tank sampling and laboratory analysis methods, issues about the sampling and analysis methods, and data sources and data that were excluded. The grouping, ANOVA, and Monte Carlo methods are discussed in subsection 3.3.3.2.

\subsubsection{Review of the Data}

This section contains a review of and some general information about the data that are used for the reactive waste calculations. The data set was prepared for use Meacham et al. (1997) for safety analysis reporting. That approach to review and preparation of the data set is described in general terms in this section and in detail in Meacham et al. (1997). An attempt was made to gather all relevant TOC and percent $\mathrm{H}_{2} \mathrm{O}$ sampling data from as many waste tanks as possible. The majority of the data were taken from the Tank Characterization Database (TCD), which contains tank waste sample measurements from 1989 through mid-1997 (as of the writing of this report). A small number of pre-1989 sample records used were taken from various other sources (e.g., process aid reports and selected core composite data) and are also included in the $\mathrm{TOC} / \mathrm{H}_{2} \mathrm{O}$ data set when post- 1989 data were not available. All reasonable efforts have been made to include all TOC and $\mathrm{H}_{2} \mathrm{O}$ sampling data available as of March 1997 in the data set.

Tank waste samples are taken in one of several ways: sampling, auger sampling, or grab (bottle-on-a-string) sampling. The core sampling method usually provides the most valuable information since it provides a complete vertical profile of the tank waste. Auger sampling is used to take samples close to the surface of the waste (penetrates approximately $40 \mathrm{~cm}$ into the waste). Grab sampling is the method used to take supernatant samples from tanks. This method is primarily used to sample double-shell tanks, which are not included in this study.

If the amount of drainable liquid from the sample was greater than $25 \mathrm{~mL}$ during extrusion, the liquid and solid phases were analyzed separately. If the amount was less than $25 \mathrm{~mL}$, the solid and liquid phases were blended together. Drainable liquid sample results existed for 29 tanks; of these, there was sufficient information for nine tanks to allow weighted averages of the solid and liquid phase results to be constructed. Solid and liquid phase results for the other 20 tanks were not combined but were all used in the ANOVA effort.

TOC is measured in a prepared sample by first oxidizing the organic species into carbon dioxide. The carbon dioxide gas analyzer then detects the amount of $\mathrm{CO}_{2}$ that is produced. In this process all of the organic species information is lost (i.e., the concentration of each organic 
species is not measured). Since each organic species has a different energy, speciation assumptions must be made in the absence of sampling information from that tank.

Fifteen percent of the collected data records were not used in the statistical calculations. The following are reasons that these data records were excluded:

- Laboratory records were reviewed and revealed an incorrect measurement or a quality assurance problem.

- Measurement was taken on a supernatant sample. The supernatant samples were not deemed to be of interest when calculating the fraction of the waste that is reactive. Note that does not include the drainable liquid samples discussed earlier.

- For some tanks, core composite and sub-core (segment or subsegment) measurements are available. When both were available, the core composites were excluded because the sub-core analyses are thought to provide the best estimates of within-tank variability.

- Sample measurements are available for more than one time period. When this is the case, the latest set of measurements is retained.

- Eleven tanks were not included in the data set because of difficulties assigning them to tank groups. These tanks are B-201, B-202, B-203, B-204, C-101, C-102, C-103, C-201, C-202, C-203 and C-204.

A primary objective of the data-gathering.effort was to obtain a relatively complete and representative set of data. There was one possible source of bias that was identified in the TOC measurements. During the period from 1992 to 1995 , TOC sample analyses were conducted only if there was a positive differential scanning calorimetry (DSC) measurement. For this reason the TOC measurements from this time period may be biased high. There is not much information available about the relationship between TOC and DSC measurement; therefore, bias correction cannot be made.

As mentioned earlier, most of the data were taken from the TCD; 4,448 of the 4,741 measurements. The remaining 293 records were taken from process aid reports, selected core composite data, and data measured in 1997 that have not yet been included in the TCD. These records were carefully reviewed to make sure they met current waste conditions in the tanks. If they did not, the records were not used.

Once the data set was assembled, all of the primary, duplicate, and triplicate sample results records from unique locations were averaged together. These unique locations include such designations as whole-segment, half-segment, or quarter-segment. In most cases, the results that were averaged were the primary and duplicate results, which are from separate chemical analysis on the same sample aliquot. The averaged results were then assigned to the surface or subsurface layers of a tank. Auger and first segments from core samples were assigned to the surface layer. Segments 2 and higher from core sampling efforts are assigned to the subsurface layer. In the isolated cases where core composites were used, these were assigned to the subsurface layer. 
Table 3.3 contains a brief summary of the $\mathrm{TOC} / \mathrm{H}_{2} \mathrm{O}$ data collected and prepared for the ANOVA calculation. The maximum TOC concentration in the table was found in Tank AX-102, in the surface layer. The minimum water concentration value of $1 \%$ was found in Tanks $\mathrm{C}-111$ and BY-111.

Table 3.4 shows details on the two highest TOC sample results found in the data set. These results were not contained within the reactive waste region (i.e., they do not represent waste that will sustain a propagating reaction). Considering the uncertainty of these estimates, there is a measurable probability that the true surface layer value is in the reactive waste region. Meacham et al. (1997) contains a more complete description and presentation of the individual data records.

Table 3.5 presents the number of tanks that have $\mathrm{TOC}$ and $\mathrm{H}_{2} \mathrm{O}$ data that were used in the reactive waste calculations. Sixty-one of the 149 SSTs have both TOC and $\mathrm{H}_{2} \mathrm{O}$ data; 64 do not. The tank grouping information is used in the ANOVA to get estimates of TOC and $\mathrm{H}_{2} \mathrm{O}$ parameters for tanks that are missing data for either or both TOC and $\mathrm{H}_{2} \mathrm{O}$. Therefore, the 64 tanks missing both TOC and $\mathrm{H}_{2} \mathrm{O}$ data had their tank contents estimated based upon their presence in a particular group. Further investigation of tank data shows that 113 tanks have less than two TOC samples (taken from fewer than two locations in a tank). Therefore, tanks having significant uncertainty in tank contents were nonetheless used to provide estimates for themselves as well as for tanks with no measurements.

Table 3.3. Summary of Data Prepared for ANOVA

\begin{tabular}{||r|r|r|r|r|r|r|r||}
\hline Constituent & Minimum & $\begin{array}{c}1^{\text {st }} \\
\text { Quartile }\end{array}$ & Median & Mean & $\begin{array}{c}3^{\text {rd }} \\
\text { Quartile }\end{array}$ & Maximum & $\begin{array}{c}\text { Observations } \\
\text { Not } \\
\text { Applicable }\end{array}$ \\
\hline TOC (wt\%) & 0.01 & 0.143 & 0.348 & 0.502 & 0.628 & 5.73 & 194 \\
\hline $\mathrm{H}_{2} \mathrm{O}(\mathrm{wt} \%)$ & 1 & 25.9 & 37.4 & 38.1 & 49.4 & 91.4 & 36 \\
\hline
\end{tabular}

Table 3.4. Tank AX-102 Data Records

\begin{tabular}{|c|c|c|c|c|c|c||}
\hline Layer & Riser ID & $\begin{array}{c}\text { Segment } \\
\text { ID }\end{array}$ & $\begin{array}{c}\text { TOC } \\
(\mathrm{wt} \%)\end{array}$ & $\begin{array}{c}\mathrm{H}_{2} \mathrm{O} \\
(\mathrm{wt} \%)\end{array}$ & $\begin{array}{c}\text { \# Obs. } \\
\text { TOC }\end{array}$ & $\begin{array}{c}\text { \# Obs. } \\
\mathrm{H}_{2} \mathrm{O}\end{array}$ \\
\hline Surface & $3 \mathrm{a}$ & 1 & 5.73 & 28.79 & 2 & 2 \\
\hline Surface & 9 & 1 & 5.58 & 32.21 & 2 & 2 \\
\hline
\end{tabular}


Table 3.5. SST Data Observations

\begin{tabular}{||c|c|c|c|}
\hline & $\begin{array}{c}\text { Tanks with } \\
\text { TOC Data }\end{array}$ & $\begin{array}{c}\text { Tanks without } \\
\text { TOC Data }\end{array}$ & Total \\
\hline \hline $\begin{array}{c}\text { Tanks with } \\
\mathrm{H}_{2} \mathrm{O} \text { data }\end{array}$ & 61 & 18 & 79 \\
\hline $\begin{array}{c}\text { Tanks without } \\
\mathrm{H}_{2} \mathrm{O} \text { data }\end{array}$ & 6 & 64 & 70 \\
\hline Total & 67 & 82 & 149 \\
\hline
\end{tabular}

\subsubsection{Estimation Methodology}

A general description of the methodology used to calculate the reactive waste estimates is given in this section. Meacham et al. (1997) contains a more complete discussion of the methodology. For this part of the study, reactive waste is defined as waste that has weight percent TOC and weight percent $\mathrm{H}_{2} \mathrm{O}$ in the following region as defined by Fauske et al. (1995) (Section 2.2):

$$
\text { TOC }>4.5 \%+0.17 * \mathrm{H}_{2} \mathrm{O}, \mathrm{H}_{2} \mathrm{O}<20 \%
$$

The objective is to calculate the proportion of each tank waste that meets this criterion. The TOC and $\mathrm{H}_{2} \mathrm{O}$ data discussed in the last section can be used to accomplish this objective. There are four steps that are taken to calculate reactive waste distributions:

1) Perform an ANOVA on the TOC data to determine the TOC distribution for each tank.

2) Perform an ANOVA on the $\mathrm{H}_{2} \mathrm{O}$ data to determine the $\mathrm{H}_{2} \mathrm{O}$ distribution for each tank.

3) Calculate the correlation between TOC and $\mathrm{H}_{2} \mathrm{O}$ using the known ordered TOC and $\mathrm{H}_{2} \mathrm{O}$ data pairs. This correlation is calculated to completely specify the bivariate distribution. of $\mathrm{H}_{2} \mathrm{O}$ and TOC.

4) Conduct a Monte Carlo simulation to estimate the proportion of reactive waste in each tank using the $\mathrm{TOC} / \mathrm{H}_{2} \mathrm{O}$ distributions and the associated uncertainty estimates from the parameters of the distributions. 


\section{Tank Grouping}

Tanks with similar waste properties are grouped together to allow estimation of TOC and $\mathrm{H}_{2} \mathrm{O}$ concentrations for unmeasured tanks using ANOVA. The tanks were organized into five groups based on waste chemistry and process waste stream information in the exact same manner as Meacham et al. (1997). The five groups are "High TOC," "Medium TOC," "Low TOC,", "Non-TOC," and "Special" tanks. This classification of tanks is not perfect because of errors in the historical record and secondary waste stream information. For example, "Non-TOC" categorized tanks may have TOC from a secondary waste stream that was not recorded in the historical record.

A different tank grouping was used for moisture concentrations in the tanks. The tanks were classified based on the general type of waste and the wetness of the waste surface in the same manner as Meacham et al. (1997). This categorization resulted in the following four groups: dry saltcake, dry sludge, wet saltcake, and wet sludge.

Eleven tanks were not able to be assigned to the five TOC groups or the four moisture groups, nor could any other group be designed for them. Therefore, these 11 tanks were removed from further consideration.

These tank groupings are principally introduced allow $\mathrm{TOC} / \mathrm{H}_{2} \mathrm{O}$ estimates to be extrapolated to tanks without any data. The extrapolation procedure used by ANOVA is quite intuitive; the group means (on the log scale) are used to estimate what is in a tank with no data. The uncertainty associated with this extrapolation depends upon how homogeneous the group of tanks is. If there is little variability among tanks in the group, the group mean will be assigned a small uncertainty (as a predictor of an unmeasured tank). If, on the other hand, the tanks in the group show a great deal of variability, then the group mean will be assigned a large uncertainty.

It is obvious that the results associated with an unmeasured tank can be dramatically altered by simply moving it from one group to another. For example, an unmeasured tank in a "low TOC" group will become a "high TOC" tank if moved to a "high TOC" group. It is therefore important that the group assignments be not arbitrarily made but accomplished according to objective characteristics that are available for all tanks. In the case of the present grouping scheme, the objective characteristics used to produce the grouping scheme come from tank process history as compiled by Agnew (1997).

Ideally, the grouping scheme should be constructed before the tanks to be measured are sampled. The tanks to be measured should be selected from the identified groups according to a well-defined experimental protocol that would ensure that a representative set of tanks is selected from each group. This is usually accomplished by selecting random subsets of tanks for measurement. If such an experimental protocol were used to select tanks for measurement, there could be little debate about the validity of the grouping used. 
In this case, the grouping actually was constructed after the tanks were measured. Under these circumstances, the critical requirement is still the same: the measured tanks must form a representative subsample of all tanks in the group. Although the decision process used to identify tanks for sampling is very complex, and many diverse criteria are used to select tanks for measurement, one of the major inputs used to identify tanks for sampling is the same process history used to construct the groups in this study. Furthermore, the process history was generally used in the same way to identify tanks for sampling. The fact that tank sampling was based on this information is a strong motivation for constructing the groups in this manner.

\section{TOC/ $\mathrm{H}_{2} \mathrm{O}$ ANOVA Calculation} calculation:

TOC and $\mathrm{H}_{2} \mathrm{O}$ data are fit separately to the following random effects ANOVA

$$
Y_{i j k l}=\mu+D_{i}+G_{j}+D G_{i j}+T_{j k}+D T_{i j k}+E_{i j k l}
$$

where

$\mathrm{Y}_{\mathrm{ijkl}}=$ TOC or $\mathrm{H}_{2} \mathrm{O}$ concentration values for sample $\mathrm{ijkl}$

$\mu=$ mean concentration for the site

$D_{i} \quad=$ deviation of tank layer $i$ (surface or subsurface)

$\mathrm{G}_{\mathrm{j}} \quad=$ deviation of tank group $\mathrm{j}$

$\mathrm{DG}_{\mathrm{ij}}=$ deviation of layer $\mathrm{i}$ and group $\mathrm{j}$ interaction

$\mathrm{T}_{\mathbf{j k}}=$ deviation of tank $\mathbf{k}$ from the $\mathrm{j}^{\text {th }}$ group mean

$\mathrm{DT}_{\mathrm{ij} \mathrm{k}}=$ deviation of layer $\mathrm{i}$ and tank $\mathrm{k}$ interaction in group $\mathrm{j}$

$\mathrm{E}_{\mathrm{ijkl}}=$ spatial deviations within layer ijk.

A multivariate ANOVA calculation for TOC and $\mathrm{H}_{2} \mathrm{O}$ is not fit since only $60 \%$ of the $\mathrm{TOC} / \mathrm{H}_{2} \mathrm{O}$ records are paired by sample.

The ANOVA is used to estimate all of the unknown parameters in the above calculation. With the exception of the site mean, the ANOVA also estimates the variance estimates for each term in the equation. These parameter estimates can, in turn, be used to obtain mean and uncertainty estimates for each tank and layer combination used to specify the joint TOC and $\mathrm{H}_{2} \mathrm{O}$ distributions for the reactive waste calculations. Using this ANOVA approach, tank/layer mean and variance estimates are obtained for tanks without sampling data as well as those with sampling data.

\section{Correlation Between TOC and $\mathrm{H}_{2} \mathrm{O}$}

The ANOVA provides estimates for all of the parameters in the joint $\mathrm{H}_{2} \mathrm{O} / \mathrm{TOC}$ distribution with the exception of the correlation between TOC and $\mathrm{H}_{2} \mathrm{O}$. The ANOVA did not estimate this parameter since the $\mathrm{H}_{2} \mathrm{O}$ and TOC ANOVAs were done separately. Sixty percent of the data could be assigned into $\mathrm{TOC} / \mathrm{H}_{2} \mathrm{O}$ pairs. The residuals from the ANOVA fits for these 
pairs were used to calculate the correlation estimate. The estimated value was $33 \%$. This parameter estimate also has uncertainty associated with it as do the TOC and $\mathrm{H}_{2} \mathrm{O}$ mean estimates. The uncertainty is considered negligible because of the large number of observations used to calculate it.

\section{Monte Carlo Simulation}

Once the distribution parameters have been specified using estimates from the ANOVA, the reactive waste estimates can be made for each tank/layer combination. This is done by integrating the $\mathrm{H}_{2} \mathrm{O} / \mathrm{TOC}$ distribution over the reactive waste region specified as by

$$
R=C_{O} \int_{\left(X_{\mathrm{H}_{2} \mathrm{O}}, X_{\mathrm{TOC}}\right) \in A} f\left(X_{\mathrm{H}_{2} \mathrm{O}}, X_{T O C}\right) d X_{\mathrm{H}_{2} \mathrm{O}} d X_{T O C}
$$

where $f\left(X_{\mathrm{H}_{2} \mathrm{O}}, \mathrm{X}_{\mathrm{rOc}}\right)$ represents the distribution of $\mathrm{H}_{2} \mathrm{O} / \mathrm{TOC}$ values in a tank, $\mathrm{A}$ is the set corresponding to the reactive waste region, and $\mathrm{R}$ is the estimate of reactive waste fraction for the tank.

Using the assumption of lognormality, the estimate of reactive waste becomes

$$
R=C_{O} \int_{Y \in \log (A)} \exp \left[-\frac{1}{2}(Y-\mu)^{T} \Gamma^{-1}(Y-\mu)\right] d Y
$$

where

$$
\begin{gathered}
Y=\left(\log \left(x_{H_{2} \mathrm{O}}\right), \log \left(X_{T O C}\right)\right) \\
C_{O}=\frac{1}{2 \pi \sqrt{1-\rho^{2} \sigma_{H_{2} O} \sigma_{T O C}}} \Gamma=\left[\begin{array}{cc}
\sigma^{{ }^{2} H_{2} O} & \rho \sigma_{H_{2} O} \sigma_{T O C} \\
\rho \sigma_{H_{2} O} \sigma_{T O C} & \left.\sigma^{2} \mu_{T O C}\right)
\end{array}\right]
\end{gathered}
$$

The means and standard deviations (i.e., $\mu$ 's and $\sigma$ 's) in the distribution specified above were obtained from the ANOVA fits. These means and standard deviations are estimates themselves and therefore have uncertainties associated with them. Since these parameters are not known, the reactive waste estimate (R) for each tank has an uncertainty and distribution associated with it also. A Monte Carlo calculation is used to estimate the distribution of $R$ empirically.

A posterior distribution is derived for each $\mathrm{TOC} / \mathrm{H}_{2} \mathrm{O}$ distribution parameter $\left(\mu_{\mathrm{H} 2 \mathrm{O}}, \mu_{\mathrm{TOC}}, \sigma\right.$ ${ }_{\mathrm{H} 2 \mathrm{O}}, \sigma_{\mathrm{TOC}}$ ) from the results of the ANOVA. The mean distributions are conditioned on the variance distributions, so there is a dependence between $\mu_{\mathrm{H} 2 \mathrm{O}}$ and $\sigma_{\mathrm{H} 2 \mathrm{O}}$ distributions and also a 
dependence between $\mu_{\text {TOC }}$ and $\sigma_{\text {TOC }}$ distributions. However, the $\mathrm{H}_{2} \mathrm{O}$ parameter distributions are assumed independent of the TOC distributions. The validity of this assumption was not checked.

Each distribution is divided into 1000 equal probability area bins. A center probability point is taken from each bin to provide 1000 pairs of TOC parameters $\left(\mu_{\text {TOC }}, \sigma_{\text {TOC }}\right)$ and 1000 pairs of $\mathrm{H}_{2} \mathrm{O}$ parameters $\left(\mu_{\mathrm{H} 2 \mathrm{O}}, \sigma_{\mathrm{H} 2 \mathrm{O}}\right)$. The TOC parameter pairs and $\mathrm{H}_{2} \mathrm{O}$ parameter pairs were randomly ordered to obtain 1000 sets of four parameters each. Each set of parameter estimates is fed into the $\mathrm{TOC} / \mathrm{H}_{2} \mathrm{O}$ distribution, and the fraction of reactive waste is calculated by integrating the distribution over the reactive waste region. The 1000 estimates of reactive waste are used to specify the reactive waste fraction distribution for each tank empirically. 


\subsection{Analysis of Results}

This section describes the results of the risk analysis that was performed for each of the tanks according to the criteria developed for this purpose.

\subsection{Base-Case Results}

This study evaluated the event frequencies associated with each tank for the three event severity/consequence classes that represent an undesired outcome (i.e., HEPA failure, dome failure, and dome failure with continued release). Ideally, these criteria would be defined and agreed upon by DOE-RL, regulators, and others. The results of this analysis were then compared to three risk thresholds: $10^{-6}, 10^{-4}$, and $10^{-2}$ events per year. The thresholds are adapted from the Nonreactor Facility Safety Manual (WHC 1989, 1995). Evaluating the tanks in this manner provides a spectrum of the potential event frequencies and consequences for each tank.

Table 4.1 shows the results of the base-case analysis for each tank by event severity consequence. For each event scenario, the frequency of the event is listed along with the results of the comparison to each of the frequency thresholds. One-hundred-thirty-eight SSTs were evaluated in the analysis (the remaining 11 were not considered, as described in Section 3.3.1). For the most stringent frequency/consequence threshold, HEPA failure evaluated at the $10^{-6}$ threshold, 53 of the 138 tanks evaluated were at or below this threshold (passed the criterion). The number of tanks meeting the threshold for this event increases dramatically to 126 when compared to $10^{-4}$. Evaluating the frequency of the dome failure event shows 70 and 130 tanks at or below the thresholds of $10^{-6}$ and $10^{-4}$, respectively. The dome failure plus continued release event severity consequence results in 89 and 132 tanks at or below the thresholds of $10^{-6}$ and $10^{-4}$, respectively. All tanks are below the $10^{-2}$ threshold for each event severity consequence considered. Forty-seven tanks had calculated frequencies of 0 for the most stringent criteria, which can be construed as less than approximately $10^{-10}$ and considered "extremely low risk" for the purposes of this analysis.

A Watch List of 20 tanks has been established in accordance with Public Law 101-510, Section 3137, "Safety Measures for Waste Tanks at Hanford Nuclear Reservation" (1990), and is documented in the Waste Tank Summary Report (Hanlon 1997). Tank AX-102, which is on the Organics Watch List, has the highest calculated frequency for all three event scenarios. Eight of the remaining tanks on the Organics Watch List also do not meet the most stringent threshold considered in this analysis (S-103, SX-106, TX-105, TX-118, U-103, U-105, U-106, and U-111). The tanks on the Organics Watch List are shown in italics in the table; nine of these tanks, however, have frequencies at or below the most stringent threshold of this analysis (A-101, B$103, \mathrm{~S}-102, \mathrm{~S}-111, \mathrm{~T}-111, \mathrm{TY}-104, \mathrm{U}-107, \mathrm{U}-203$, and U-204). And eight of the tanks on the 
Table 4.1. Tank-by-Tank Base-Case Risk Results for Three Event Severity Consequences

\begin{tabular}{|c|c|c|c|c|c|c|c|c|c|c|c|c|}
\hline \multirow[b]{2}{*}{ Tank $^{(a)}$} & \multicolumn{4}{|c|}{ HEPA Failure } & \multicolumn{4}{|c|}{ Dome Failure } & \multicolumn{4}{|c|}{ Dome Failure \& Continued Release } \\
\hline & Frequency & $10^{-6}$ & $10^{-4}$ & $10^{-2}$ & Frequency & $10^{-6}$ & $10^{-4}$ & $10^{-2}$ & Frequency & $10^{-6}$ & $10^{-4}$ & $10^{-2}$ \\
\hline A101 & $0 \mathrm{E}+00$ & Pass & Pass. & Pass & $0 \mathrm{E}+00$ & Pass & Pass & Pass & $0 \mathrm{E}+00$ & Pass & Pass & Pass \\
\hline $\mathrm{A} 102$ & $2 \mathrm{E}-04$ & lail & Fail & Pass & $8 \mathrm{E}-05$ & Fail & Pass & Pass & $3 \mathrm{E}-05$ & Fail & Pass & Pass \\
\hline $\mathrm{A103}$ & $6 \mathrm{E}-05$ & Fail & Pass & Pass & $3 \mathrm{E}-05$ & Fail & Pass & Pass & $2 \mathrm{E}-05$ & Fail & Pass & Pass \\
\hline A104 & $3 \mathrm{E}-06$ & Fiil & Pass & Pass & $0 \mathrm{E}+00$ & Pass & Pass & Pass & $0 \mathrm{E}+00$ & Pass & Pass & Pass \\
\hline A105 & $3 \mathrm{E}-05$ & Fail & Pass & Pass & $6 \mathrm{E}-06$ & Fail & Pass & Pass & $0 \mathrm{E}+00$ & Pass & Pass & Pass \\
\hline $\mathrm{A106}$ & $4 \mathrm{E}-05$ & læail & Pass & Pass & $2 \mathrm{E}-05$ & Fail & Pass & Pass & $1 \mathrm{E}-05$ & Fail & Pass & Pass \\
\hline $\mathrm{AX101}$ & $8 \mathrm{E}-04$ & latil & Fail & Pass & $7 \mathrm{E}-04$ & Fail & Fail & Pass & $7 \mathrm{E}-04$ & lail & Fail & Pass \\
\hline$A X 102$ & $2 \mathrm{E}-03$ & Fail & Fail & Pass & $1 \mathrm{E}-03$ & Fail & Fail & Pass & $8 \mathrm{E}-04$ & Fail & Fail & Pass \\
\hline $\mathrm{AX} 103$ & $4 \mathrm{E}-04$ & Fail & Fail & Pass & $3 \mathrm{E}-04$ & Fail & Fail & Pass & $3 \mathrm{E}-04$ & Fail & Fail & Pass \\
\hline $\mathrm{AX104}$ & $1 \mathrm{E}-06$ & Fail & Pass & Pass & $0 \mathrm{E}+00$ & Pass & Pass & Pass & $0 \mathrm{E}+00$ & Pass & Pass & Pass \\
\hline B101 & $4 \mathrm{E}-06$ & Fail & Pass & Pass & $1 \mathrm{E}-06$ & Fail & Pass & Pass & $0 \mathrm{E}+00$ & Pass & Pass & Pass \\
\hline $\mathrm{B} 102$ & $1 \mathrm{E}-05$ & Fail & Pass & Pass & $7 \mathrm{E}-06$ & Fail & Pass & Pass & $5 \mathrm{E}-06$ & Fail & Pass & Pass \\
\hline$B 103$ & $0 \mathrm{E}+00$ & Pass & Pass & Pass & $0 \mathrm{E}+00$ & Pass & Pass & Pass & $0 \mathrm{E}+00$ & Pass & Pass & Pass \\
\hline $\mathrm{B} 104$ & $3 \mathrm{E}-07$ & Pass & Pass & Pass & $0 \mathrm{E}+00$ & Pass & Pass & Pass & $0 \mathrm{E}+00$ & Pass & Pass & Pass \\
\hline $\mathrm{B} 105$ & $3 \mathrm{E}-05$ & Fail & Pass & Pass & $2 \mathrm{E}-05$ & Fail & Pass & Pass & $2 \mathrm{E}-05$ & Fail & Pass & Pass \\
\hline $\mathrm{B} 106$ & $0 \mathrm{E}+00$ & Pass & Pass & Pass & $0 \mathrm{E}+00$ & Pass & Pass & Pass & $0 \mathrm{E}+00$ & Pass & Pass & Pass \\
\hline $\mathrm{B} 107$ & $3 \mathrm{E}-06$ & Fail & Pass & Pass & $1 \mathrm{E}-06$ & Fail & Pass & Pass & $0 \mathrm{E}+00$ & Pass & Pass & Pass \\
\hline $\mathrm{B} 108$ & $2 \mathrm{E}-06$ & Fail & Pass & Pass & $0 \mathrm{E}+00$ & Pass & Pass & Pass & $0 \mathrm{E}+00$ & Pass & Pass & Pass \\
\hline B109 & $0 \mathrm{E}+00$ & Pass & Pass & Pass & $0 \mathrm{E}+00$ & Pass & Pass & Pass & $0 \mathrm{E}+00$ & Pass & Pass & Pass \\
\hline $\mathrm{B} 110$ & $0 \mathrm{E}+00$ & Pass & Pass & Pass & $0 \mathrm{E}+00$ & Pass & Pass & Pass & $0 \mathrm{E}+00$ & Pass & Pass & Pass \\
\hline B111 & $0 \mathrm{E}+00$ & Pass & Pass & Pass & $0 \mathrm{E}+00$ & Pass & Pass & Pass & $0 \mathrm{E}+00$ & Pass & Pass & Pass \\
\hline $\mathrm{B} 112$ & $0 \mathrm{E}+00$ & Pass & Pass & Pass & $0 \mathrm{E}+00$ & Pass & Pass & Pass & $0 \mathrm{E}+00$ & Pass & Pass & Pass \\
\hline $\mathrm{BX} 101$ & $1 \mathrm{E}-05$ & Fail & Pass & Pass & $2 \mathrm{E}-06$ & Fail & Pass & Pass & $0 \mathrm{E}+00$ & Pass & Pass & Pass \\
\hline $\mathrm{BX} 102$ & $1 \mathrm{E}-05$ & Fail & Pass & Pass & $6 \mathrm{E}-06$ & Fail & Pass & Pass & $5 \mathrm{E}-06$ & Fail & Pass & Pass \\
\hline BX103 & $0 \mathrm{E}+00$ & Pass & Pass & Pass & $0 \mathrm{E}+00$ & Pass & Pass & Pass & $0 \mathrm{E}+00$ & Pass & Pass & Pass \\
\hline BX104 & $0 \mathrm{E}+00$ & Pass & Pass & Pass & $0 \mathrm{E}+00$ & Pass & Pass & Pass & $0 \mathrm{E}+00$ & Pass & Pass & Pass \\
\hline BX105 & $3 \mathrm{E}-05$ & Fail & Pass & Pass & $1 \mathrm{E}-05$ & Fail & Pass & Pass & $7 \mathrm{E}-06$ & Friil & Pass & Pass \\
\hline $\mathrm{BX106}$ & $2 \mathrm{E}-06$ & Fail & Pass & Pass & $0 \mathrm{E}+00$ & Pass & Pass & Pass & $0 \mathrm{E}+00$ & Pass & Pass. & Pass \\
\hline $\mathrm{BX} 107$ & $0 \mathrm{E}+00$ & Pass & Pass & Pass & $0 \mathrm{E}+00$ & Pass & Pass & Pass & $0 \mathrm{E}+00$ & Pass & Pass & Pass \\
\hline BX108 & $9 \mathrm{E}-06$ & lail & Pass & Pass & $3 \mathrm{E}-06$ & Fail & Pass & Pass & $0 \mathrm{E}+00$ & Pass & Pass & Pass \\
\hline BX109 & $0 \mathrm{E}+00$ & Pass & Pass & Pass & $0 \mathrm{E}+00$ & Pass & Pass & Pass & $0 \mathrm{E}+00$ & Pass & Pass & Pass \\
\hline BX110 & $8 \mathrm{E}-06$ & Fail & Pass & Pass & $0 \mathrm{E}+00$ & Pass & Pass & Pass & $0 \mathrm{E}+00$ & Pass & Pass & Pass \\
\hline BX111 & $0 \mathrm{E}+00$ & Pass & Pass & Pass & $0 \mathrm{E}+00$ & Pass & Pass & Pass & $0 \mathrm{E}+00$ & Pass & Pass & Pass \\
\hline $\mathrm{BX} 112$ & $0 \mathrm{E}+00$ & Pass & Pass & Pass & $0 \mathrm{E}+00$ & Pass & Pass & Pass & $0 \mathrm{E}+00$ & Pass & Pass & Pass \\
\hline BY101 & $2 \mathrm{E}-05$ & Fail & Pass & Pass & $1 \mathrm{E}-05$ & Fail & Pass & Pass & $6 \mathrm{E}-06$ & Fail & Pass & Pass \\
\hline BY102 & $0 \mathrm{E}+00$ & Pass & Pass & Pass & $0 \mathrm{E}+00$ & Pass & Pass & Pass & $0 \mathrm{E}+00$ & Pass & Pass & Pass \\
\hline BY103 & $4 \mathrm{E}-05$ & Fail & Pass & Pass & $3 \mathrm{E}-05$ & Fail & Pass & Pass & $3 E-05$ & Fail & Pass & Pass \\
\hline BY104 & $1 \mathrm{E}-05$ & Fail & Pass & Pass & $7 \mathrm{E}-07$ & Pass & Pass & Pass & $0 \mathrm{E}+00$ & Pass & Pass & Pass \\
\hline BY105 & $3 \mathrm{E}-07$ & Pass & Pass & Pass & $0 \mathrm{E}+00$ & Pass & Pass & Pass & $0 \mathrm{E}+00$ & Pass & Pass & Pass \\
\hline BY106 & $\mathrm{OE}+00$ & Pass & Pass & Pass & $0 \mathrm{E}+00$ & Pass & Pass & Pass & $0 \mathrm{E}+00$ & Pass & Pass & Pass \\
\hline BY107 & $0 \mathrm{E}+00$ & Pass & Pass & Pass & $0 \mathrm{E}+00$ & Pass & Pass & Pass & $0 \mathrm{E}+00$ & Pass & Pass & Pass \\
\hline BY108 & $0 \mathrm{E}+00$ & Pass & Pass & Pass & $0 \mathrm{E}+00$ & Pass & Pass & Pass & $0 \mathrm{E}+00$ & Pass & Pass & Pass \\
\hline BY109 & $3 \mathrm{E}-05$ & Fail & Pass & Pass & 1E-05 & Fail & Pass & Pass & $1 \mathrm{E}-05$ & Fail & Pass & Pass \\
\hline BY110 & $0 \mathrm{E}+00$ & Pass & Pass & Pass & $0 \mathrm{E}+00$ & Pass & Pass & Pass & $0 \mathrm{E}+00$ & Pass & Pass & Pass \\
\hline BY111 & $2 E-06$ & Fail & Pass & Pass & $0 \mathrm{E}+00$ & Pass & Pass & Pass & $0 \mathrm{E}+00$ & Pass & Pass & Pass \\
\hline BY112 & $0 \mathrm{E}+00$ & Pass & Pass & Pass & $0 \mathrm{E}+00$ & Pass & Pass & Pass & $0 \mathrm{E}+00$ & Pass & Pass & Pass \\
\hline $\mathrm{Cl} 104$ & $0 \mathrm{E}+00$ & Pass & Pass & Pass & $0 \mathrm{E}+00$ & Pass & Pass & Pass & $0 \mathrm{E}+00$ & Pass & Pass & Pass \\
\hline $\mathrm{C} 105$ & $1 \mathrm{E}-05$ & Fail & Pass & Pass & $2 \mathrm{E}-06$ & frail & Pass & Pass & $0 E+00$ & Pass & Pass & Pass \\
\hline $\mathrm{C} 106$ & $8 \mathrm{E}-04$ & Fail & Fail & Pass & 2E-04 & Fail & rail & Pass & $0 \mathrm{E}+00$ & Pass & Pass & Pass \\
\hline C107. & $1 E-05$ & Fail & Pass & Pass & $1 \mathrm{E}-06$ & Fail & Pass & Pass & $0 \mathrm{E}+00$ & Pass & Pass & Pass \\
\hline $\mathrm{C} 108$ & $0 \mathrm{E}+00$ & Pass & Pass & Pass & $0 \mathrm{E}+00$ & Pass & Pass & Pass & $0 \mathrm{E}+00$ & Pass & Pass & Pass \\
\hline $\mathrm{C} 109$ & $0 \mathrm{E}+00$ & Pass & Pass & Pass & $0 \mathrm{E}+00$ & Pass & Pass & Pass & $0 \mathrm{E}+00$ & Pass & Pass & Pass \\
\hline C110 & $0 \mathrm{E}+00$ & Pass & Pass & Pass & $0 \mathrm{E}+00$ & Pass & Pass & Pass & $0 \mathrm{E}+00$ & Pass & Pass & Pass \\
\hline C111 & $4 \mathrm{E}-07$ & Pass & Pass & Pass & $0 \mathrm{E}+00$ & Pass & Pass & Pass & $0 \mathrm{E}+00$ & Pass & Pass & Pass \\
\hline C112 & $0 \mathrm{E}+00$ & Pass & Pass & Pass & $0 \mathrm{E}+00$ & Pass & Pass & Pass & $0 \mathrm{E}+00$ & Pass & Pass & Pass \\
\hline$\$ 101$ & $0 \mathrm{E}+00$ & Pass & Pass & Pass & $0 E+00$ & Pass & Pass & Pass & $0 \mathrm{E}+00$ & Pass & Pass & Pass \\
\hline
\end{tabular}


Table 4.1 (contd)

\begin{tabular}{|c|c|c|c|c|c|c|c|c|c|c|c|c|}
\hline \multirow[b]{2}{*}{ Tank $^{(a)}$} & \multicolumn{4}{|c|}{ HEPA Failure } & \multicolumn{4}{|c|}{ Dome Failure } & \multicolumn{4}{|c|}{ Dome Failure \& Continued Release } \\
\hline & Frequency & $10^{-6}$ & $10^{-4}$ & $10^{-2}$ & Frequency & $10^{-6}$ & $10^{-4}$ & $10^{-2}$ & Frequency & $10^{-6}$ & $10^{-4}$ & $10^{-2}$ \\
\hline$S 102$ & 9E-07 & Pass & Pass & Pass & $0 \mathrm{E}+00$ & Pass & Pass & Pass & $0 \mathrm{E}+00$ & Pass & Pass & Pass \\
\hline$S 103$ & 5E-05 & Fail & Pass & Pass & $3 \mathrm{E}-05$ & Fail & Pass & Pass & $3 E-05$ & Fail & Pass & Pass \\
\hline$\$ 104$ & $0 \mathrm{E}+00$ & Pass & Pass & Pass & $0 \mathrm{E}+00$ & Pass & Pass & Pass & $0 \mathrm{E}+00$ & Pass & Pass & Pass \\
\hline$S 105$ & $2 \mathrm{E}-05$ & Fail & Pass & Pass & $1 \mathrm{E}-05$ & l'ail & Pass & Pass & $7 \mathrm{E}-06$ & Fail & Pass & Pass \\
\hline$\$ 106$ & $2 \mathrm{E}-05$ & Fail & Pass & Pass & $1 \mathrm{E}-05$ & Fail & Pass & Pass & $1 \mathrm{E}-05$ & Fail & Pass & Pass \\
\hline S107 & $0 \mathrm{E}+00$ & Pass & Pass & Pass & $0 \mathrm{E}+00$ & Pass & Pass & Pass & $0 \mathrm{E}+00$ & Pass & Pass & Pass \\
\hline S108 & $3 \mathrm{E}-05$ & Fail & Pass & Pass & $2 \mathrm{E}-05$ & Fail & Pass & Pass & $2 \mathrm{E}-05$ & Fail & Pass & Pass \\
\hline S109 & $0 \mathrm{E}+00$ & Pass & Pass & Pass & $0 \mathrm{E}+00$ & Pass & Pass & Pass & $0 \mathrm{E}+00$ & Pass & Pass & Pass \\
\hline$\$ 110$ & 5E-05 & Fail & Pass & Pass & $4 \mathrm{E}-05$ & Fail & Pass & Pass & $3 \mathrm{E}-05$ & Fail & Pass & Pass \\
\hline$S 111$ & $0 \mathrm{E}+00$ & Pass & Pass & Pass & $0 \mathrm{E}+00$ & Pass & Pass & Pass & $0 \mathrm{E}+00$ & Pass & Pass & Pass \\
\hline $\mathrm{S} 112$ & $3 \mathrm{E}-05$ & Fail & Pass & Pass & $1 \mathrm{E}-05$ & Fail & Pass & Pass & $9 \mathrm{E}-06$ & Fail & Pass & Pass \\
\hline SX101 & $6 \mathrm{E}-04$ & Fail & Fail & Pass & $5 \mathrm{E}-04$ & Fail & Fail & Pass & $5 \mathrm{E}-04$ & Fail & Fail & Pass \\
\hline $\mathrm{SX} 102$ & $1 \mathrm{E}-05$ & Fail & Pass & Pass & $2 \mathrm{E}-06$ & Fail & Pass & Pass & $2 E-06$ & Fail & Pass & Pass \\
\hline$S X 103$ & 1E-04 & Fail & Fail & Pass & $9 \mathrm{E}-05$ & Fail & Pass & Pass & $8 \mathrm{E}-05$ & Fail & Pass & Pass \\
\hline $\mathrm{SX} 104$ & $6 \mathrm{E}-05$ & Fail & Pass & Pass & $4 \mathrm{E}-05$ & Fail & Pass & Pass & $4 \mathrm{E}-05$ & Fail & Pass & Pass \\
\hline$S X 105$ & $8 \mathrm{E}-05$ & Fail & Pass & Pass & $6 \mathrm{E}-05$ & Fail & Pass & Pass & $5 \mathrm{E}-05$ & Fail & Pass & Pass \\
\hline$S X 106$ & $6 \mathrm{E}-04$ & Fail & Fail & Pass & $5 \mathrm{E}-04$ & Fail & Fail & Pass & $5 \mathrm{E}-04$ & Fail & Fail & Pass \\
\hline $\mathrm{SX} 107$ & $3 \mathrm{E}-06$ & Fail & Pass & Pass & $2 E-06$ & Fail & Pass & Pass & $0 \mathrm{E}+00$ & Pass & Pass & Pass \\
\hline SX108 & $0 \mathrm{E}+00$ & Pass & Pass & Pass & $0 \mathrm{E}+00$ & Pass & Pass & Pass & $0 \mathrm{E}+00$ & Pass & Pass & Pass \\
\hline SX109 & $7 \mathrm{E}-06$ & Fail & Pass & Pass & $5 \mathrm{E}-06$ & Fail & Pass & Pass & $2 \mathrm{E}-06$ & Fail & Pass & Pass \\
\hline SX110 & $1 \mathrm{E}-05$ & Fail & Pass & Pass & $5 E-06$ & Fail & Pass & Pass & $3 \mathrm{E}-06$ & Fail & Pass & Pass \\
\hline SX111 & $2 \mathrm{E}-05$ & Fail & Pass & Pass & $9 \mathrm{E}-06$ & Fail & Pass & Pass & $9 \mathrm{E}-06$ & Fail & Pass & Pass \\
\hline $\mathrm{SX} 112$ & $5 \mathrm{E}-06$ & Fail & Pass & Pass & $2 \mathrm{E}-06$ & Fail & Pass & Pass & $0 \mathrm{E}+00$ & Pass & Pass & Pass \\
\hline SX113 & $5 \mathrm{E}-07$ & Pass & Pass & Pass & $0 \mathrm{E}+00$ & Pass & Pass & Pass & $0 \mathrm{E}+00$ & Pass & Pass & Pass \\
\hline $\mathrm{SX} 114$ & $1 \mathrm{E}-05$ & Fail & Pass & Pass & $6 \mathrm{E}-06$ & Fail & Pass & Pass & $0 \mathrm{E}+00$ & Pass & Pass & Pass \\
\hline SX115 & $4 \mathrm{E}-06$ & Fail & Pass & Pass & $0 \mathrm{E}+00$ & Pass & Pass & Pass & $0 \mathrm{E}+00$ & Pass & Pass & Pass \\
\hline $\mathrm{T101}$ & $2 \mathrm{E}-05$ & Fail & Pass & Pass & $1 E-05$ & Fail & Pass & Pass & $7 \mathrm{E}-06$ & Fail & Pass & Pass \\
\hline T102 & $\mathrm{OE}+00$ & Pass & Pass & Pass & $0 \mathrm{E}+00$ & Pass & Pass & Pass & $0 \mathrm{E}+00$ & Pass & Pass & Pass \\
\hline T103 & $2 \mathrm{E}-06$ & Fail & Pass & Pass & $0 \mathrm{E}+00$ & Pass & Pass & Pass & $0 \mathrm{E}+00$ & Pass & Pass & Pass \\
\hline T104 & $0 \mathrm{E}+00$ & Pass & Pass & Pass & $0 \mathrm{E}+00$ & Pass & Pass & Pass & $0 \mathrm{E}+00$ & Pass & Pass & Pass \\
\hline $\mathrm{T} 105$ & $0 \mathrm{E}+00$ & Pass & Pass & Pass & $0 \mathrm{E}+00$ & Pass & Pass & Pass & $0 \mathrm{E}+00$ & Pass & Pass & Pass \\
\hline $\mathrm{T106}$ & $9 \mathrm{E}-06$ & Fail & Pass & Pass & $0 \mathrm{E}+00$ & Pass & Pass & Pass & $0 \mathrm{E}+00$ & Pass & Pass & Pass \\
\hline $\mathrm{T} 107$ & $0 \mathrm{E}+00$ & Pass & Pass & Pass & $0 \mathrm{E}+00$ & Pass & Pass & Pass & $0 \mathrm{E}+00$ & Pass & Pass & Pass \\
\hline T108 & $4 E-05$ & Fail & Pass & Pass & $2 \mathrm{E}-05$ & Fail & Pass & Pass & $1 \mathrm{E}-05$ & Fail & Pass & Pass \\
\hline T109 & $2 \mathrm{E}-06$ & Fail & Pass & Pass & $2 \mathrm{E}-06$ & Fail & Pass & Pass & $0 \mathrm{E}+00$ & Pass & Pass & Pass \\
\hline $\mathrm{T} 110$ & $7 \mathrm{E}-06$ & Fail & Pass & Pass & $3 \mathrm{E}-06$ & Fail & Pass & Pass & $0 \mathrm{E}+00$ & Pass & Pass & Pass \\
\hline$T 111$ & $0 \mathrm{E}+00$ & Pass & Pass & Pass & $0 \mathrm{E}+00$ & Pass & Pass & Pass & $0 \mathrm{E}+00$ & Pass & Pass & Pass \\
\hline $\mathrm{T} 112$ & $6 \mathrm{E}-06$ & Fail & Pass & Pass & $3 \mathrm{E}-06$ & Fail & Pass & Pass & $3 \mathrm{E}-06$ & Fail & Pass & Pass \\
\hline T201 & $2 \mathrm{E}-05$ & Fail & Pass & Pass & $8 E-06$ & Fail & Pass & Pass & $0 \mathrm{E}+00$ & Pass & Pass & Pass \\
\hline $\mathrm{T} 202$ & $3 \mathrm{E}-05$ & Fail & Pass & Pass & $2 \mathrm{E}-05$ & Fail & Pass & Pass & $0 \mathrm{E}+00$ & Pass & Pass & Pass \\
\hline T203 & $2 \mathrm{E}-05$ & Fail & Pass & Pass & $0 \mathrm{E}+00$ & Pass & Pass & Pass & $0 \mathrm{E}+00$ & Pass & Pass & Pass \\
\hline T204 & $5 \mathrm{E}-06$ & Fail & Pass & Pass & $0 \mathrm{E}+00$ & Pass & Pass & Pass & $0 \mathrm{E}+00$ & Pass & Pass & Pass \\
\hline TX101 & $5 \mathrm{E}-06$ & Fail & Pass & Pass & 2E-06 & Fail & Pass & Pass & $0 \mathrm{E}+00$ & Pass & Pass & Pass \\
\hline TX102 & $1 \mathrm{E}-06$ & Fail & Pass & Pass & $0 \mathrm{E}+00$ & Pass & Pass & Pass & $0 \mathrm{E}+00$ & Pass & Pass & Pass \\
\hline TX103 & $1 \mathrm{E}-05$ & Fail & Pass & Pass & $7 \mathrm{E}-06$ & Fail & Pass & Pass & $\mathrm{OE}+00$ & Pass & Pass & Pass \\
\hline TX104 & $4 \mathrm{E}-04$ & Fail & Fail & Pass & $3 \mathrm{E}-04$ & Fail & Fail & Pass & $2 \mathrm{E}-04$ & Fail & Fail & Pass \\
\hline$T X 105$ & $5 \mathrm{E}-05$ & Fail & Pass & Pass & $4 \mathrm{E}-05$ & Fail & Pass & Pass & $4 \mathrm{E}-05$ & Fail & Pass & Pass \\
\hline TX106 & $3 \mathrm{E}-05$ & Fail & Pass & Pass & $2 \mathrm{E}-05$ & Fail & Pass & Pass & $2 \mathrm{E}-05$ & Fail & Pass & Pass \\
\hline TX107 & $5 \mathrm{E}-06$ & Fail & Pass & Pass & $2 \mathrm{E}-06$ & Fail & Pass & Pass & $0 \mathrm{E}+00$ & Pass & Pass & Pass \\
\hline TX108 & $2 \mathrm{E}-05$ & Fail & Pass & Pass & $1 \mathrm{E}-05$ & Fail & Pass & Pass & $1 \mathrm{E}-05$ & Fail & Pass & Pass \\
\hline \begin{tabular}{|l|} 
TX109 \\
\end{tabular} & $1 \mathrm{E}-05$ & Fail & Pass & Pass & $6 \mathrm{E}-06$ & Fail & Pass & Pass & $6 \mathrm{E}-06$ & Fail & Pass & Pass \\
\hline TX110 & $3 \mathrm{E}-05$ & Fail & Pass & Pass & $2 \mathrm{E}-05$ & Fail & Pass & Pass & $2 \mathrm{E}-05$ & Fail & Pass & Pass \\
\hline TX111 & $1 \mathrm{E}-04$ & Fail & Pass & Pass & $8 \mathrm{E}-05$ & Fail & Pass & Pass & $7 \mathrm{E}-05$ & Fail & Pass & Pass \\
\hline TX112 & $2 \mathrm{E}-05$ & Fail & Pass & Pass & 1E-05 & Fail & Pass & Pass & $1 E-05$ & Fail & Pass & Pass \\
\hline TX113 & $3 \mathrm{E}-05$ & Fail & Pass & Pass & $2 \mathrm{E}-05$ & Pail & Pass & Pass & $2 \mathrm{E}-05$ & Fail & Pass & Pass \\
\hline TX114 & $3 \mathrm{E}-05$ & Fail & Pass & Pass & $2 \mathrm{E}-05$ & Fail & Pass & Pass & $1 \mathrm{E}-05$ & Fail & Pass & Pass \\
\hline
\end{tabular}


Table 4.1 (contd)

\begin{tabular}{|c|c|c|c|c|c|c|c|c|c|c|c|c|}
\hline \multirow[b]{2}{*}{$\operatorname{Tank}^{(a)}$} & \multicolumn{4}{|c|}{ HEPA Failure } & \multicolumn{4}{|c|}{ Dome Failure } & \multicolumn{4}{|c|}{ Dome Failure \& Continued Release } \\
\hline & Frequency & $10^{-6}$ & $10^{-4}$ & $10^{-2}$ & Frequency & $10^{-6}$ & $10^{-4}$ & $10^{-2}$ & Frequency & $10^{-6}$ & $10^{-4}$ & $10^{-2}$ \\
\hline TX115 & $5 \mathrm{E}-05$ & Fail & Pass & Pass & $4 E-05$ & Fail & Pass & Pass & $4 \mathrm{E}-05$ & Fail & Pass & Pass \\
\hline TX116 & $4 \mathrm{E}-05$ & Fail & Pass & Pass & $4 \mathrm{E}-05$ & Fail & Pass & Pass & $3 \mathrm{E}-05$ & Fail & Pass & Pass \\
\hline TX117 & $3 \mathrm{E}-05$ & Fail & Pass & Pass & $2 \mathrm{E}-05$ & Fail & Pass & Pass & $2 \mathrm{E}-05$ & Fail & Pass & Pass \\
\hline TX118 & $1 \mathrm{E}-04$ & Fàil & Fail & Pass & $1 \mathrm{E}-04$ & Fail & Pass & Pass & $8 \mathrm{E}-05$ & Fail & Pass & Pass \\
\hline TY101 & $0 \mathrm{E}+00$ & Pass & Pass & Pass & $0 \mathrm{E}+00$ & Pass & Pass & Pass & $0 \mathrm{E}+00$ & Pass & Pass & Pass \\
\hline TY102 & $0 \mathrm{E}+00$ & Pass & Pass & Pass & $0 \mathrm{E}+00$ & Pass & Pass & Pass & $0 \mathrm{E}+00$ & Pass & Pass & Pass \\
\hline TY103 & $0 \mathrm{E}+00$ & Pass & Pass & Pass & $0 \mathrm{E}+00$ & Pass & Pass & Pass & $0 \mathrm{E}+00$ & Pass & Pass & Pass \\
\hline TY104 & $0 \mathrm{E}+00$ & Pass & Pass & Pass & $0 \mathrm{E}+00$ & Pass & Pass & Pass & $0 \mathrm{E}+00$ & Pass & Pass & Pass \\
\hline TY105 & $0 \mathrm{E}+00$ & Pass & Pass & Pass & $0 \mathrm{E}+00$ & Pass & Pass & Pass & $0 \mathrm{E}+00$ & Pass & Pass & Pass \\
\hline TY106 & $0 \mathrm{E}+00$ & Pass & Pass & Pass & $0 \mathrm{E}+00$ & Pass & Pass & Pass & $0 \mathrm{E}+00$ & Pass & Pass & Pass \\
\hline $\mathrm{U} 101$ & 2E-06 & Fail & Pass & Pass & $0 \mathrm{E}+00$ & Pass & Pass & Pass & $0 \mathrm{E}+00$ & Pass & Pass & Pass \\
\hline $\mathrm{U} 102$ & 2E-06 & Fail & Pass & Pass & $0 \mathrm{E}+00$ & Pass & Pass & Pass & $0 \mathrm{E}+00$ & Pass & Pass & Pass \\
\hline U103 & $2 \mathrm{E}-04$ & Fail & Fail & Pass & 1E-04 & Fail & Fail & Pass & $7 \mathrm{E}-05$ & Fail & Pass & Pass \\
\hline U104 & $9 \mathrm{E}-06$ & Fail & Pass & Pass & $4 \mathrm{E}-06$ & Fail & Pass & Pass & $4 \mathrm{E}-06$ & Fail & Pass & Pass \\
\hline 0105 & $2 \mathrm{E}-05$ & Fail & Pass & Pass & 1E-07 & Pass & Pass & Pass & $0 \mathrm{E}+00$ & Pass & Pass & Pass \\
\hline 0106 & $2 \mathrm{E}-04$ & Fail & Fail & Pass & $2 \mathrm{E}-05$ & Fail & Pass & Pass & $3 \mathrm{E}-06$ & Fail & Pass & Pass \\
\hline 0107 & $0 \mathrm{E}+00$ & Pass & Pass & Pass & $0 \mathrm{E}+00$ & Pass & Pass & Pass & $0 \mathrm{E}+00$ & Pass & Pass & Pass \\
\hline U108 & $0 \mathrm{E}+00$ & Pass & Pass & Pass & $0 \mathrm{E}+00$ & Pass & Pass & Pass & $0 \mathrm{E}+00$ & Pass & Pass & Pass \\
\hline $\mathrm{U109}$ & $0 \mathrm{E}+00$ & Pass & Pass & Pass & $0 \mathrm{E}+00$ & Pass & Pass & Pass & $0 \mathrm{E}+00$ & Pass & Pass & Pass \\
\hline $\mathrm{U} 110$ & $4 \mathrm{E}-07$ & Pass & Pass & Pass & $0 \mathrm{E}+00$ & Pass & Pass & Pass & $0 \mathrm{E}+00$ & Pass & Pass & Pass \\
\hline U111 & $1 \mathrm{E}-04$ & Fail & Pass & Pass & $7 \mathrm{E}-05$ & Fail & Pass & Pass & $6 \mathrm{E}-05$ & Fail & Pass & Pass \\
\hline U112 & $4 \mathrm{E}-06$ & Fail & Pass & Pass & $2 \mathrm{E}-06$ & Fail & Pass & Pass & $0 \mathrm{E}+00$ & Pass & Pass & Pass \\
\hline $\mathrm{U} 201$ & $0 \mathrm{E}+00$ & Pass & Pass & Pass & $0 \mathrm{E}+00$ & Pass & Pass & Pass & $0 \mathrm{E}+00$ & Pass & Pass & Pass \\
\hline $\mathrm{U} 202$ & $7 E-06$ & Fail & Pass & Pass & $0 \mathrm{E}+00$ & Pass & Pass & Pass & $0 \mathrm{E}+00$ & Pass & Pass & Pass \\
\hline U203 & $0 \mathrm{E}+00$ & Pass & Pass & Pass & $0 \mathrm{E}+00$ & Pass & Pass & Pass & $0 \mathrm{E}+00$ & Pass & Pass & Pass \\
\hline U204 & $0 \mathrm{E}+00$ & Pass & Pass & Pass & $0 \mathrm{E}+00$ & Pass & Pass & Pass & $0 \mathrm{E}+00$ & Pass & Pass & Pass \\
\hline Total & & 53 Pass & 126 Pass & 138 Pass & & 70 Pass & 130 Pass & 138 Pass & & 89 Pass & 132 Pass & 138 Pass \\
\hline (a)Bolc & & $s \operatorname{tank}$ & n the 0 & sanics wa & & & & & & & & \\
\hline
\end{tabular}


list have extremely low calculated frequencies according to this analysis (all but S-102). ${ }^{(a)}$ Note that Tanks C-102 and C-103 are on the Organics Watch List but were among the 11 SSTs not considered in this analysis.

Figure 4.1 shows the frequency of an event of sufficient energy to burst a HEPA filter for each tank as a function of the number of observations of TOC for that tank. The results show that, in general, the frequency is greatly reduced by having additional information about the tank contents. This emphasizes the fact that one of the greatest contributions to risk is the lack of. knowledge about the key factors controlling the likelihood and magnitude of a undesired reaction in the organic-nitrate mixture.

The risk, measured as the calculated frequency of the three event severity consequences, is plotted in Figure 4.2 for the 24 tanks with the highest frequency of dome failure plus potential continued release of tank contents. These results confirm the expectation that using a lower threshold screening criterion (frequency of a HEPA filter failure) identifies those tanks with the risk as the highest likelihood of more significant events. The group of tanks with HEPA failure risks greater than $9 \mathrm{E}-05$ includes the 10 tanks with highest frequencies of dome failure plus potential continued release.

To consider whether waste depth can be used as a controlling parameter, the frequency of a dome failure plus potential continued release event is plotted versus depth for tanks with a depth of a meter or less (Figure 4.3). There are 46 such tanks for which there are 68 observations of moisture levels and 38 observations of TOC in the data set. None of the 10 tanks with less than $0.25 \mathrm{~m}$ of waste show measurable dome failure plus potential continued release frequency. Likewise, all 10 show low risk values for HEPA failure events (less than 3E-05 per year). Of the remaining tanks in the set of 46 , the three that show the most significant values in the figure are all from the tank group characterized as having the potential for high organic salt contents. Hence, for tanks in the other groups, one can consider those with one meter or less to be of acceptably low risk, especially if there is at least one measurement from the tank, and that measurement confirms the expectation of low risk.

Evaluation of surface moisture as a controlling parameter for organic-nitrate events is shown in Figure 4.4. The plot of dome failure plus potential continued release frequency versus the mean surface moisture as calculated by the ANOVA methodology shows that tanks with greater than $45 \%$ moisture show no significant risk. Only tanks with at least one observation of moisture are included in this plot. To allow more detail, Tank AX-102, with a frequency of $8 \mathrm{E}-04$ and 30\% moisture, is excluded from this plot. As discussed previously, Tank AX-102 has the highest calculated frequencies for all three event severity consequences and therefore is the highest-risk tank for this safety issue.

(a) Tanks A-101, S-111, and U-107 were determined to need controls to ensure safety in Colson et al. (1997), which used a similar analysis approach. 


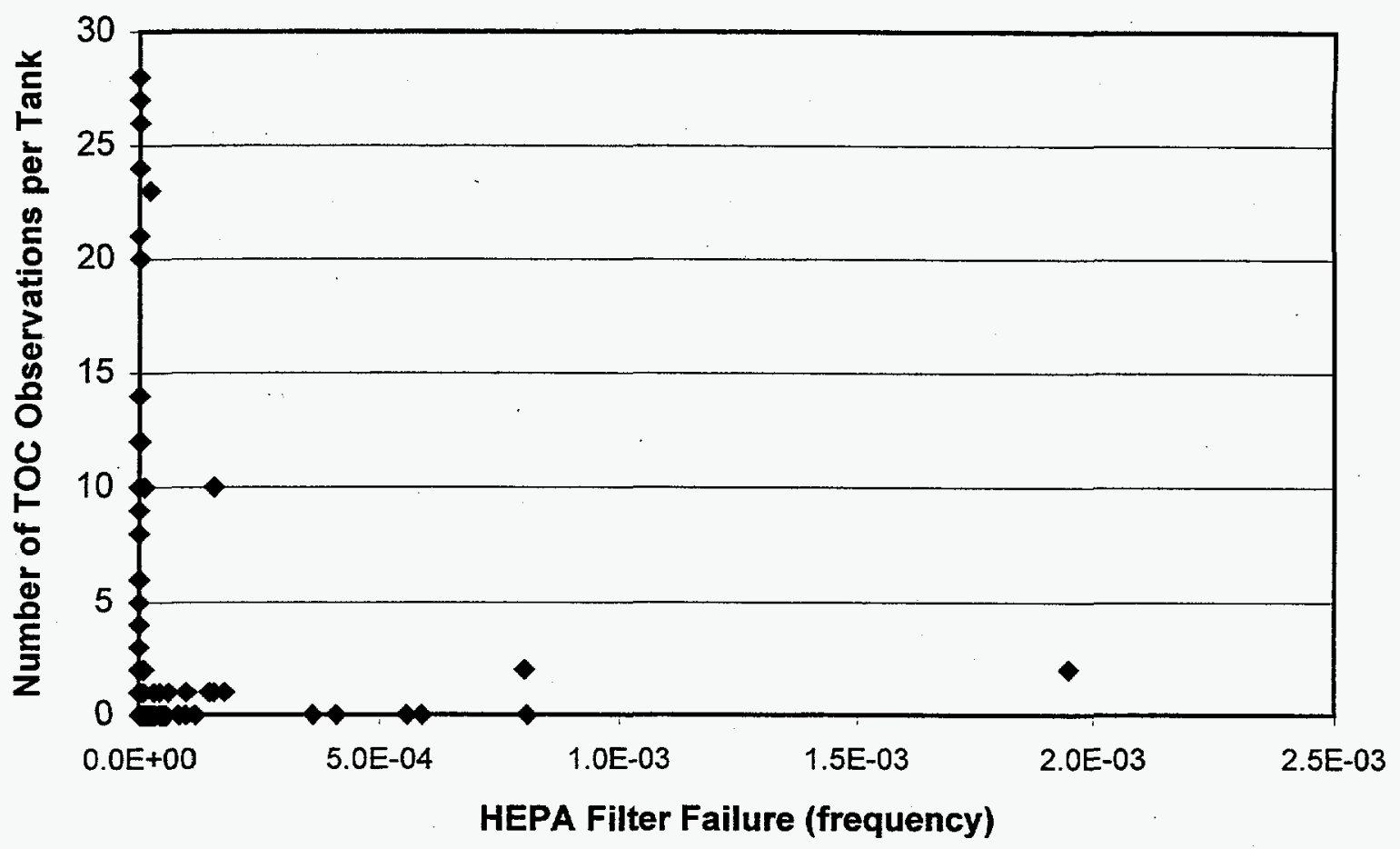

Figure 4.1. HEPA Filter Failure Frequency Versus Number of TOC Observations per Tank

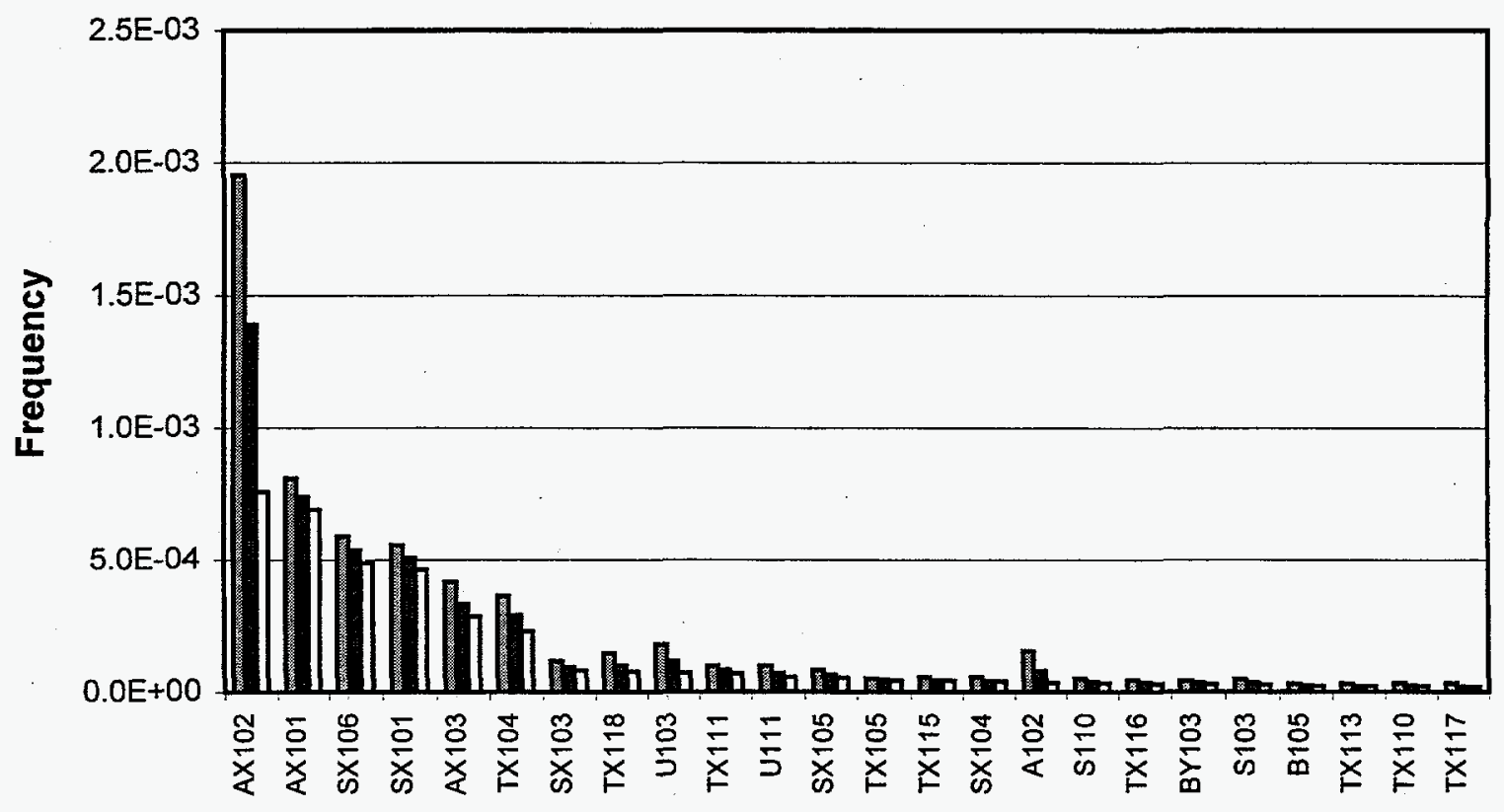

Tanks Ordered by Frequency

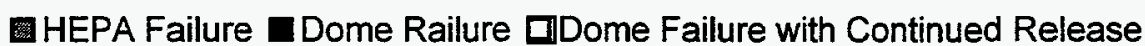

Figure 4.2. Tanks Sorted by Dome Failure with Continued Release Frequency 


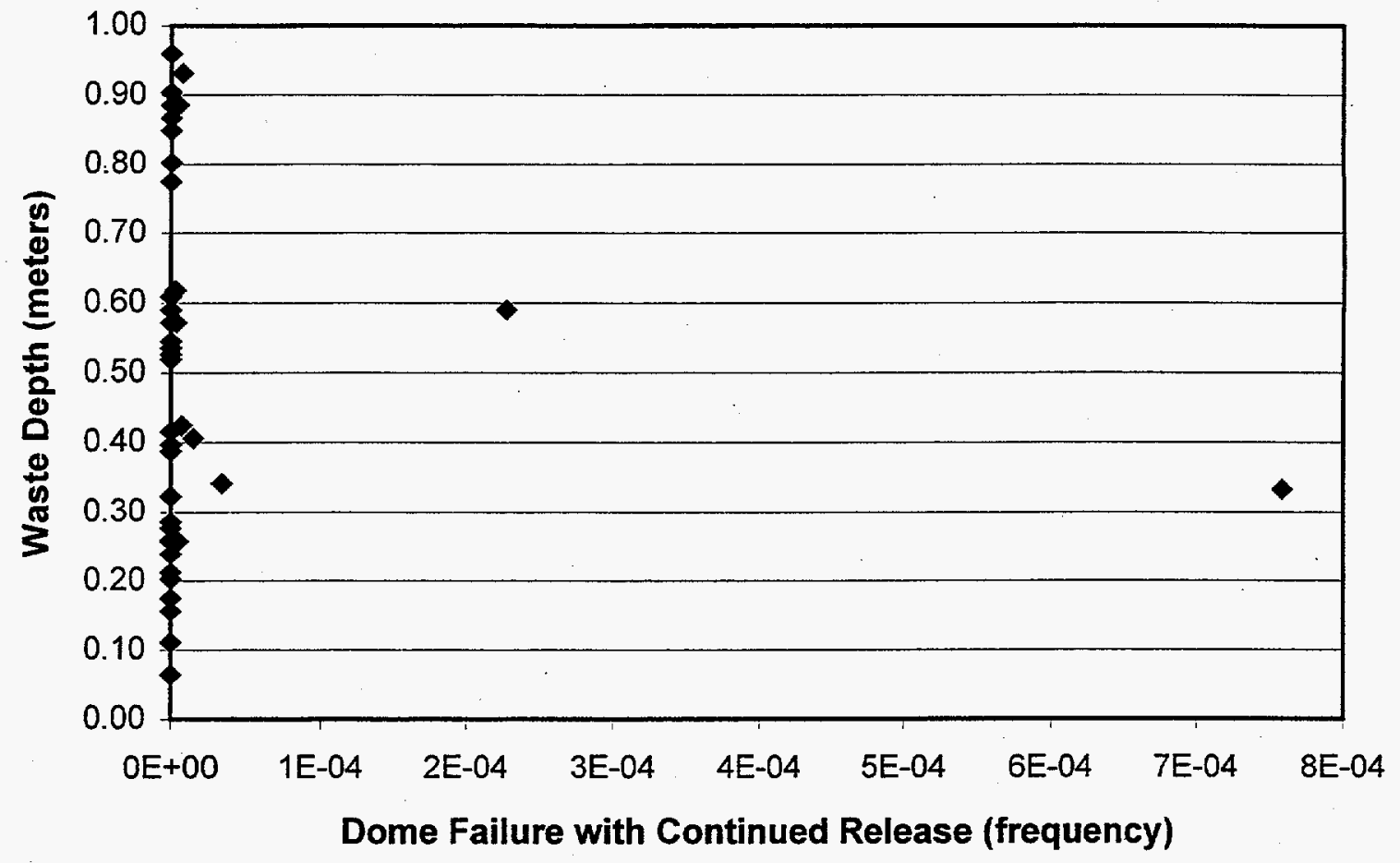

Figure 4.3. Dome Failure with Continued Release Frequency Versus Waste Depth

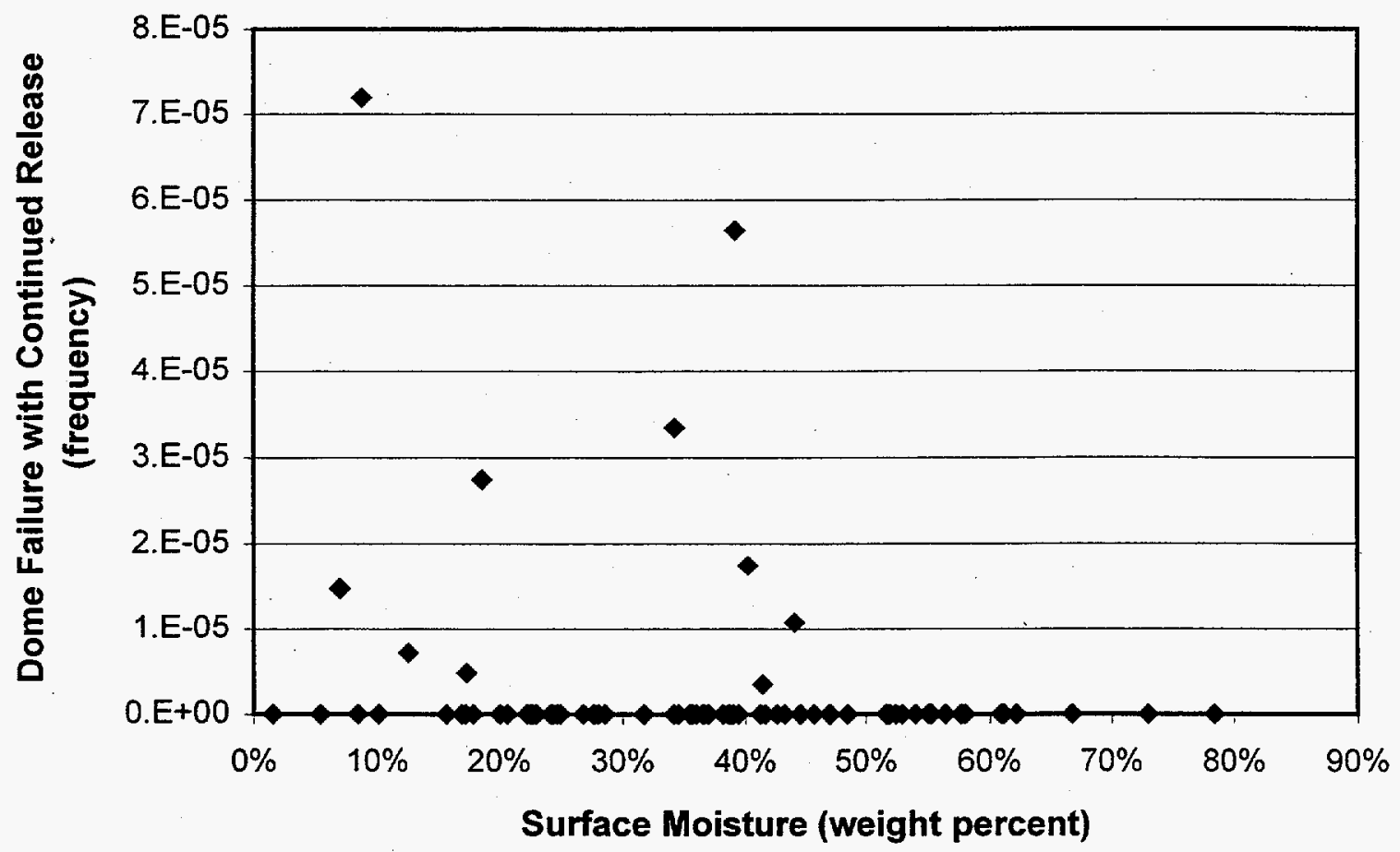

Figure 4.4. Dome Failure with Continued Release Frequency Versus Percent Surface Moisture 


\subsection{Scenario Analysis}

Scenario analyses were formulated and studied to analyze the robustness and flexibility of the result. Several scenarios were considered and are described in the next sections.

\subsubsection{Energy Speciation of TOC}

Because the amount of information concerning the actual chemical species composing the TOC is extremely limited, one of the major assumptions employed in the base-case analysis is that all of the TOC behaves in a manner similar to acetate. To evaluate the sensitivity of the frequency results to different chemical speciation of the TOC, we used available data from three double-shell tanks, SY-101, SY-103, and AW-105, and 23 SSTs.

The hazards associated with an organic-bearing waste are directly related to the energy that can be released when the organics and the nitrogen-based oxidants react. Because of the difficulties of directly and accurately measuring the energy that will be released by a waste when a propagating reaction occurs, Hanford has used TOC, a fairly easily measured quantity; as a measure of the potential energetics of a waste.

Hanford processes used a wide variety of organics that eventually became part of the waste streams that are stored in the underground tanks. In addition, reactions between the organics introduced into the waste and other components in the wastes, including radiolytically generated oxidants, have changed the nature of the organics present in the wastes. In general, these aging reactions will result in a less energetic organic or inorganic carbon species (Camaioni et al. 1994; Barefield et al. 1996). Of the aging products, oxalate is the least energetic (per gram of carbon) organic species, and carbonate is the least energetic overall carbon species with respect to oxidation.

Energetics can be directly related to TOC (Burger 1995) if the identities of the organics are known and if we assume a reaction mechanism. The Project Hanford Management Contractor chose acetate as the representative organic and nitrate as the representative oxidant to estimate waste energetics; assuming the most energetic reaction between acetate and nitrate in the absence of hydroxide provides a conversion factor of $27.1 \mathrm{~kJ}$ per gram of carbon. The amount of energy per gram of carbon that is produced by a reaction between an organic and nitrate and/or nitrite in the absence of hydroxide is directly dependent on the identity of the organic assuming the same reaction pathways. If the organic carbon were oxalate the conversion factor for the maximum nitrate reaction would be $7 \mathrm{~kJ} / \mathrm{g} \mathrm{TOC}$, and if the organic carbon were HEDTA, one of the complexants used at Hanford, the comparable conversion factor would be $30.9 \mathrm{~kJ} / \mathrm{g}$ TOC. Unfortunately, identifying the organics in Hanford wastes requires elaborate, non-routine analytical methods, and some of the analytical procedures are still being developed. Fortunately, some organics, particularly oxalate, have been identified for some wastes, though not routinely. 
Because a variety of organics with a wide range of potential maximum energetics exist in the Hanford organic-bearing wastes, and because it is difficult to directly measure waste energetics, we must rely on measurements that can be directly or indirectly related to energetics. The TOC measurement, although fraught with difficulties, provides a direct path for estimating the energetics of a waste with a known TOC content. The current approach used to estimate energetics for a waste with a known TOC is to use the conversion factor (k) for the maximum energetics acetate and nitrate reaction in the absence of hydroxide $(27.1 \mathrm{~kJ} / \mathrm{g} \mathrm{C})$. This may or may not provide an accurate estimate of the waste's maximum energetics.

The estimate of the maximum waste energetics based on TOC can be improved by knowing the identity of the organics and their individual contribution to the TOC in the waste. From this information, the factor, $\mathrm{k}$, to convert TOC to energetics can be calculated based on the energetics for each individual organic component of the TOC and an assumed reaction pathway (Burger 1995) (see Equation 4.1).

$$
k=\frac{\Delta H}{g T O C}=\left[\left(\frac{\Delta H_{O r g(1)}}{g C_{O r g(1)}}\right)\left(\frac{g C_{O r g(1)}}{g T O C}\right)+\left(\frac{\Delta H_{O r g(2)}}{g C_{O r g(2)}}\right)\left(\frac{g C_{O r g(2)}}{g T O C}\right)+\ldots+\left(\frac{\Delta H_{O r g(i)}}{g C_{O r g(i)}}\right)\left(\frac{g C_{O r g(i)}}{g T O C}\right)\right]
$$

where $\Delta \mathrm{H}_{\mathrm{Org}(\mathrm{i})} / \mathrm{g} \mathrm{C}_{\mathrm{Org}(\mathrm{i})}$ is the enthalpy change on a carbon (C) basis for organic(i), and $\mathrm{g} \mathrm{C}_{\text {org(i) }} / \mathrm{g}$ TOC is the contribution of organic (i) to TOC; organic (i) could be HEDTA, acetate, or any other organic contributing to the organic carbon in the waste. Table 4.2 provides the individual conversion factors for each organic species identified by Campbell; the enthalpy changes provided are from Burger (1995) and supplemented by Burger for missing compounds. Information on the identities of organics in wastes is limited. The identities of about $90 \%$ of the organic species in wastes have only been reported for Tanks SY-101 and SY-103 by Campbell et al. (1994a, 1994b, 1994c, 1995, 1996), who have been characterizing organic-bearing wastes. Additional information about organic speciation will be available in late 1997; partial information about organic speciation, oxalate, is available for (26) tanks (Carlson 1997).

Table 4.2. Energetics Conversion Factors for Organic Species ${ }^{(a)}$

\begin{tabular}{|c|c|c|c|c|c|c|c|c|c|c|c|}
\hline \multirow{3}{*}{ Oxidant } & \multicolumn{11}{|c|}{$\Delta \mathrm{H}, \mathrm{kJ} / \mathrm{g} \mathrm{C}$} \\
\hline & \multicolumn{11}{|c|}{ Organic Species } \\
\hline & IDA & NTA & Citrate & ED3A & EDTA & HEDTA & Succinate & Glycolate & Formate & Acetate & Oxalate \\
\hline Nitrate & 25.50 & 24.30 & 20.30 & 29.80 & 27.90 & 30.90 & 22.80 & 20.70 & 14.20 & 27.10 & 6.95 \\
\hline Nitrite & 32.70 & 31.10 & 26.10 & 38.00 & 36.70 & 40.10 & 29.60 & 26.60 & 18.70 & 34.80 & 8.88 \\
\hline
\end{tabular}


To illustrate how improved knowledge of the identity of the organics in wastes can affect waste energetics and thus the associated risk that organic-bearing wastes pose, the resolution team used the organic speciation data provided by Carlson (1997) and Campbell et al. (1994a, $1994 b, 1994 c, 1995,1996)$ to estimate TOC to energetics conversion factors using three approaches (see Table 4.3 for distribution of non-oxalate organics). In general, the organic species distribution used to calculate the conversion factor, $\mathrm{k}$, using Equation 4.1 was based first on the oxalate contribution, and any residual non-oxalate organic carbon was distributed based on Campbell's Tank SY-101 and SY-103 data. Carlson provided the team additional oxalate and TOC data from the TCD after his report was published.

Three sets of conversion factors were calculated: 1) for each of the individual tanks having oxalate information, 2) based on the average for all 26 tanks with surface and subsurface oxalate information, and 3) based on the average oxalate fraction for each Heasler/Meacham tank group (Meacham et al. 1997). The first set of conversion factors was applied to only the tanks with available oxalate information. The second set of conversion factors for the surface and subsurface was applied to all 149 tank wastes using TOC generated by ANOVA. The third set of conversion factors composed of the average for each Heasler/Meacham group was applied to each ANOVA TOC estimate depending on which group the tank belonged to. Table 4.4 provides the calculated conversion factors for nitrate and nitrite oxidants for each tank, each group, and the average for all of these tanks.

Only the nitrate conversion factors were used in this scenario test; however, further exercises should partition the oxidant based on tank information and use both the nitrate and nitrite conversion factors for tanks showing significant risk, given the roughly $30 \%$ higher conversion factors for nitrate.

Comparing the TOC-to-energy conversion factors for nitrate presented in Table 4.4 with that for acetate finds a substantially lower conversion factor when organic speciation is used. Table 4.5 shows the expected reduction in calculated event frequencies when the smaller conversion factors are applied. This indicates that increased knowledge about organic speciation can reduce the estimated energetics for a particular waste. Thus an important result of this work

Table 4.3. Distribution of Non-Oxalate Organics

\begin{tabular}{|c|c|c|c|c|c|c|c|c|c|c|}
\hline \multirow{3}{*}{ Location } & \multicolumn{10}{|c|}{ Organic Species } \\
\hline & \multicolumn{10}{|c|}{ Fraction, g C/g TOC } \\
\hline & IDA & NTA & Citrate & ED3A & EDTA & HEDTA & Succinate & Glycolate & Formate & Acetate \\
\hline Surface & 0.21 & 0.06 & 0.08 & 0.05 & 0.23 & 0.00 & 0.01 & 0.03 & 0.22 & 0.12 \\
\hline Subsurface & 0.14 & 0.06 & 0.14 & 0.07 & 0.22 & 0.00 & 0.01 & 0.00 & 0.24 & 0.12 \\
\hline
\end{tabular}


Table 4.4. Conversion Factors (TOC to $\Delta \mathrm{H}$ ) for Tanks with Measured Oxalate

\begin{tabular}{|c|c|c|c|c|c|}
\hline \multirow[b]{3}{*}{ Tank } & \multirow{3}{*}{$\begin{array}{l}\text { Heasler- } \\
\text { Meacham } \\
\text { Group }\end{array}$} & \multicolumn{4}{|c|}{ Conversion Factors, $\mathrm{kJ} / \mathrm{g} \mathrm{C}$} \\
\hline & & \multicolumn{2}{|c|}{ Surface } & \multicolumn{2}{|c|}{ Subsurface } \\
\hline & & Nitrate & Nitrite & Nitrate & Nitrite \\
\hline A-101 & 1 High & 16.38 & 21.18 & 15.88 & 20.53 \\
\hline A-102 & 1 High & 11.32 & 14.58 & (a) & (a) \\
\hline$c-104$ & 1 High & 19.27 & 24.94 & 19.81 & 25.65 \\
\hline $\mathrm{C}-106$ & 1 High & 6.95 & 8.88 & (a) & (a) \\
\hline $8-107$ & 1 High & 11.42 & 14.71 & 15.74 & 20.35 \\
\hline $\mathrm{U}-105$ & 1 High & 18.79 & 24.32 & 18.49 & 23.93 \\
\hline $\mathrm{U}-106$ & 1 High & 23.22 & 30.09 & 21.26 & 27.54 \\
\hline $\mathrm{U}-107$ & 1 High & 15.20 & 19.63 & 18.37 & 23.77 \\
\hline \multicolumn{2}{|c|}{ Group 1 Average } & 15.32 & 19.79 & 18.26 & 23.63 \\
\hline B-109 & 2 Middle & 20.75 & 26.87 & 7.51 & 9.60 \\
\hline BY-102 & 2 Middle & 23.31 & 30.21 & 9.43 & 12.12 \\
\hline $8-101$ & 2 Middle & (b) & (b) & (b) & (b) \\
\hline $8-102$ & 2 Middle & 9.96 & 12.80 & 16.01 & 20.69 \\
\hline $\mathrm{U}-102$ & 2 Middle & 17.78 & 23.00 & 20.84 & 26.99 \\
\hline \multicolumn{2}{|c|}{ Group 2 Average } & 17.95 & 23.22 & 13.44 & 17.35 \\
\hline B-106 & 3 Low & 20.58 & 26.65 & 15.42 & 19.92 \\
\hline BY-104 & 3 Low & 13.89 & 17.93 & 11.80 & 15.21 \\
\hline BY-105 & 3 Low & 7.86 & 10.07 & 12.00 & 15.47 \\
\hline$B Y-106$ & 3 Low & 12.40 & 15.99 & 11.60 & 14.94 \\
\hline BY-107 & 3 Low & 15.96 & 20.63 & 11.92 & 15.37 \\
\hline BY-108 & 3 Low & 10.23 & 13.16 & 16.27 & 21.04 \\
\hline $\mathrm{BY}-110$ & 3 Low & 11.21 & 14.43 & 12.10 & 15.60 \\
\hline \multicolumn{2}{|c|}{ Group 3 Average } & 13.16 & 16.98 & 13.02 & 16.79 \\
\hline $5 X-108$ & 4 No-TOC & 6.95 & 8.88 & (a) & (a) \\
\hline \multicolumn{2}{|c|}{ Group 4 Average } & 6.95 & 8.88 & (a) & (a) \\
\hline B-203 & 5 Special & (a) & (a) & 6.95 & 8.88 \\
\hline$C-103$ & 5 Special & 21.91 & 28.38 & 22.08 & 28.61 \\
\hline \multicolumn{2}{|c|}{ Group 5 Average } & 21.91 & 28.38 & 14.52 & 18.75 \\
\hline AW-105 & $6 \mathrm{DST}^{(\mathrm{c})}$ & 23.31 & 30.21 & (a) & (a) \\
\hline$S Y-101$ & $6 \mathrm{DST}^{(\mathrm{c})}$ & 20.37 & 26.38 & 14.91 & 19.26 \\
\hline$S Y-103$ & $6 \mathrm{DST}^{(\mathrm{c})}$ & 23.31 & 30.21 & 12.87 & 16.59 \\
\hline \multicolumn{2}{|c|}{ Group 6 Average } & 22.33 & 28.93 & 13.89 & 17.92 \\
\hline \multicolumn{2}{|c|}{ Average for all Tanks } & 15.9 & 20.6 & 14.8 & 19.1 \\
\hline
\end{tabular}


Table 4.5. Number of Tanks with Calculated Frequencies Less Than Threshold Criteria by Speciation Case

\begin{tabular}{|c|c|c|c|c|c|c|c|c|c|}
\hline \multirow[t]{2}{*}{ Scenario } & \multicolumn{3}{|c|}{ HEPA Failure } & \multicolumn{3}{|c|}{ Dome Failure } & \multicolumn{3}{|c|}{$\begin{array}{l}\text { Dome Failure and } \\
\text { Continued Release }\end{array}$} \\
\hline & $10^{-6}$ & $10^{-4}$ & $10^{-2}$ & $10^{-6}$ & $10^{-4}$ & $10^{-2}$ & $10^{-6}$ & $10^{-4}$ & $10^{-2}$ \\
\hline Base Case & 53 & 126 & 138 & 70 & 130 & 138 & 89 & 132 & 138 \\
\hline $\begin{array}{l}\text { Site Average Speciation - } \\
\text { (uncontrolled initiators) }\end{array}$ & 87 & 133 & 138 & 106 & 133 & 138 & 116 & 134 & 138 \\
\hline $\begin{array}{l}\text { Site Average Speciation - } \\
\text { (controlled initiators) }\end{array}$ & 137 & 138 & 138 & 138 & 138 & 138 & 138 & 138 & 138 \\
\hline $\begin{array}{l}\text { Group Average Speciation - } \\
\text { (uncontrolled initiators) }\end{array}$ & 94 & 133 & 138 & 114 & 133 & 138 & 125 & 134 & 138 \\
\hline $\begin{array}{l}\text { Group Average Speciation - } \\
\text { (controlled initiators) }\end{array}$ & 134 & 138 & 138 & 138 & 138 & 138 & 138 & 138 & 138 \\
\hline
\end{tabular}

is to point out the high potential for risk reduction from a more thorough analysis by using, for example, speciation data obtained directly for each waste type (tank group) and by including both nitrate and nitrite data in the model. We also find that the risk ordering is not substantially altered by the consideration of organic speciation. Inclusion of speciation data results in insignificant relative ordering of the tanks in Table 4.1. Thus, the risk-based prioritization of actions (characterization, remediation, or controls) for risk resolution (if required by risks exceeding acceptable thresholds) remains valid.

\subsubsection{Mitigation Scenario Analysis}

Three strategies were proposed as potential methods for reducing the risk associated with an organic-nitrate reaction in Hanford's SSTs. The first strategy would be to control the initiators or events that cause a reaction to start; the other two would be to change the characteristics of the waste either by adding moisture or by reducing the energy content of the waste, thus reducing the reactivity of the waste. Following the discussion of all mitigation scenarios, the effect of their application will be discussed (Section 4.2.4).

\subsubsection{Control Ignition Sources}

Risk Assessment for Condensed-Phase Organic-Nitrate Reactions in Hanford SingleShell Tanks (Daling et al. 1997) identified organic-nitrate initiating events and quantified the frequency of these events. The initiating events were determined by evaluating tank farm activities and natural phenomena for events that were energetic enough to initiate a reaction and would come in contact with the waste. Estimates were developed for both "mitigated" and "unmitigated" initiator frequencies. These frequencies are listed in Table 4.6. Mitigation of initiators could include such items as limiting access to the tank farms, revised operating procedures, and installing equipment to prevent the event. (For further explanation of the development of initiator frequencies, see Section 6 of Daling et al. [1997].) The current project scope did not include or evaluate these frequency estimates. 
Table 4.6. Organic-Nitrate Initiator Frequencies

\begin{tabular}{|l||c|c||}
\hline \multicolumn{1}{|c||}{ Type of Initiator } & $\begin{array}{c}\text { Unmitigated Frequency } \\
\text { (per SST-yr) }\end{array}$ & $\begin{array}{c}\text { Mitigated Frequency } \\
\text { (per SST-yr) }\end{array}$ \\
\hline \hline Failed video or still camera lights & $1.80 \mathrm{e}-02$ & $7.20 \mathrm{e}-05$ \\
\hline $\begin{array}{l}\text { Slag or hot metal from welding or } \\
\text { torch cutting activities }\end{array}$ & $2.70 \mathrm{e}-02$ & $1.10 \mathrm{e}-04$ \\
\hline Vehicle fuel fire & $3.30 \mathrm{e}-03$ & $3.40 \mathrm{e}-06$ \\
\hline Rotary core mode drilling & $2.70 \mathrm{e}-02$ & $2.20 \mathrm{e}-05$ \\
\hline Lightning strike & $2.50 \mathrm{e}-06$ & $1.30 \mathrm{e}-06$ \\
\hline Flammable gas burn & $1.0 \mathrm{e}-04$ & $5.0 \mathrm{e}-06$ \\
- Seismic & $8.3 \mathrm{e}-04$ & $1.2 \mathrm{e}-04$ \\
- Other sources & $9.3 \mathrm{e}-04$ & $1.3 \mathrm{e}-04$ \\
\hline - Total & $2.00 \mathrm{e}-01$ & $2.00 \mathrm{e}-03$ \\
\hline Bulk waste heatup & & \\
(Tank C-106 only) & & \\
\hline
\end{tabular}

\subsubsection{Add Moisture to Waste}

Adding moisture has been postulated as a possible mitigation strategy for organic-nitrate reactions. Moisture could be added using a number of fairly well-understood methods including sprinkler systems and humidifiers. The addition of moisture is assumed to increase the average water content of the waste and to decrease the spatial variability of the water content. It is assumed to act both on the surface of the waste and in the subsurface; however, it is assumed to be more effective on the surface. The effect of moisture addition on the probability of having a given amount of reactive waste was estimated by adjusting the input parameters to the reactive waste estimate. The method used to adjusted input parameters for the reactive waste estimate, described below, assumed that only the surface of the waste would be affected. The surface input parameters to the reactive waste estimate were set to $30 \%$ for mean moisture, $10 \%$ for spatial variability, and $10 \%$ for uncertainty (RSD).

\subsubsection{Reduce Energy Content of Waste}

Another mitigation strategy is to reduce the energy content of the waste. A potential method for performing this action would be to process the waste through the evaporator, causing thermal degradation of the TOC as in the past. This is also another way of considering the effects of natural waste aging. The method for determining the effect of purposefully reducing the energy content of tank waste is to assume that the energy content would be reduced on both 
the surface and subsurface but that the reduction in the surface waste would be greater than in the subsurface waste. To estimate the potential effects of energy reduction on reactive waste volumes, the median TOC value was reduced by $50 \%$ and the uncertainty for the surface set to $25 \%$ while the uncertainty for the subsurface waste set to $50 \%$.

Table 4.7 shows the summary results of the comparison of the mitigated tank frequencies to the threshold criteria for each event scenario. The base-case summary has been included in this table to facilitate comparisons. Reducing the energy associated with the TOC and controlling the initiating events result in a significant increase in the number of tanks with calculated frequencies below the frequency thresholds. Adding moisture did not result in a similar reduction of frequency and, in fact, resulted in fewer tanks with calculated frequencies lower than the frequency thresholds. This is probably due to the assumed effectiveness of the mitigative action and the randomness of the Monte Carlo simulations.

\subsubsection{Sampling Effects}

To assess the impacts of additional sampling on risk from uncertainty about tank contents, two case studies were performed assuming each tank with less than two observations was sampled. In two cases, it was assumed that two core samples were taken; in the other two, 25 surface samples were presumed taken. The presumed results obtained from the additional samples were taken as equal to the mean values calculated in the tank contents estimate; therefore; uncertainty is reduced.

The impact of these assumptions is the reduced estimated uncertainty in the data since the values assumed were the predicted mean values. The most straightforward finding of this analysis is that the biggest contribution to the risk is the uncertainty in the information about the tank contents. Figure 4.1 (Section 4.1) showed that, generally, the calculated frequency .

Table 4.7. Number of Tanks with Calculated Frequencies Less Than Threshold Criteria by Mitigative Action Scenario

\begin{tabular}{|c|c|c|c|c|c|c|c|c|c|}
\hline \multirow{2}{*}{ Scenario } & \multicolumn{3}{|c|}{ HEPA Failure } & \multicolumn{3}{|c|}{ Dome Failure } & \multicolumn{3}{|c|}{$\begin{array}{l}\text { Dome Failure and } \\
\text { Continued Release }\end{array}$} \\
\hline & $10^{-6}$ & $10^{-4}$ & $10^{-2}$ & $10^{-6}$ & $10^{-4}$ & $10^{-2}$ & $10^{-6}$ & $10^{-4}$ & $10^{-2}$ \\
\hline Base Case & 53 & 126 & 138 & 70 & 130 & 138 & 89 & 132 & 138 \\
\hline Reduce Energy & 130 & 137 & 138 & 136 & 138 & 138 & 136 & 138 & 138 \\
\hline Add Moisture & 70 & 130 & 138 & 77 & 130 & 138 & 88 & 131 & 138 \\
\hline Control Ignition & 129 & 138 & 138 & 132 & 138 & 138 & 134 & 138 & 138 \\
\hline $\begin{array}{l}\text { Remediate and } \\
\text { Control Ignition }\end{array}$ & 138 & 138 & 138 & 138 & 138 & 138 & 138 & 138 & 13 \\
\hline
\end{tabular}


decreases dramatically as the number of measurements of the organic contents increases. As uncertainty in the waste contents is reduced, the frequency of unwanted events will also drop for those tanks that turn out to have low amounts of reactive waste. Table 4.8 shows the number of tanks that have calculated frequencies at or below the specified threshold for each of the sampling scenarios evaluated. This table shows how reducing uncertainty reduces risk.

High uncertainty in the contents of most tanks results from these facts: 1) tank contents show high spatial imhomogeneity, 2) few locations are available for sampling in each tank, and 3) many tanks have not been sampled.

Statistical grouping methods are relied upon to estimate the contents of each tank within a group of similar tanks. As a result, the estimates have high uncertainties, which translate to larger risks for tanks with few measurements. In fact, none of the waste samples obtained to date represent material that would cause the sampled tank to be considered at risk of an organicnitrate event if one could be assured that the entire tank contents have the same composition as the sample.

\subsubsection{Conclusions from Scenario Tests}

The overall finding from these tests is that the base-case estimates are conservative and that mitigation actions of the type considered can have a significant effect on risk reduction. Also, we see that one result of the application of the recommended strategy (Colson 1997) is a priority-ordered basis for selecting which tanks require mitigation actions, if any.

Table 4.8. Number of Tanks with Calculated Frequencies Less Than Threshold Criteria by Sampling Effects Case

\begin{tabular}{|c|c|c|c|c|c|c|c|c|c|}
\hline \multirow{2}{*}{ Scenario } & \multicolumn{3}{|c|}{ HEPA Failure } & \multicolumn{3}{|c|}{ Dome Failure } & \multicolumn{3}{|c|}{$\begin{array}{l}\text { Dome Failure and } \\
\text { Continued Release }\end{array}$} \\
\hline & $10^{-6}$ & $10^{-4}$ & $10^{-2}$ & $10^{-6}$ & $10^{-4}$ & $10^{-2}$ & $10^{-6}$ & $10^{-4}$ & $10^{-2}$ \\
\hline Base case & 53 & 126 & 138 & 70 & 130 & 138 & 89 & 132 & 138 \\
\hline $\begin{array}{l}2 \text { samples per tank } \\
\text { (controlled initiators) }\end{array}$ & 120 & 136 & 138 & 131 & 137 & 138 & 133 & 137 & 138 \\
\hline $\begin{array}{l}2 \text { samples per tank } \\
\text { (uncontrolled initiators) }\end{array}$ & 136 & 138 & 138 & 137 & 138 & 138 & 137 & 138 & 138 \\
\hline $\begin{array}{l}25 \text { surface samples per tank } \\
\text { (controlled initiators) }\end{array}$ & 120 & 136 & 138 & 131 & 137 & 138 & 134 & 137 & 138 \\
\hline $\begin{array}{l}25 \text { surface samples per tank } \\
\text { (uncontrolled initiators) }\end{array}$ & 136 & 138 & 138 & 137 & 138 & 138 & 137 & 138 & 138 \\
\hline
\end{tabular}


It is also useful to note the specific tanks that were the least responsive to risk reduction through application of the scenario tests (e.g., AX-102 and U-103). This provided yet another measure of those tanks that should be the highest priority for safety related actions, be they characterization, mitigation, or controls.

\subsection{Make Decisions}

Quantitative risk calculations provide valuable information for making difficult decisions under conditions of high uncertainty. Quantitative risk predictions allow prioritization of decisions about risk management. The preferred finding of any safety analysis would be that there is no significant risk to the health of workers or the public or to any programs that might be affected by a particular risk factor. Indeed, this has been determined to be the case for some factors (e.g., criticality and ferrocyanide) affecting safety risks associated with the Hanford waste tanks. However, it may not be possible to achieve this level of risk contribution from other risk factors without changing (or removing) the tank contents. Then, it is vital to be able to select the highest-value actions to be taken to manage the risk represented by those frequency factors that remain a concern. Quantitative evaluations of risk provide that tool. In the case studied in this report, the analysis focuses attention on a particular small set of tanks for action.

Having a quantitative risk calculation allows one to evaluate approaches to risk reduction through formal value of information analyses, sensitivity or uncertainty analyses, or by conducting scenario tests by varying the inputs to the calculation. The results of each of these approaches were used in this report to develop a characterization plan for reducing the risks associated with the organic-nitrate safety issue.

The greatest contribution to risk is uncertainty in knowledge. By far the largest contribution to the risk from this factor is uncertainty in knowledge about the waste contents and about their spatial distribution. Individual samples taken from the tanks do not show significant risk. Furthermore, with the exception of a few tanks, sampling and analysis results are found to dramatically reduce the estimated risk.

Another contribution to the risk is the uncertainty in relating what is known about the tank contents (from historical records, sampling data, etc.) to risk. The inpuits required by the risk calculation may not faithfully represent the information available. This is not just a difficulty with using a quantitative risk-based approach. It is the risk that must be managed, and if one cannot relate what is known about the tank contents to the risk of an explosion, for example, then actions must be taken, be they characterization work, the institution of operational controls, or remediation actions. The work in this report uses quantitative risk estimates to prioritize and focus these actions to optimize and accelerate their effects on risk reduction. This is a key characteristic of the recommended strategy that calls for an iterative approach to obtaining the understanding required to guide risk reduction and waste remediation actions. 


\subsection{Results and Conclusions}

This section summarizes the results of implementing the risk-based, focused decision management approach to justify characterization of Hanford tank waste. Conclusions are drawn and recommendations are made for further characterization.

\subsection{Analysis Summary Conclusions}

A tolerable set of risk criteria is crucial to classification of tanks. For instance, if a burst HEPA filter frequency of once every one hundred years is tolerable to the decision makers, then all 138 SSTs that were analyzed can be classified as acceptable. However, if the frequency must be reduced to less than once in a million years, then 85 tanks require either remediative action or additional characterization (remembering that information uncertainty is a major contribution to the frequency) to improve the reliability of that calculation. Choosing different acceptance criteria (from Table 4.1) would focus remediation and/or characterization actions on a different number of tanks.

Analysis of the results on a tank-by-tank basis shows that a major contribution to the risk for many tanks may be the uncertainty about the estimates of tank contents, (i.e., lack of information about tank contents). For example, there are 104 tanks for which there are fewer than two observations included in the data set. The contents of these tanks are estimated as being the average of the group to which they are assigned. There is a large uncertainty in the group assignments and therefore a large uncertainty in the tank contents estimates. To test the impact of obtaining additional data from these tanks, the analysis was repeated; and the uncertainty in this average value was reduced (for this test) to that found in tanks that have two or more measurements. The results (discussed in Section 4.2.3) indicate there are large effects from obtaining data from the unsampled tanks. While this is not a completely reliable prediction of the impact of additional sampling, since the actual contents of the unsampled tanks may well exceed the predicted value, the uncertainty will be significantly reduced by having sample data such that an estimate of risk will rely less on uncertainty and more on an estimated tank contents mean.

The arrangement of tanks into groups that are expected to have similar contents is a vital element of the risk calculation. Only in this way can any statistically meaningful analysis be conducted given the small number of samples from any given tank. Thus we conducted the scenario tests using the various approaches to tank grouping (see Section 4.2.4). There are some differences among the ANOVA estimates and, by inference, the calculated organic-nitrate safety risk. Accounting for the uncertainty in the tank waste groupings and the grouping process will reduce uncertainty in tank contents estimates. 
Another question remaining is the relation between the total amount of organic carbon and the energy content of the waste. The acetate representation of TOC is a very rough approximation. Unfortunately, few data exist on the distribution of chemical species in each tank. To consider the value of obtaining that type of information, speciation information was estimated according to the method described in Section 4.2.1. Most tanks showed reduced frequency with this approach, but a few showed higher frequency because the surface material was predicted to have higher energy content and thus was easier to ignite by a surface source-the most likely ignition source.

Computer modeling, calculations, and analysis tools must be sound for the frequency calculations to be meaningful. For this reason, a critique of these tools was conducted by Barry Wise of Eigenvector Research. The results were basically positive and are summarized in Appendix D.

Both adding water and reducing the organic fuel content (either by waste aging or by some intervention) were considered as possible remediation actions. Adding water had a relatively small effect; only limited amounts of water could be added to SSTs because of possible leaks. A decrease in the energy content (as described in subsection 4.2.2.3) was seen to have a much larger effect. Thus this result and those of the speciation scenario point to the value of knowing more about the amount of energy stored in the organic salts and the potential for reducing that energy through chemical or radiochemical means.

\subsection{Plan Characterization}

As a result of this analysis, the following recommendations are made for planning future charaacterization activities:

- Take initial action to ascertain the risk of the 11 ungrouped SSTs. The 11 tanks in Table 5.1 have the most uncertainty associated with them, such that no risk calculations were made during this analysis. These 11 tanks must have characterization work performed so that their tank contents can be estimated and the risk for organic-nitrate reaction calculated as with the other 138 SSTs. It is important to note that characterization work can include laboratory experiments designed to increase our understanding of the physical and chemical phenomena of concern, tests on wastes or waste simulants, and studies of historical records as well as sampling and analysis work.

- Focus near-term characterization work on the 12 tanks that show a predicted HEPA filter failure rate in excess of $10 E-5$ per year. A large fraction of the past sampling and analysis actions have focused (for reasons that may be fully justified for other events) on tanks thought to be at low risk of runaway organic-nitrite events. While that low risk was confirmed, what is needed to define the actions (if any) required to remediate this risk factor is more data about the higher risk group(s) of tanks. 
Table 5.1. Tanks Not Currently Amenable to Grouping
B-201
C-101
C-201
B-202
C-102
C-202
B-203
C-103
C-203
B-204
C-204

Table 5.2 shows the recommended prioritized order of SSTs for near-term characterization work. This list is in addition to the 11 tanks identified in Table 5.1 that were not included in this analysis because we lack the data necessary to estimate TOC and moisture amounts. The prioritization was performed on the 12 tanks having a calculated HEPA filter failure probability of $10 \mathrm{E}-05$ or greater. Of these 12 , the six with the highest probability of dome failure with continued release (the most severe event analyzed) greater than 10E-05 are listed first. The next three tanks have the highest priority of dome failure (second most severe event analyzed) greater than 10E-05. The last three tanks are listed in the order of their probability for HEPA filter failure. The effect of this prioritization method is to work initially on the tanks that have the highest calculated risk, considering both the potential consequence and the probability of each consequence. In this manner the highest probability and most severe event consequence tanks will be resolved first.

Table 5.2. Prioritized Order for Near-Term Characterization Work

\begin{tabular}{|c|c|}
\hline Order & Tank \\
\hline 1 & AX-102 \\
\hline 2 & AX-101 \\
\hline 3 & SX-106 \\
\hline 4 & SX-101 \\
\hline 5 & AX-103 \\
\hline 6 & TX-104 \\
\hline 7 & C-106 \\
\hline 8 & U-103 \\
\hline 9 & TX-118 \\
\hline 10 & U-106 \\
\hline 11 & A-102 \\
\hline 12 & SX-103 \\
\hline
\end{tabular}


- Focus on the tank waste surface to accelerate resolution. The risk calculation shows that the highest contribution to event initiation comes from surface ignition. Therefore, understanding the ignition capability of the tank waste surface area will reduce uncertainty in the margin of safety. In addition, better understanding of the surface ignition sources, their ability to ignite organic-nitrate reactive waste, the contents of the tank waste surface will go far in reducing the uncertainty component of organic-nitrate risk.

- Obtain data that will more directly demonstrate the energetic contents of the waste. The use of TOC measurements as an indirect measure of energetic contents introduces uncertainty, a major contribution to risk. Thus it would be very valuable to obtain data that not only directly measure the energetic contents of the waste but also calibrate the TOC data, making it possible to use the extensive TOC data more effectively. Unless a connection can be made to the body of existing data, any new measurements will need to be obtained several times in several tanks to obtain a reasonable approximation of the spatial distribution of the waste in the tanks of concern.

- Declare the following tanks as having extremely low risk and thus having no need of additional characterization in relation to this safety issue. Should an independent assessment of data quality (when performed) be confirmatory, the tanks in Table 5.3 can be declared to have extremely low risk. No additional characterization is required in relation to the organic-nitrate safety issue. Both the data uncertainty and the relation between the data and the information required in the risk calculation must be evaluated before making conclusive decisions about those tanks that show marginal or greater risk.

- Establish defensible risk criteria that are acceptable for decision making. Work with DOE to determine what risk criteria are acceptable for making decisions about characterization and/or remediation actions.

- Perform an independent review of the data set to confirm quality in its application and use. Two issues will be addressed by this recommendation. First, since the existing model that relates TOC to waste energetics was not evaluated in this analysis, this basic presumption must be reviewed. In any case, the TOC measurements are used as an indirect measure of energetic contents, so at a minimum that uncertainty must be quantified and included in the risk evaluation. Ideally, a direct measure of energetics is preferred. However, unless a connection can be made to the body of existing data, any different measurements will need to be obtained multiple times in multiple tanks to obtain a reasonable approximation of the spatial distribution of the waste in the tanks of concern. Secondly, high confidence in the data used to complete an analysis must be maintained by a finalizing a data set of historical records that is stationary except for the addition of new data points from incremental characterization actions. 
Table 5.3. Tanks with Extremely Low Estimated Risk for Organic-Nitrate Event

\begin{tabular}{|cccccc||}
\hline A-101 & B-103 & B-106 & B-109 & B-110 & B-111 \\
B-112 & BX-103 & BX-104 & BX-107 & BX-109 & BX-111 \\
BX-112 & BY-102 & BY-106 & BY-107 & BY-108 & BY-110 \\
BY-112 & C-104 & C-108 & C-109 & C-110 & C-112 \\
S-101 & S-104 & S-107 & S-109 & S-111 & SX-108 \\
T-102 & T-104 & T-105 & T-107 & T-111 & TY-101 \\
TY-102 & TY-103 & TY-104 & TY-105 & TY-106 & U-107 \\
U-108 & U-109 & U-201 & U-203 & U-204 & \\
\hline
\end{tabular}




\subsection{References}

Agnew SF. 1997. Hanford Tank Chemical and Radionuclide Inventories: HDW Model Rev. 4. LA-UR-96-3860; Los Alamos National Laboratory, Los Alamos, New Mexico.

AIChE. 1995. Guidelines for Chemical Reactivity Evaluation and Application to Process Design. American Institute of Chemical Engineers, New York.

Babad H, MD Crippen, DA Turner, and MA Gerber. 1993. "Resolving the Safety Issue for Radioactive Waste Tanks with High Organic Content." In Proceedings of Waste Management '93. Tucson, Arizona.

Babad H and DA Turner. 1993. Interim Criteria for Organic Watch List Tanks at the Hanford Site. WHC-EP-0681, Westinghouse Hanford Company, Richland, Washington.

Barefield EK, D Boatwright, A Deshpande, F Doctorovich, CL Liotta, HM Neumann, and S Seymore. 1996. Mechanisms of Gas Generation from Simulated SY Tank Farm Wastes: FY 1995 Progress Report. PNL-11247, Pacific Northwest National Laboratory, Richland, Washington.

Burger LL. 1995. Calculation of Reaction Energies and Adiabatic Temperatures for Waste Tank Reactions. PNL-8557 Rev. 1, Pacific Northwest Laboratory, Richland, Washington.

Camaioni DM, WD Samuels, BD Lenihan, SA Clauss, KL Wahl, and JA Campbell. 1994. Organic Tanks Safety Program - Waste Aging Studies. PNL-10161, Pacific Northwest Laboratory, Richland, Washington.

Campbell JA, RW Stromatt, MR Smith, DW Koppenaal, RM Bean, TE Jones, DM Strachan, and H Babad. 1994a. "Organic Analysis at the Hanford Nuclear Site." Anal. Chem., Vol. 66, No. 24.

Campbell JA, S Clauss, K Grant, V Hoopes, B Lerner, R Lucke, G Mong, J Rau, and R Steele. 1994b. Flammable Gas Safety Program - Analytical Methods Development FY 1993 Progress Report. PNL-9062, Pacific Northwest Laboratory, Richland, Washington.

Campbell JA, SA Clauss, KE Grant, FV Hoopes, BD Lerner, RB Lucke, GM Mong, JK Rau, KL Wahl, and RT Steele. 1994c. Flammable Gas Safety Program - Analytical Methods Development FY 1994 Progress Report. PNL-10127, Pacific Northwest Laboratory, Richland, Washington.

Campbell JA, SA Clauss, V Hoopes, J Rau, KH Wahl, KE Grant, GM Mong, and RD Scheele. 1995. Organic Analysis and Analytical Methods Development: FY 1995 Progress Report. PNL10776, Pacific Northwest Laboratory, Richland, Washington. 
Campbell JA, SA Clauss, KE Grant, V Hoopes, GM Mong, J Rau, R Steele, and KH Wahl. 1996. Flammable Gas Safety Program - Actual Waste Organic Analysis FY1996 Progress Report. PNNL-11307, Pacific Northwest National Laboratory, Richland, Washington.

Carlson CD. 1997. Speciation of Organic Carbon in Hanford Waste Storage Tanks: Part 1. PNNL-11480, Pacific Northwest National Laboratory, Richland, Washington.

Colson SD, RE Gephart, VL Hunter, J Janata, and LG Morgan. 1997. A Risk-Based Focused Decision-Management Approach for Justifying Characterization of Hanford Tank Waste. PNNL-11231, Pacific Northwest National Laboratory, Richland, Washington.

Colson SD, RE Gephart, VL Hunter, J Janata, and LG Morgan. 1998. "A Risk- and OutcomeBased Strategy for Justifying Characterization to Resolve Tank Waste Safety Issues." Science and Technology for Disposal of Radioactive Tank Wastes. Plenum Publishing Corporation, New York (in press).

Daling PM, JL Bryant, TJ DeForest, PG Heasler, VL Hunter, SJ Lee, M Plys, CS Simmons, JJ Toth, J Ulvila, and MD Zentner. 1996. Risk Assessment for Condensed-Phase OrganicNitrate Reactions in Hanford Single-Shell Tanks. Pacific Northwest National Laboratory, Richland, Washington.

DOE. 1996. Recommendation 93-5 Implementation Plan. DOE/RL-94-0001, U.S. Department of Energy, Richland, Washington.

Fauske HK, M Epstein, DR Dickenson, RJ Cash, and JE Meacham. 1995. The Contact Temperature Ignition (CTI) Criteria for Propagating Chemical Reactions Including the Effect of Moisture and Application to Hanford Waste. WHC-SD-WM-ER-496 Rev. 0, Westinghouse Hanford Company, Richland, Washington.

Fisher FD. 1990. The Kyshtym Explosion and Explosion Hazards with Nitrate-Nitrite Bearing Wastes with Acetates and Other Organic Salts. WHC-SD-CP-LB-033 Rev. 0, Westinghouse Hanford Company, Richland, Washington.

Goheen SC, JA Campbell, GE Fryxell, LL Burger, RT Hallen, T Jones, GS Klinger, BP McGrail, LG Morgan, LR Pederson, RG Riley, and DS Sklarew. 1997. Characterization Strategy Report for the Organic Safety Issues, Hanford Tank Characterization and Safety Issue Resolution Project. PNNL-11533, Pacific Northwest National Laboratory, Richland, Washington.

Hanlon BM. 1997. Waste Tank Summary Report for Month Ending September 30, 1997. WHC-EP-0182-114, Lockheed Martin Hanford Corporation, Richland, Washington.

Klem JJ. 1990. Inventory of Chemicals Used at Hanford Site Production Plants and Support Operations, 1944-1980. WHC-EP-0172, Westinghouse Hanford Company, Richland, Washington. 
Kubic WL. 1996. An Evaluation of Reactive Chemical Hazards During Rotary Mode Core Sampling. TSA10-CN-WT-SA-CH-001 Rev. 1, Los Alamos National Laboratory, Los Alamos, New Mexico.

Meacham JE, AB Webb, NW Kirch, JA Lechelt, DA Reynolds, GS Barney, DM Camaioni, F Gao, RT Hallen, and PG Heasler. 1997. Organic Complexant Topical Report. HNF-SD-WMCN-058, Duke Engineering Services Hanford, Richland, Washington.

Medvedev ZA. 1979. Nuclear Disaster in the Urals. Translated by G Saunders. WH Norton and Company, New York.

Postma AK, JE Meacham, GS Barney, GL Borsheim, RJ Cash, MD Crippen, DR Dickinson, JM Grigsby, DW Jeppson, M Kummerer, JM McLaren, CS Simmons, and BC Simpson. 1994. Ferrocyanide Safety Program: Safety Criteria for Ferrocyanide Watch List Tanks. WHC-EP0691, Westinghouse Hanford Company, Richland, Washington.

Sharkey JJ, RS Cutro, WJ Fraser, and GT Wildman. 1992. "Plant Safety Testing Program for Reducing Risks Associated with Large-Scale Chemical Manufacturing Operations." Plont/ Operations Progress, 11(4):238-246.

Strachan DM, WW Schulz, and DA Reynolds. 1993. Hanford Site Organic Waste Tanks; History, Waste Properties, and Scientific Issues. PNL-8473, Pacific Northwest Laboratory, Richland, Washington.

Webb AB, JL Stewart, DA Turner, MG Plys, B Malinovic, JM Grigsby, DM Camaioni, PG Heasler, WD Samuels, and JJ Toth. 1995. Preliminary Safety Criteria for Organic Watch List Tanks at the Hanford Site. WHC-SD-WM-SARR-033 Rev 0, Westinghouse Hanford Company, Richland, Washington.

WHC. 1989. Nonreactor Facility Safety Analysis Manual. WHC-CM-4-46 Rev. 1, Westinghouse Hanford Company, Richland, Washington.

WHC. 1995. Nonreactor Facility Safety Analysis Manual. WHC-CM-4-46 Rev. 4, Westinghouse Hanford Company, Richland, Washington.

Wilson GR and IE Reep. 1991. A Plan to Implement Remediation of Waste Tank Safety Issues at the Hanford Site. WHC-EP-0411 Rev. 1, Westinghouse Hanford Company, Richland, Washington.

Wodrich DD and JL Deichman. 1992. Hanford Site Radioactive Waste Storage Tank Safety Issues: The Path to Resolution. WHC-SA-1328, Westinghouse Hanford Company, Richland, Washington. 
Appendix A

Implementing the Recommended Strategy 


\section{Appendix A}

\section{Implementing the Recommended Strategy}

This project addresses the limited implementation of the strategy recommended by Colson et al. (1997) and shown in Figure A.1 for the organic-nitrate safety issue in Hanford radioactive waste tanks. The recommended strategy calls for using 1) structured logic techniques to describe the safety issue and 2) decision analysis methods (e.g., risk assessment, uncertainty evaluation, sensitivity analyses) to assess the cost and risk of following one approach rather than another. The recommended strategy helps identify critical data and modeling uncertainties whose resolution is the foundation for implementing technically defensible waste characterization studies. Scope and schedule prevented the full implementation of the recommended strategy. Following are the most significant features of the full strategy that were not employed:

- A value of information analysis requiring information about the value of information for other safety and operations issues. Such information was not available.

- A quality assurance committee to validate the quality of the data and to determine that the data used faithfully represented the information required by the models used in the analysis. To meet scope and schedule constraints, we used the best data and models available from the Project Hanford Management Contractor (PHMC) as of June 1997.

- Full participation of a resolution team involving non-contractor experts as needed to implement the most defensible solution. Premature termination of project funding led to a restricted role for the members of the resolution team who were not staff of Pacific Northwest National Laboratory (PNNL) in the final disposition of the work.

Implementing the recommended strategy required organizing a resolution team to evaluate the safety issue and to design a characterization plan according to the strategy developed in Colson et al. (1997) for each of the Hanford SSTs. In addition to the resolution team, the recommended strategy calls for an independent peer review of the results (which was not included in the work scope) and a Data Quality Assurance Team (which was not in the work scope) to assure the resolution team that the data being used provided a meaningful measure of the parameters in the reaction model as represented by the structured logic diagram of the phenomena being evaluated.

As noted, the scope did not allow the full application of the recommended strategy. Given this limited scope, the same input data set being used by Hanford's Tank Waste Safety Project (Meacham et al. 1997) were used so that the safety issue and tank-by-tank recommended characterization plan could be compared directly. The work scope was further limited by the change in funding from direct to overhead. At that juncture, the resolution team was reduced to key staff from PNNL. 


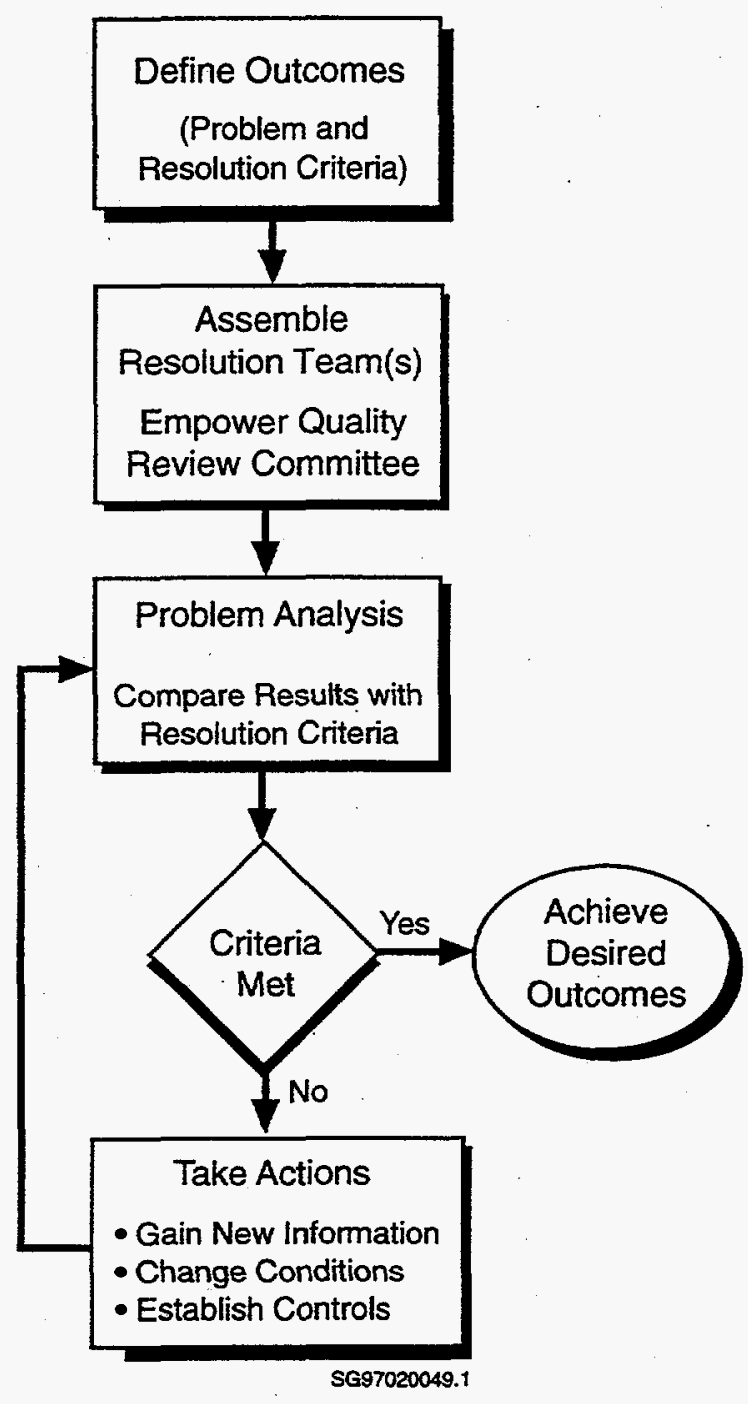

Figure A.1. Recommended Strategy

\section{A.1 Project Objectives}

The objectives of the project are to use existing information about the tank contents to classify each tank according to its organic-nitrate risk and to prepare a characterization plan using the results of this analysis.

Analyzing the uncertainty in the information and calculations and their sensitivity to types of information about the waste will lead to developing a characterization plan designed to reduce the uncertainty in making sound decisions about any actions required to mitigate this safety issue. 
The role of characterization work is to allow the classification to have sufficient certainty to enable action with confidence. Characterization work will be justified by its value compared with the costs of mitigation and control options. Full justification of characterization actions requires integration across all needs for such information. It may to too costly, relative to a mitigation action, to obtain a particular piece of information unless it also addresses other safety or operations issues as well. Since this analysis did not address all needs for characterization work, the analysis will be limited in that respect.

\section{A.2 Analysis Process}

A resolution team of specialists was recruited from PNNL, other Hanford contractors, universities, and industry to address the perceived technical issues (see Table A.1). The team met on November 16-17, 1996, to define the current understanding of the organic-nitrate safety issue and to plan the initial work. It was decided to apply the strategy to a small set of representative tanks to establish the nature of the technical problems that would need to be addressed before evaluating the risks for all tanks.

The process to be followed, as dictated by the recommended strategy, involved the steps shown in Figure A.2 in a phased approach. These steps are described fully in Colson et al. (1997) and summarized below.

Table A.1. Resolution Team for Organic-Nitrate Safety Issue

External Members
Name
Gene Ashby
David Leggett
Ffrancon Williams
Barry Wise
PNNL Members
Valeria Hunter, Team Leader
Gailann Rice
Tom Ferryman
Randy Scheele
Leon Stock
Other
Jim Chinnis
Jake Ulvila

External Members

Name

Gene Ashby

David Leggett

Ffrancon Williams

Barry Wise

PNNL Members

Valeria Hunter, Team Leader

Gailann Rice

Tom Ferryman

Randy Scheele

Other.

Jake Ulvila
Expertise
Organic Chemistry
Thermodynamics
Radiation Chemistry
Statistics/Sampling

Risk/Decision Analysis

Project Assistant

Statistics/Sampling

Thermodynamics

Organic Chemistry

Decision Science

Decision Science
Affiliation

Georgia Institute of Technology

Hazard Evaluation Labs

University of Tennessee

Eigenvector, Inc.

PNNL Ex Officio Members

Steve Colson

Roy Gephart

(Jiri) Art Janata

Larry Morgan

Decision Science Assoc.

Decision Science Assoc. 


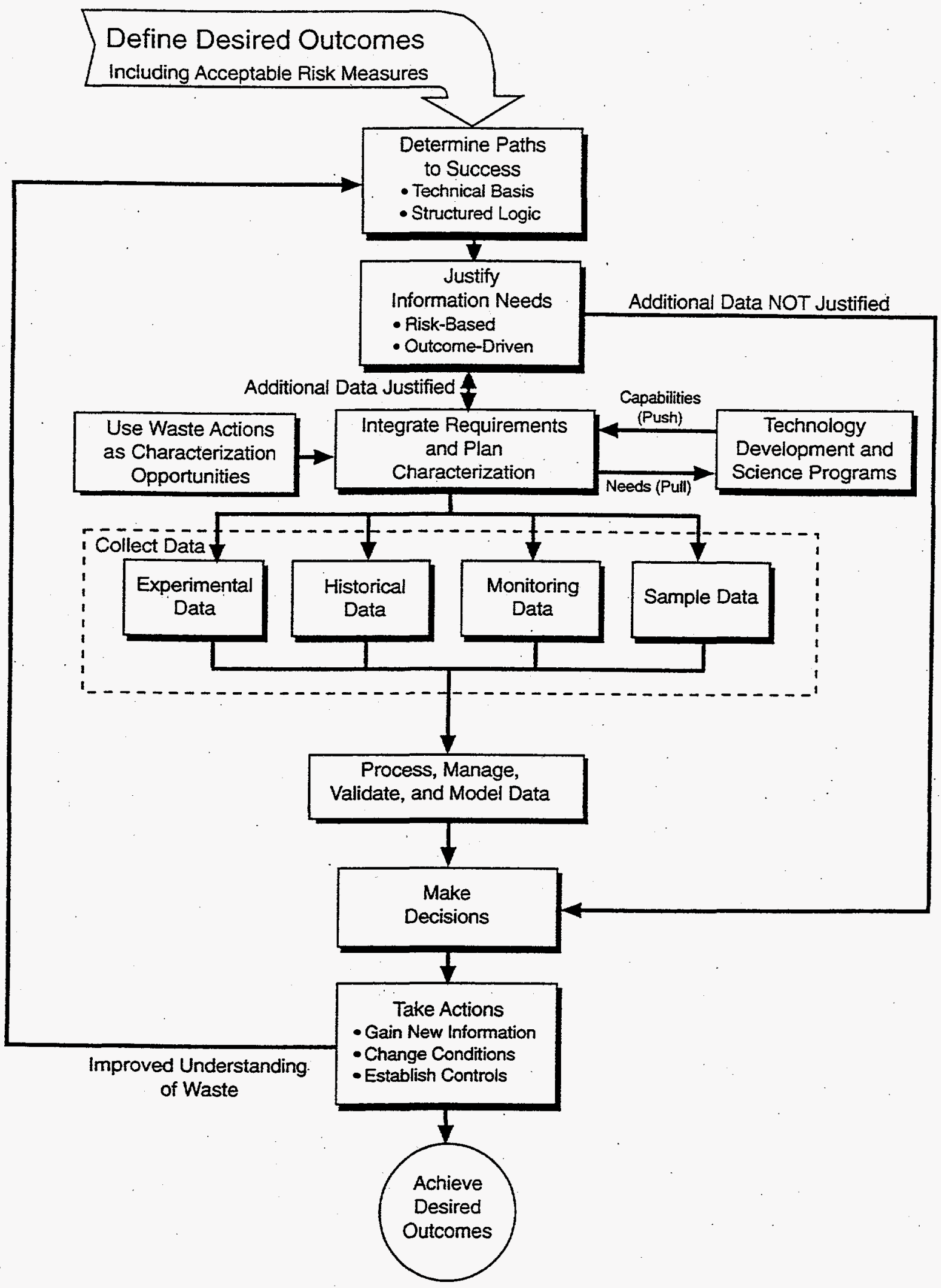

Figure A.2. Problem Analysis Process 


\section{A.2.1 Define Desired Outcomes}

It is important to keep the complexity of acceptable risk as simple as possible and yet capable of providing information of sufficient quality for decision making. In this case, we decided that an event that caused any significant amount of hazardous material to be ejected from the tank would be considered unacceptable to DOE, the Hanford workers, and the public whether or not it was widely dispersed. Thus it is not necessary to include consequence calculations such as dosage to onsite or offsite personnel in the risk analysis, which greatly reduces the uncertainty in the results. The focus will be on minimizing the risk of smaller-scale events to provide protection from larger-scale versions of the same phenomena. The resolution team also decided to develop a model of the organic-nitrate explosion phenomena in an iterative manner, evolving its complexity (and information requirements) only to the extent needed to support sound decision making. This leads to the identification and quantification of parameters that, if known with sufficient accuracy, could be used with assurance to classify a tank as having extremely low risk (or not). For example, if most of the waste is water, it cannot be caused to burn and explode by oxidation of the organic components. Likewise, if the amount of waste is sufficiently small, it cannot contain enough energy to breach the tank containment, because empty tanks cannot explode.

\section{A.2.2 Determine Paths to Success}

Structured logic is to be used to develop a description of phenomena that might lead to an explosion caused by reactions of the organic salts (fuels) and the nitrates and nitrites (oxidants) stored in the tanks. Structured logic is a technical analysis tool for documenting the options for resolution of the problem, the means to calculate the risk of the reaction, and the associated information needs.

\section{A.2.3 Justify Information Needs}

The risk is the product of the probability of the contents being in a hazardous (explosive) state and the frequency of the event initiators (e.g., sparks). The risk calculation also estimates the frequency of any likely initiation sources. Initially, existing information is used for the risk calculation. Then, for those tanks having unacceptable risk, obtaining additional information will be considered as a means of reducing uncertainty (and thereby reducing risk).

\section{A.2.4 Integrate Requirements and Plan Characterization}

Having completed the work outlined for the first phase of the project, the resolution team met on January 30-31, 1997, to evaluate the Phase 1 results and plan the work for project completion. The resolution team considered the overall model as represented in the structured logic diagram and found it technically sound. Questions were raised about both data quality and the validity of various assumptions or approaches used with the overall representation of the phenomena. These questions were to be addressed or defined as uncertainties to be considered in the characterization plan. One approach to addressing these questions was to conduct tests of 
scenarios related to 1) the effect of additional data on "unsampled" tanks, 2) the sensitivity of the results to tank grouping approaches, 3 ) the effects of degradation of the organic components of the waste, and 4) the effects of remediation by addition of water or reduction of the amount of organic material in a tank. Formal decision analysis tools, including uncertainty and value of information analyses, were then to be used to prepare a characterization plan for those tanks for which reducing the uncertainty in the input information was expected to be more valuable than taking remediative actions.

\section{A.2.5 Collect Data}

The full implementation of the recommended strategy calls for a careful and independent evaluation of the information provided by the PHMC - how accurate are the data and how well do they represent the information requirements of the reaction mechanism description. Because of funding and time limitations, the project leaders were unable to implement this element of the strategy. The best approach available to the resolution team was to use the information available for the 1997 Organic Complexant Topical Report (Meacham et al. 1997), which should represent the best understanding of this organic-nitrate safety issue from the perspective of the PHMC team. Using the same information will also provide for a direct comparison of the results of this analysis and that reported in Meacham et al. (1997). Data collection is discussed in Section 3 of the main report.

\section{A.2.6 Process, Manage, Validate, and Model Data}

A complete risk-based analysis was performed for 138 of the 149 SSTs. Eleven SSTs were not considered in this analysis because their waste is so diverse that there was no basis for a statistical analysis to estimate their contents or determine the uncertainties. Data processing, management, validation, and modeling are discussed in Section 3 of the main report.

\section{A.2.7 Make Decisions and Take Actions}

The results of the analysis are discussed with reference to a "base case" calculation wherein all organic carbon is assumed to be sodium acetate. Various scenarios were proposed and analyzed to determine the flexibility and robustness of the recommended solution, including speciation of the organic carbon, mitigation scenarios, and additional sampling. The base-case analysis and the scenario analyses are discussed in Section 4 of the report.

\section{A.2.8 Plan Characterization}

The results of this Phase 2 work were being analyzed when PNNL was asked to stop work by DOE (for reasons given in Figure A.3, Stop Work Order). Because this work was providing information about an important safety issue, PNNL management decided to complete the project with an effort that was reduced in scope but sufficient to provide a draft report of the primary conclusions of the analysis. The resolution team was reduced to key PNNL staff. At this time, the information being provided about the tank contents was also under refinement by 


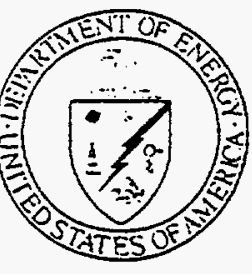

97-WSD-083

\section{Department of Energy}

Richland Operations Office

P.O. Box 550

Richland, Washington 99352

Director

Pacific Northwest National Laboratory

Richland, Washington 99352

Dear Sir:

CONTRACT NO. DE-AC06-76RL01830 - PNNL DIRECTED CHANGE TO THE FISCAL YEAR 1997 WORK PLAN

PNNL is directed to stop all work on the Safety Issue Resolution and Characterization Demonstration Project. The reason for this work stoppage is the recognition that the basic approach outlined by PNNL in the "Outcome-Based Strategy for Tank Waste Management: A Risk, Technical and Economic Basis for Characterization of Hanford Site Tank Wastes,". PNNL-11231, is being incorporated into the Data Quality Objective of our Organic Complexant Program.

$\mathrm{RL}$ recognizes that there may be some close out charges associated with this work stoppage. Please submit a change request if there are additional charges.

If you have any questions, please contact Jim Poppiti, on 376-4550.

$$
\text { Sincerely, }
$$

WSD:JAP

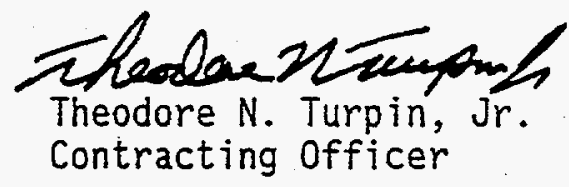

cc: S. D. Colson, PNNL

B. D. Shipp, PNNL

Figure A.3. Stop Work Order 
the Hanford Tank Waste Safety Project, the results of which are reported in Meacham et al. (1997). A stable data set was not available until June 30, 1997, at which time the resolution team began its final analyses and scenario testing.

A.3 References

Colson SD, RE Gephart, VL Hunter, J Janata, and LG Morgan. 1997. A Risk-Based Focused Decision-Management Approach for Justifying Characterization of Hanford Tank Waste. PNNL-11231, Pacific Northwest National Laboratory, Richland, Washington.

Meacham JE, AB Webb, NW Kirch, JA Lechelt, DA Reynolds, GS Barney, DM Camaioni, F Gao, RT Helen, and PG Heasler. 1997. Organic Complexant Topical Report. HCF-SD-WECN-058, Duke Engineering Services Hanford, Richland, Washington.

A. 8 


\section{Appendix B}

Structured Logic Diagram for the Organic-Nitrate Safety Issue 
NOTICE

Page(s) size did not permit electronic reproduction. Information may be purchased by the general public from the National Technical Information Service, U.S. Department of Commerce, Springfield, VA 22161 (Area Code 703-487-4650). DOE and DOE contractors may purchase information by contacting DOE's Office of Scientific and Technical Information, P.O. Box 62, Oak Ridge, TN 37831, Attn: Information Services (Area Code 423-576-8401). 
Appendix C

Initiator Frequencies for Organic-Nitrate Waste 


\section{Appendix C}

\section{Initiator Frequencies for Organic-Nitrate Waste}

This document shows the derivation of ignition probability incorporated in the organics risk model. The list is assumed to encompass all of the ignitors for the solid organic-nitrate rapid propagation. It was assumed that:

1. the video camera/light ignitor is a point source that could ignite only dry surface reactive waste

2. the torch ignitor is a non-point source that could ignite damp or dry surface reactive waste

3. the cutting ignitor is a point source that could ignite only dry surface reactive waste

4. the vehicle fuel fire ignitor is a non-point source that could ignite damp or dry surface reactive waste

5. the rotary mode core drilling upset ignitor is a point source that could ignite any reactive waste (surface or subsurface, damp or dry)

6. lightning will find and ignite any reactive waste (surface or subsurface, damp or dry)

7. the flammable gas ignitor will find and ignite dry surface reactive waste

8. solvent fires will find and ignite damp or dry surface reactive waste

9. bulk heating will find and ignite any reactive waste (surface or subsurface, damp or dry), but it applies only to Tank C-106.

The frequency of ignition by a point source is the ratio of the volume of material that could be ignited to the volume of all waste in the appropriate region of the tank then multiplied by the appropriate initiator frequency. The frequency of ignition by a non-point source depends on the "footprint" of the source. A detailed analysis of this is shown on the last page of this appendix. The general formula is shown for each component of the ignition frequency. This is first reduced to the terms of the standard inputs to the model and then to the current "unmitigated" values of those inputs, where available. The total frequency of ignition is calculated as the sum of its component probabilities. This treats ignition sources as mutually 
exclusive. It is a reasonable approximation if component probabilities are small. A table of "unmitigated" and "mitigated" frequencies for the ignitors follows the calculation of ignition probabilities. A diagram describing the treatment of non-point sources is on the last page. This treatment of ignition is in the risk model. Table C.1, which contains a list of organic nitrrate initiator frequencies, follows the figure.

\section{Let}

$\mathrm{R}=$ the total volume of reactive waste in $\mathrm{m}^{3}$ (input)

$\mathrm{W}=$ the total volume of waste in the tank in $\mathrm{m}^{3}$ (input)

$\mathrm{d}=$ the diameter of the tank in $\mathrm{m}$ (input)

$F_{S}=$ the fraction of reactive waste that is at the surface (input)

$\mathrm{F}_{\mathrm{D}}=$ the fraction of surface reactive waste that is dry ( $<5 \%$ wt. moisture)(input)

$\mathrm{h}=$ the depth of the surface in $\mathrm{m}$ (input), currently set at $20 \mathrm{~cm}=0.2 \mathrm{~m}$

$r_{v}=$ the radius of the vehicle fuel fire's footprint in $\mathrm{m}$ (input), currently set at $2.0 \mathrm{~m}$

$r_{\text {torch }}=$ the radius of the torch's footprint in $\mathrm{m}$ (input), currently set at $1.0 \mathrm{~m}$

$\mathrm{S}=$ the volume of reactive waste at the surface in $\mathrm{m}^{3}=\mathrm{F}_{\mathrm{S}} \mathrm{R}$

$D=$ the volume of dry reactive waste at the surface in $m^{3}=F_{D} F_{s} R$

$\mathrm{W}_{\mathrm{S}}=$ the total volume of surface waste in $\mathrm{m}^{3}=\pi \mathrm{D}^{2} \mathrm{~h} / 4$

$r_{t}=$ the radius of the tank in $m=D / 2$

$\mathrm{r}_{\mathrm{sr}}=$ the radius of the surface reactive waste in $\mathrm{m}$

$\mathrm{r}_{\mathrm{dr}}=$ the radius of the dry surface reactive waste in $\mathrm{m}$.

\section{Then}

$$
\begin{aligned}
\mathrm{R} & =\pi \mathrm{r}_{\mathrm{sr}}{ }^{2} \mathrm{~h} \\
\mathrm{r}_{\mathrm{sr}} & =\left[\mathrm{R}_{\mathrm{s}} /(\pi \mathrm{h})\right]^{1 / 2} \\
\mathrm{r}_{\mathrm{sr}} & =\left[\mathrm{F}_{\mathrm{s}} \mathrm{R} /(\pi \mathrm{h})\right]^{1 / 2} \\
\mathrm{R}_{\mathrm{d}} & =\pi \mathrm{r}_{\mathrm{dsr}}{ }^{2} \mathrm{~h} \\
\mathrm{r}_{\mathrm{dr}} & =\left[\mathrm{R}_{\mathrm{d}} /(\pi \mathrm{h})\right]^{1 / 2} \\
\mathrm{r}_{\mathrm{dr}} & =\left[\mathrm{F}_{\mathrm{d}} \mathrm{F}_{\mathrm{s}} \mathrm{R} /(\pi \mathrm{h})\right]^{1 / 2}
\end{aligned}
$$

\section{C.1 Ignition Frequency}

The equation used to calculate ignition frequencies is in the following form:

$\mathrm{F}$ (ignition) $\approx \mathrm{F}$ (electrical ignites) $+\mathrm{F}$ (torch ignites) $+\mathrm{F}$ (cutting ignites) $+\mathrm{F}$ (vehicle fuel fire ignites) $+\mathrm{F}$ (rotary mode core drilling upset ignites) $+\mathrm{F}$ (lightning ignite) $+\mathrm{F}$ (flammable gas ignites) $+\mathrm{F}$ (solvent fire ignites) $+\mathrm{F}$ (bulk heating ignites) 
where

$$
\begin{aligned}
& \mathrm{F} \text { (electrical ignite) } \quad=\mathrm{F}(\text { electrical }) \cdot \mathrm{P}(\text { electrical hits dry surface reactive waste }) \\
& =\mathrm{F} \text { (electrical) } \cdot \mathrm{Min}\left\{1.0, \mathrm{R}_{\mathrm{d}} / \mathrm{W}_{\mathrm{S}}\right\} \\
& =\mathrm{F} \text { (electrical) } \cdot \operatorname{Min}\left\{1.0, \mathrm{~F}_{\mathrm{d}} \mathrm{F}_{\mathrm{S}} \mathrm{R} /\left(\pi \mathrm{d}^{2} \mathrm{~h} / 4\right)\right\} \\
& =F(\text { electrical }) \cdot \operatorname{Min}\left\{1.0, F_{d} F_{S} R /\left(\pi d^{2} h / 4\right)\right\} \text { per tank-year } \\
& =\mathrm{F} \text { (electrical) } \cdot \operatorname{Min}\left\{1.0, \mathrm{~F}_{\mathrm{d}} \mathrm{F}_{\mathrm{S}} \mathrm{R} /\left(0.2 \pi \mathrm{d}^{2} \mathrm{~h} / 4\right)\right\} \text { per tank-year }
\end{aligned}
$$

$\mathrm{F}$ (cutting ignites) $\quad=\mathrm{F}($ cutting $) \cdot \mathrm{P}$ (cutting hits dry surface reactive waste)

$=\mathrm{F}$ (cutting) $\cdot \operatorname{Min}\left\{1.0, \mathrm{R}_{\mathrm{d}} / \mathrm{W}_{\mathrm{s}}\right\}$

$=\mathrm{F}$ (cutting) $\cdot \operatorname{Min}\left\{1.0, \mathrm{~F}_{\mathrm{d}} \mathrm{F}_{\mathrm{S}} \mathrm{R} /\left(\pi \mathrm{d}^{2} \mathrm{~h} / 4\right)\right\}$

$=\mathrm{F}$ (cutting) $\cdot \operatorname{Min}\left\{1.0, \mathrm{~F}_{\mathrm{d}} \mathrm{F}_{\mathrm{S}} \mathrm{R} /\left(\pi \mathrm{d}^{2} \mathrm{~h} / 4\right)\right\}$ per tank-year

$=\mathrm{F}$ (cutting) $\cdot \operatorname{Min}\left\{1.0, \mathrm{~F}_{\mathrm{d}} \mathrm{F}_{\mathrm{S}} \mathrm{R} /\left(0.2 \pi \mathrm{d}^{2} / 4\right)\right\}$ per tank-year

$\mathrm{F}($ vehicle fire)

$=\mathrm{F}$ (vehicle fuel fire $) \cdot \mathrm{P}($ vehicle fire hits surface reactive waste)

$=F($ vehicle fuel fire $) \cdot \operatorname{Min}\left\{1.0, \pi\left(r_{s r}+r_{v}\right)^{2} /\left(\pi r_{t}^{2}\right)\right\}$, if $R_{s}>0 ;=0$, otherwise

$=F($ vehicle fuel fire $) \cdot \operatorname{Min}\left\{1.0,\left(\left(F_{S} R /(\pi h)\right)^{1 / 2}+r_{v}\right)^{2} /\left(d^{2} / 4\right)\right\}$, if $F_{S} R>0$; $=0$, otherwise

$=F($ vehicle fuel fire $) \cdot \operatorname{Min}\left\{1.0,\left(\left(F_{S} R /(\pi h)\right)^{1 / 2}+r_{v}\right)^{2} /\left(d^{2} / 4\right)\right\}$ per tankyear, if $F_{s} R>0 ;=0$, otherwise

$=\mathrm{F}($ vehicle fuel fire $) \cdot \operatorname{Min}\left\{1.0,\left(\left(\mathrm{~F}_{\mathrm{S}} \mathrm{R} /(0.2 \pi)^{1 / 2}+2.0\right)^{2} /\left(\mathrm{d}^{2} / 4\right)\right\}\right.$ per tankyear, if $F_{S} R>0 ;=0$, otherwise

$\mathrm{F}$ (rotary mode core $\quad=\mathrm{F}$ (rotary mode core drilling upset) $\cdot \mathrm{P}$ (rotary mode core drilling drilling upset ignites) upset hits reactive waste)

$=\mathrm{F}($ rotary mode core drilling upset $) \cdot \operatorname{Min}\{1.0, \mathrm{R} / \mathrm{W}\}$

$=\mathrm{F}$ (rotary mode core drilling upset) $\cdot \operatorname{Min}\{1.0, \mathrm{R} / \mathrm{W}\}$ per tank-year

$\mathrm{F}($ lightning ignites $) \quad=\mathrm{F}($ lightning $) \cdot \mathrm{P}($ lightning hits reactive waste $)$

$=\mathrm{F}$ (lightning) $\cdot 1.0$

$=(2.5 \mathrm{E}-06)$ per tank-year 
$\mathrm{F}$ (flammable gas ignites)

$\mathrm{F}$ (solvent fire ignite) $=\mathrm{F}$ (solvent fires) $\cdot \mathrm{P}($ solvent fires hit surface reactive waste)

$=\mathrm{F}$ (solvent fires) $\cdot 1.0$, if $\mathrm{R}_{\mathrm{S}}>0 ;=0$, otherwise

$=F$ (solvent fires) per tank-year, if $F_{s} R>0 ;=0$, otherwise

$\mathrm{F}$ (bulk heating ignites) $=\mathrm{F}$ (bulk heating) $\cdot \mathrm{P}($ bulk heating hits reactive waste $)$

$=\mathrm{F}$ (bulk heating) $\cdot 1.0$, if tank $\mathrm{C}-106 ;=0$, otherwise

\section{C.2 Effective Area of Ignition for Vehicle Fuel Fires}

The diagram of a tank cross-section (see Figure C.1), which shows the waste surface. A vehicle fuel fire is a non-point ignition source; it burns over an area shown in the diagram as a "gasoline footprint." If any part of the gasoline's footprint will ignite any part of the reactive waste at the surface, then its effective ignition area has radius $r_{e}=r_{s r}+r_{v}$.

A similar analysis will apply to the torch footprint. Here, the gasoline footprint is replaced by the torch's footprint. Hence, $r_{e}=r_{s r}+r_{\text {torch }}$.

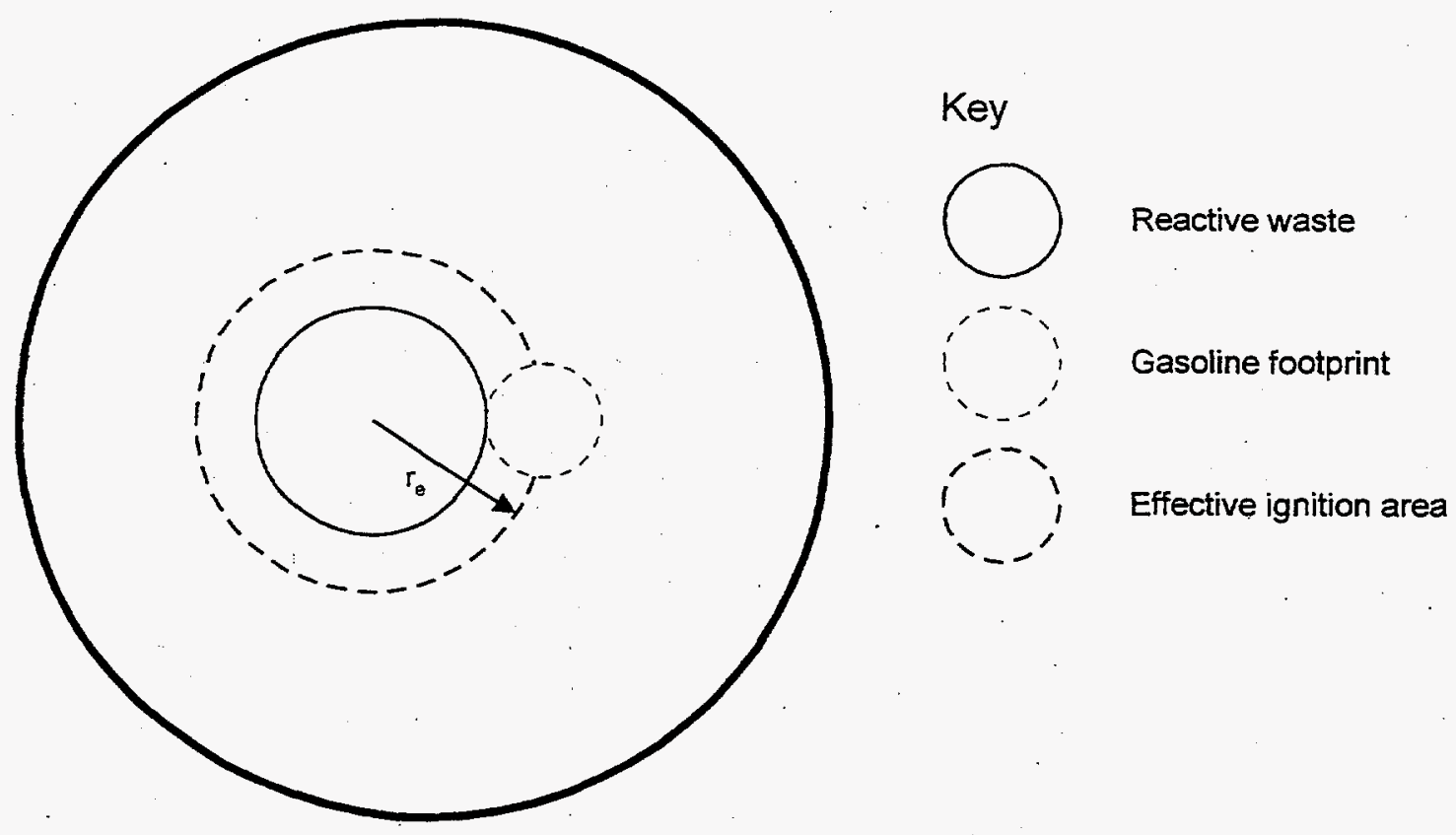

Figure C.1. Illustration of Tank Waste Surface Cross-Section 
Table C.1. Organic-Nitrate Initiator Frequencies

\begin{tabular}{|l||c|c|}
\hline \multicolumn{1}{|c|}{ Type of Initiator } & $\begin{array}{c}\text { Unmitigated Frequency } \\
\text { (per SST-yr) }\end{array}$ & $\begin{array}{c}\text { Mitigated Frequency } \\
\text { (per SST-yr) }\end{array}$ \\
\hline \hline Failed video or still camera lights & $1.8 \mathrm{E}-02$ & $7.2 \mathrm{E}-05$ \\
\hline $\begin{array}{l}\text { Slag or hot metal from welding or } \\
\text { torch cutting activities }\end{array}$ & $2.7 \mathrm{E}-02$ & $1.1 \mathrm{E}-04$ \\
\hline Vehicle fuel fire & $3.3 \mathrm{E}-03$ & $3.0 \mathrm{E}-06$ \\
\hline Rotary core mode drilling & $2.7 \mathrm{E}-02$ & $2.2 \mathrm{E}-05$ \\
\hline Lightning strike & $3.0 \mathrm{E}-03$ & $1.0 \mathrm{E}-06$ \\
\hline $\begin{array}{l}\text { Flammable gas burn } \\
\text { - Seismic }\end{array}$ & $1.0 \mathrm{E}-04$ & $5.0 \mathrm{E}-06$ \\
Other sources & $8.3 \mathrm{E}-04$ & $1.2 \mathrm{E}-04$ \\
Total & $9.3 \mathrm{E}-04$ & $1.3 \mathrm{E}-04$ \\
\hline $\begin{array}{l}\text { Bulk waste heatup } \\
\text { (Tank 241-C-106 only) }\end{array}$ & $2.0 \mathrm{E}-01$ & $2.0 \mathrm{E}-03$ \\
\hline
\end{tabular}


Appendix D

Letter Report from Barry W. Wise:

Review of Analysis of Variance Model Calculations 


\section{Eigenvector Research, Inc.}

830 Wapato Lake Road

Manson, WA 98831

Phone: (509)687-2022

e-mail: bmw@eigenvector.com

July 16,1997

Dr. Steven D. Colson

Battelle, Pacific Northwest Laboratories

Mail Stop K2-12

P.O. Box 999

Richland, WA 99352

Dear Steve:

I have reviewed the "Appendix F Calculation Notes for Analysis of Variance (ANOVA) Model." In general, the methodology for estimating the distributions of combustible waste are sound given the definition of combustible waste given in the document. The calculations also appear to have been carried out correctly.

My main concern is with some of the assumptions that went into the model. In particular, the model appears very sensitive to the parameter $\rho$, the assumed correlation between moisture content and TOC. This was taken in the model to be fixed at $p=0.32$. If $\rho$ were actually lower (say zero), one would get much larger reactive waste volumes. I think that it would be a useful exercise to determine the overall sensitivity of the results to this parameter.

Other concerns are largely due to possible bias in the model caused by the lack of randomness of the sampling procedure. Some of these biases cause the results to more conservative, others effect it the opposite way. In the end they probably largely cancel.

I have attached the running dialog that I had with Pat Heasler of your staff concerming the calculations. Pat answered all of my questions quite satisfactorily. In all, I think that this is a reasonable approach to determining which tanks are potential safety hazards. Also, it makes good use of the available data.

Please call or write if you have any questions regarding this matter.

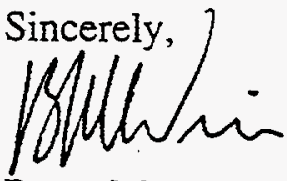

Barry M. Wise, Ph.D.

President

Enclosure

D.1 
$>$ Pat:

$>$ sound pretty stupid, but I just want to be sure that I know what

$>$ you mean. Hopefully, your version and mine have the things in the

> same layout on the pages so I can refer to page number and paragraph

$>$ in my questions.

$>$

$>$ P1\$2 "The screenirg operation compares upper $95 \%$ bound bounds on

these fractions to a $5 \%$ screening threshold". First off, the 5\%

$>$ screening threshold refers to the fact that you don't want the waste

$>$ to be more than $5 \%$ combustible, right? Also, the "bound bounds" part...

$>$ is this a typo, or does it refer to a situation where we want. to be

$>95 \%$ certain that $95 \%$ of the waste is non-conbustible?

Response:

I must remind you that this $5 \%$ threshold for combustible waste is for Joe Meacham's project and not Valeria's. Valeria's evaluation uses the uncertainty distribution we put on combustible waste while Joe's evaluation compares the upper $95 \%$ bound on combustible to a 5\% threshold. Being 95\% certain that the fraction of combustible waste is below $5 \%$ is equivalent to being $95 \%$ certain the non-combustible waste is above $95 \%$. In our simplified worla, combustible waste + non-combustible waste $=100 \%$ bound bounds is a typo.

$>$ PI last 9 "Also the current strategy is to categorize any tanks

$>$ without sampling data as "inderterminant" even though this screening

$>$ calculation categorizes all tanks into one of the three categories

> Iisted above." This is probably a pretty good idea. I understand how

$>$ the model will put them in a category based on similarity to other

$>$ tanks in their group. But still, it would be a hard sell to say

$>$ they are safe without any data at aIl on the particular tank.

The basic objective for this analysis are quite different in Joe's verses Valeria's project. In Joe's, he wants to end of with a safety categorization using the present data. Valeria's VOI needs a prababilistic description of how much we think we know about combustible waste now for ALI TANKS. The VOI analysis will then determine whether this is enough.

It would be a hard sell to say that the present extrapolations are "good enough" because we can't say that we have an unbiased sample of the waste.

$>$

$>$ P2I3 "Therefore the data used for this study typically represents a

$>$ measurement on the drained (solid) partion of the sample. However, we have

$>$ averaged together the solid and Iiquid TOC measurements to form a best

> sample estimate for samples with significant portions of drainable liquid."

$>$ It isn't.clear to me how the samples would be averaged together. How

$>$ was this done? I assume some sort of weighted average, but how was

$>$ the weighting determined? 
We attempted to average the solid and liquid portions together using their mass. That is if the solid was $20 \%$ of the sample and iquid $-80 \%$, these are the weights that were used.

$>$ P2I5 In the TGA measurements, woulan't volatile organics (those with

$>$ a significant vapor pressure at cemperatures less than 120C) get

$>$ classed as "moisture" with this measurement, since the should come

$>$ off the sample along with the water?

$>$

Could be. I have been in discussions where objections such as this have come up. However, I have not spent much time reviewing the measurements in this detail. The people who have are Nick Kirch, Dan Reynolds, and Jim Toth.

> P3 \#2 "...measurements on the Iiquid portion of the waste are excluded."

$>$ Shouldn't they be included if they have a significant amount of TOC?

$>$ What if they were very high in flammable liquid?

$>$

If I could include them I would. This is a big problem when trying to deal with a DST, which will have a lot of liquid. My strategy would be to do a separate analysis on liquid and solid andtry to combine the results with the solid.

However, to do this, you need to know how much liquid and how much solid is in the tank and what biases your sampling may have. I don't have good info concerning this.

> P3I3 "All data collected is presented in Section 6.0 of this appendix."

$>$ I didn't get that part. I understand the data is available in electronic

$>$ form. Could I have it?

I didn't print out the data because it is about 300 pages long. I have it in electronic form and will send that to you when the next version is ready. $>$

$>$ P3I4 "These groupings are based upon tank process history and should help

$>$ reduce the biases associated with the current set of sampling data."

$>$ I agree that it should help, but it will also introduce some bias of

$>$ its own, but it does probably help things balance out.

$>$

The grouping can not introduce bias on tanks that have data. I would expect the grouping to reduce bias for the extrapolated tanks, as Iong as we construct

the grouping from historical information and not the TOC/H2O data set.

$>$ P395 Regarding the bias due to only doing TOC after a positive DSC--it

$>$ would be interesting to estimate the sensitivity of the analysis to

$>$ this bias, i.e. suppose that the measurements were biased high and

$>$ then see what would happen if the bias was "removed". This is probably

$>$ beyond the scope of anything you'd like to get into, but it is always

$>$ useful to see how things like this propagate through an analysis: 
It would be useful; I actually have some information concerning this from a study Camioni and Clark performed. But this requires much more work than I have money for. A related issue is why not use the DSC measurements in the analysis?

We tried to do this at one time, but had severe problems. Some people don't believe the DSC measurements are worth much..

$>$

$>$ P4I2. Adaition of the core composite data would have the effect of Iowering

$>$ the estimate of the variance within the tank. I guess that 93 measurements

$>$ wouldn't have much effect on the overall, but this should at least be

$>$ mentioned.

You are correct that composite poines would lower the variance. I know they have hardly any effect because 1) there are few additions and 2) the additions are usually single data points to a single tank layer; Such a data point won't even enter into the variance calculation.

$>$

$>$ P7 \#3 Is the correlation between moisture and TOC significant? Just curious.

Yes it is significant, we have about 300 paired points and they produce a value of rho $=32 \%$.

$>$

> P7 \#4 I'a like to see a complete description of the Monte Carlo simulation

$>$ in words, just to make sure I'm thinking about this the right way. As I

$>$ understand it, the ANOVA model estimates deviations in the means due

$>$ to groups and layers along with the variance. However, these estimates

$>$ are themselves uncertain. Therefore, the Monte Carlo is used to tweak

$>$ the estimates of the ANOVA model parameters within their estimated

$>$ distribtions.

$>$ Each tweak of the ANOVA model gives a different estimated distribution of

$>$ the waste. These distributions are then "composited" to form the final

$>$ estimate of the distribution. Let me know if my thinking is fuzzy on this.

$>$

Your description looks correct to me. If we assumed the ANOVA parameters exactly described whats in the tank, we could plug them into an integral equation and produce a single number for combustible waste fraction. However they are not certain, and the ANOVA procedure gives us uncertainties, in the form of standard errors on all these parameters. These uncertainties can be propogated to combustible waste using Monte Carlo Simulation.

$>$ P7 Eq. F-1, where did this come from? I assume there is a reference to $>$ this. Is $\mathrm{H} 20$ in wtor?

This comes from Fauski's work, it is discussed in detail in another appendix, which he has written. H2O is in wto. 
$>$ P8I4 It is assumed that the distribution for EACF TANK is -bivariate $>$ Iognormal, right? With this, however, it would seem that you'd have $>$ to specify a scale for the distribution (which I think you do later). $>$ The scale is about the size of a core, right?

REPLY :

Correct, the distribution is describing a unit of waste about the size of a core segment.

$>$

$>$ P9I2 "This uncertainty distribution describes how close the calculated

> values are to the true...." Really, the uncertainty cistribution

> ESTIMATES how close the calculated values are to the true, doesn't it?

REPLY :

The uncertainty distributions are Bayesian posteriors. For this exercise and in the risk analyses, we are considering the "true fraction of combustible waste" to be a rancom variable. From this perspective, we do not have an estimate of the posterior, but the actual distribution and is not an estimate of this desired distribution.

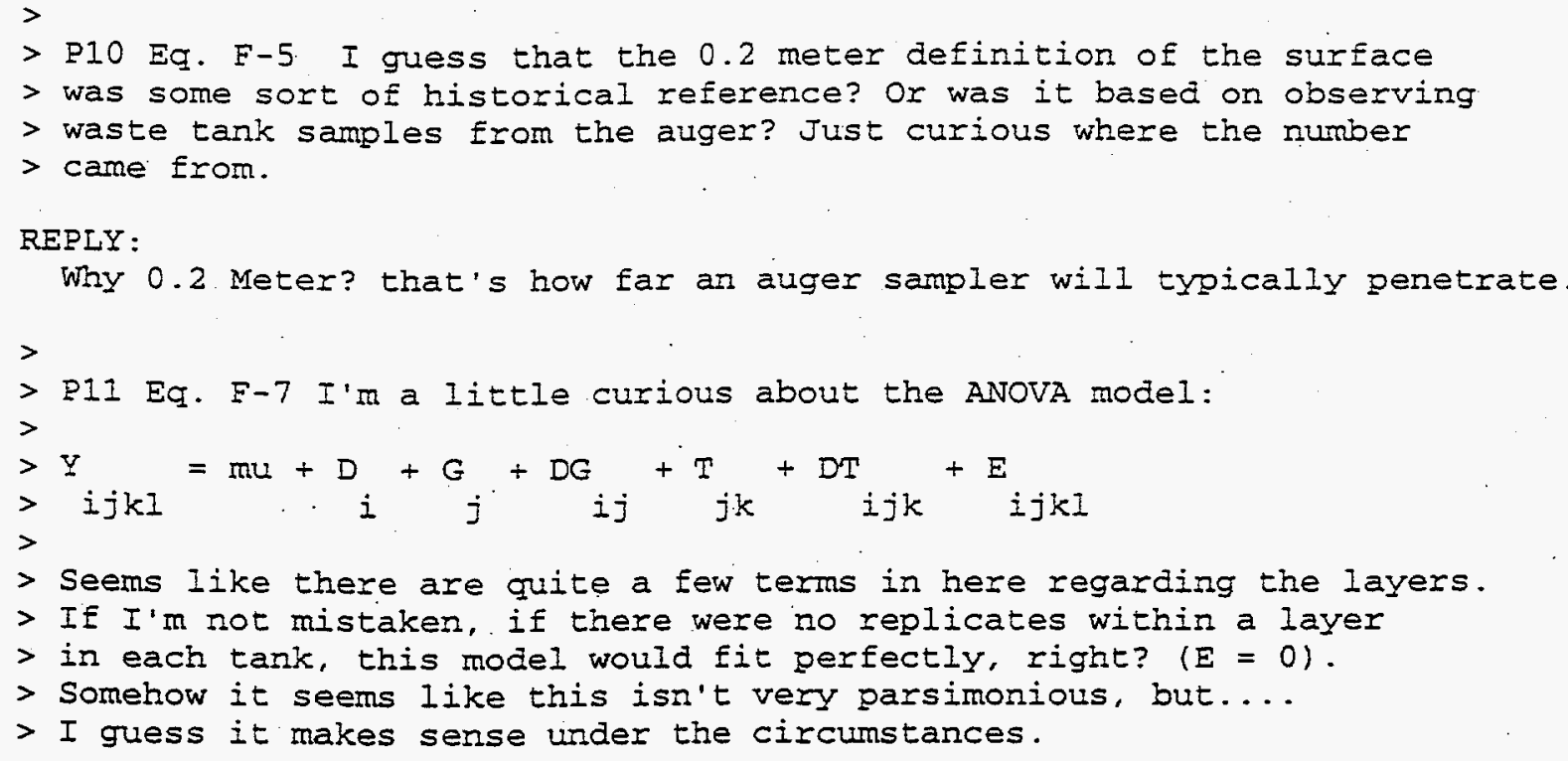

REPLY :

This model has enougi terms, so that when data exists in each layer, the model fits perfectiy (i.e. the data in each layer is just averaged together to determine a layer mean). Erom a regression point of view, it would be correct to say that the model is not parsimonious. In fact, one can make a stronger statement: If the above model was interpreted as a regression model (i.e. all the terms in the model were considered to be parameters instead of random variables), the model would be unsolvable. The reason we can solve this at all is because we assume that all these terms are random variables, which changes the standard regression normal equations into ridge-regression equations. 
We need all the terms in the model because we need to account: for these variations WHEN DATA IS MISSING. These models do this sort-of thing in a defendable manner. If all the layers had data, one coúld simply use something like;

$$
Y i j k I=U i j k+E i j k l
$$

and get a reasonable answer.

$>$ PII\$3 "all terms in the model are considered to be random variabies

$>$ (with the exception of mu)" OK, so I'll show I'm not a statistician

$>$ by asking. what is the significance of mu not being a random variable?

REPIY :

A general rule; If there is a lot of data available to estimate a parameter in one of these ANOVA models, it doesn't matter much whether you consider it fixed or random. Big differences occur when littie data (i.e. Dof) exists.

Another convention, in ANOVA models, the grand mean, is always considered fixed because there is only one of them.

$>$

$>$ P12\$2 I'm having some trouble pairing up the elements of sigma

$>$ with the original terms in the model. Am I missing something?

$>$ PI2 II I don't see where SIGMA = Iinf sig^2_D, sig^2_D, sig^2_G,

$>\operatorname{sig}^{\wedge} 2$ G.... comes from. When I compare this to eqn $F-7$, I don't

$>$ see the correspondence. Why does the beta coefficient for both the

$>2 n d$ and $3 r a$ terms have variance sig^2_D?

REPLY:

The model has been re-parameterized into vector form. In this form, beta represents all the terms present in F-7, arranged in some order. The order is

Beta $=\{U, D 1, D 2, G 1, G 2, G 3, G 4, D G 11, D G 12, \ldots$.$\} . So the second and third terms$ describe the $\mathrm{Di}$, the 4 th through 7'th describe the $\mathrm{G}$. One of the biggest tasks in the typicall ANOVA program is keeping all these parameters straight.

$>$

$>$ PI2 12 OK, so I not a statistician. Coula you explain why $Y$ is

$>$ distributed as $X$ sigma $X '$ ??

REPLY :

Comes from the algebra of random vectors. If $\mathrm{ZI}$ and $\mathrm{z} 2$ are independent random vectors and $A$ is a matrix, then:

and

$$
E(A Z 1+Z 2)=A^{*} E(Z 1)+E(Z 2)
$$

$$
\operatorname{Cov}(A Z 1+Z 2)=A \operatorname{Cov}(Z 1) A+\operatorname{COv}(Z 2)
$$

To get the distribution of $Y$, use $Y=X B+E$ with $Z I=B$ and $E=Z 2$. 
$>$ P12 Eqn F-13 It appears that beta is being estimated using.a

$>$ ridge type regression where each coefficient has associated ridge

$>$ parameter $\operatorname{sig}^{\wedge} 2 / \mathrm{sig}^{\wedge} 2$ D, etc. This suggests that the terms with

$>$ small sig^2_D will be forced to zero faster than the other terms,

$>$ right? Is this because you expect these terms, with small variance.

$>$ to be closer to zero? Is this some sort of maximum likIihood

$>$ estimate? I can see, however, that the riage parameter for the

$>$ mu term will be 0 , which means that this term is not restricted

$>$ in the estimation. Given that, I don't see how mu is "fixed" the

$>$ estimation problem. Can you explain?

REPLY:

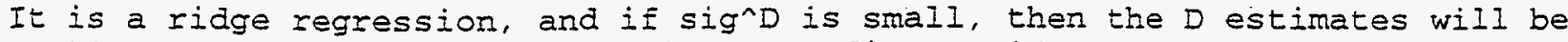
small. The difference between this and ordinary ridge regression is that the data determines an appropriate magnitude for the ridge parameters. Since the ridge parameters are sigma's they are determined by maximum IikeIihood.

Notation: the term fixed parameter means nothing more than non-ranodom. ANovA terms are divided into random and fixed (non-random) terms.

$>$

$>$ P12 How do. you get SIGMA - (sigma sub beta tilde?)

REPLY:

The notation is not the best. As you can see $Y$ and $B$ are portions of a multivariate normal distribution. If you want to estimate $B$ and know $Y$, a bayesian argument wiII tell you that the best estimate for B (SmaII RMSE) is given by the conditional expectation;

$$
E(B \mid Y)=(X T X \text { and so on }
$$

and the conditional variance of $B$ about this estimate is;

$$
\operatorname{Cov}(B \mid Y)=\operatorname{sigma\wedge } 2(x T X \text { and so on) }
$$

In other words, sigma-tilde-beta is really $\operatorname{Cov}(B \mid Y)$.

$>$

$>$ P12, Last $\mathbb{I}$ Who determined that a core is about the right size for

$>$ safety considerations? That was previously, right?

\section{REPIY:}

This is basically my assessment. When running the risk calculations we seem to be finding that the tank is dangerous when it has one-half to one-quarter cubic meter of reactive waste. This results in a dimension of $0.6 \mathrm{M}$ and thats "close". to the sample size.

$>$

$>$ P13 $\$ 2$ Actual estimates are produced with F-12? "The procedure produces

$>$ the best estimates...." by what criteria?

REPLY: Best in terms of root mean square error.

$>$

$>$ P13 $\$ 4$ Do any particular samples tend to have paired TOC/F20 numbers?

$>$ Would this add any bias? Or are the paired samples totally at random?

D. 7 
REPLY :

The pairing is not at random. There could be bias. Ohe positive fact. We have made this calculation through several revisions of the data set. During these revisions the amount of paired data has risen from 15\% to 60\%??? and the correlation has varied little; it has remained in the 30-40\% range.

$>$ P14 II Is the effect of putting a tank in the wrong class considered?

$>$ Is there any way to be wrong on this?

REPLY:

IT is considered in the following sense. The ANOVA variance components determine how good any tank grouping is at predicting what's in unsampled tanks, even

a grouping with some problems. For this to work, what you really need is an unbiased sample of tanks from the grouping.

$>$

$>$ P14 "A single rho was computed for all available E_ijkI (H20, TOC)

$>$ pairs. $60 \%$ of the data? I thought it was $\% 18$ ? Or is it that there

$>$ is data on $18 \%$ of the layers but $60 \%$ of the ones that have been

$>$ measured have paired data?

$>$

REPLY:

I think about $60 \%$ of the moisture/h20 data is paired. Don't know what $18 \%$ refers to.

$>$ PI4 It was decided that rho was perfectly known... . what if it were

$>$ zero? Wouldn't that put a lot more tanks in the unsafe category under

$>$ current conditions (since the ones with high TOC are assumed to have

$>$ high water given a positive rho?)?

REPLY: If tho were 0 , one would get much larger reactive waste estimates. 


\section{Distribution}

No. of

Copies

Offsite

2 DOE/Office of Scientific and Technical Information

Dr. E. C. Ashby

2516 Flair Knoll Drive

Atlanta, GA 30345

Dr. David J. Leggett

Hazard Evaluation Labs

7 Deer Park Drive

Monmouth Junction, NJ 08852

Dr. Jacob Ulvila

Decision Science Associates, Inc. 10980 Poplar Ford Trail

Manassas, VA 22110-2106

Dr. T Ffrancon Williams

Department of Chemistry

University of Tennessee

552 Buehler Hall

Knoxville, TN 37996-1600

Dr. Barry Wise

Eigenvector Research, Inc.

830 Wapato Lake Road

Manson, WA 98831
No. of

Copies

Onsite

3 DOE Richland Operations Office

J. E Kinzer

S7-50

J. K. McCluskey

S7-54

J. A Poppiti

S7-54

2 Duke Engineering Services Hanford

J. E. Meacham

S7-14

L. M Stock

S7-14

45 Pacific Northwest National Laboratory

S. Q. Bennett

K7-90

J. W. Brothers

K9-20

D. M. Camaioni

K2-44

S. D. Colson (12)

K8-88

T. J. DeForest

K7-97

T. A. Ferryman (2)

K5-12

T. A. Fryberger

K8-84

R. E. Gephart (3)

K9-76

R. T. Hallen

K2-12

S. W. Heaberlin

K8-31

P. G. Heasler (2)

K5-12

V. L. Hunter (5)

K7-97

L. G. Morgan

K6-48

P. J. Pelto

K7-97

M. J. Quadrel

K9-70

R. D. Scheele (2)

P7-25

B. D. Shipp

K9-01

G. M. Stokes

K9-95

J. J. Toth

K7-94

T. W. Wood

K7-94

Information Release (5)

K1-06

Distr.1 